\title{
WestVirginiaUniversity
}

THE RESEARCH REPOSITORY @ WVU

Graduate Theses, Dissertations, and Problem Reports

2003

\section{Finite element damage modeling of plain weave fabrics}

Kaarthik K. Sikkil

West Virginia University

Follow this and additional works at: https://researchrepository.wvu.edu/etd

\section{Recommended Citation}

Sikkil, Kaarthik K., "Finite element damage modeling of plain weave fabrics" (2003). Graduate Theses,

Dissertations, and Problem Reports. 1398.

https://researchrepository.wvu.edu/etd/1398

This Thesis is protected by copyright and/or related rights. It has been brought to you by the The Research Repository @ WVU with permission from the rights-holder(s). You are free to use this Thesis in any way that is permitted by the copyright and related rights legislation that applies to your use. For other uses you must obtain permission from the rights-holder(s) directly, unless additional rights are indicated by a Creative Commons license in the record and/ or on the work itself. This Thesis has been accepted for inclusion in WVU Graduate Theses, Dissertations, and Problem Reports collection by an authorized administrator of The Research Repository @ WVU. For more information, please contact researchrepository@mail.wvu.edu. 


\title{
Finite Element Damage Modeling of Plain Weave Fabrics
}

\author{
Kaarthik K Sikkil \\ Thesis submitted to the \\ College of Engineering and Mineral Resources \\ at West Virginia University \\ in partial fulfillment of the requirements \\ for the degree of \\ Master of Science \\ in \\ Mechanical Engineering
}

\author{
Ever J. Barbero, Ph.D., Chairman \\ Jacky C. Prucz, Ph.D., Associate Chairman \\ Bruce Kang, Ph.D., Associate Professor \\ Thomas M. Damiani, Ph.D., Post Doctoral Research Associate
}

\section{Department of Mechanical and Aerospace Engineering}

\section{Morgantown, West Virginia}

2003

Keywords: Composites, Plain Weave Fabric, Elastic Modulus, Damage 


\title{
ABSTRACT \\ Finite Element Damage Modeling of Plain Weave Fabrics
}

\begin{abstract}
Kaarthik K Sikkil
Unidirectional laminated composites exhibit excellent in-plane properties, but poor interlaminar properties, as there are no reinforcements in the thickness direction. This leads to poor damage tolerance and impact resistance when inter-laminar stresses are present. To overcome these problems, plain weave fabrics are used as reinforcements in composites in order to obtain balanced ply properties and improved inter-laminar properties. But these advantages are at the cost of reduced stiffness and strength in the in-plane directions. Therefore, it is important to study the mechanical behavior of such composites in order to fully realize their potential. In this work, the geometrical model needed for finite element discretization of the plain weave fabrics are developed for three different configurations- single lamina, iso-phase, and out-of-phase. Next, a procedure to determine the longitudinal elastic modulus under tensile loading is presented. Then, a meso level damage model is used for predicting the non-linear behavior of the plain weave laminates under tensile loading. The damage model is validated for the tensile response of T300/5208 laminate for four configurations, $[10 /-10]_{2 \mathrm{~s}},[0 / 45 /-45 / 90]_{\mathrm{s}}$, [30/$30]_{2 \mathrm{~s}}$ and $[45 /-45]_{2 \mathrm{~s}}$. Then, the damage behavior of iso-phase and out-of-phase plain weave fabrics are analyzed using finite element methods. Also, the modes of meso level damage are also identified from the analysis. Comparisons with experimental data are provided in order to support validity of the proposed models.
\end{abstract}




\section{Dedicated to my parents}

Smt. Usha Kannan \& Sri. V. Kannan

\&

my family 


\section{ACKNOWLEDGEMENTS}

I would like to express my sincere gratitude and appreciation to Dr. Ever J. Barbero, for giving me an opportunity to work under him as a research assistant and guiding me to complete my thesis. His vast knowledge in composites has inspired me a lot. I would like to thank Dr. Jacky C. Prucz, Dr. Bruce Kang and Dr. Thomas M. Damiani for serving on my committee. Special thanks to Paolo Lonetti from University of Calabria, Italy for helping me out with the damage model. I would like to thank all my friends who have always been there for me through the good and bad times. Thanks to my roommates Venkatesh Parthasarathy and Sairam P. Thiagarajan who never made me feel homesick.

I would like to thank my parents for their constant advice and guidance, for always pushing me to go after my goals, and for sacrificing so much for me.

Finally, I would like to thank the almighty for showing me the right path in life. 


\section{TABLE OF CONTENTS}

CHAPTER 1: INTRODUCTION AND LITERATURE REVIEW ............................ 1

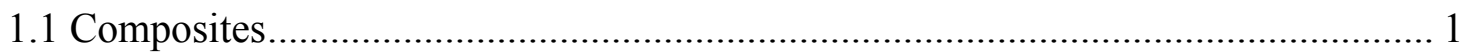

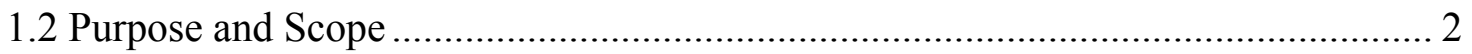

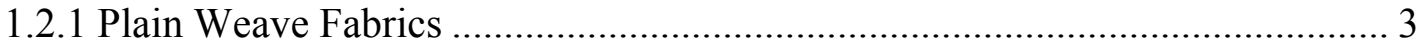

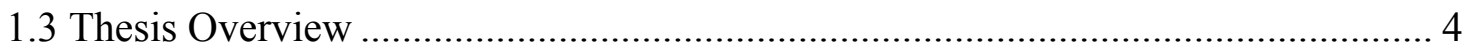

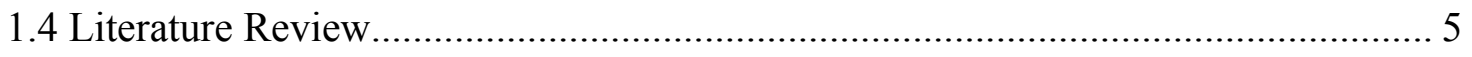

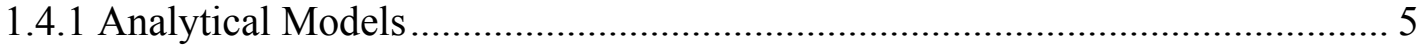

1.4.2 Finite Element Models ................................................................................ 11

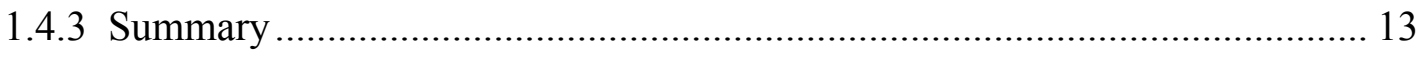

\section{CHAPTER 2: 3-D GEOMETRIC AND FINITE ELEMENT MODELS OF PLAIN}

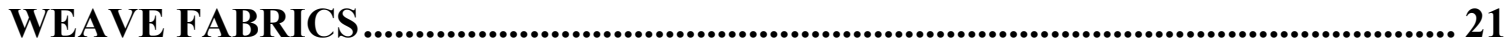

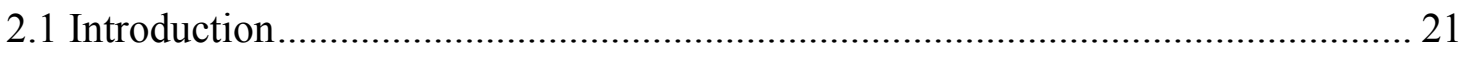

2.2 Geometrical Models.................................................................................... 21

2.2.1 2-D Geometrical model based on measurements by CERL .......................... 21

2.2.2 2-D Geometrical model based on measurements by Ito and Chou................. 23

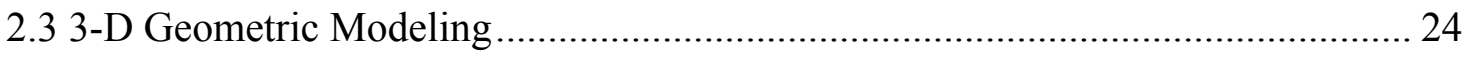

2.3.1 Geometric modeling of a Single Lamina ..................................................... 24

2.3.2 Geometric Modeling of Iso-phase and Out-of-Phase Lamina ........................ 25

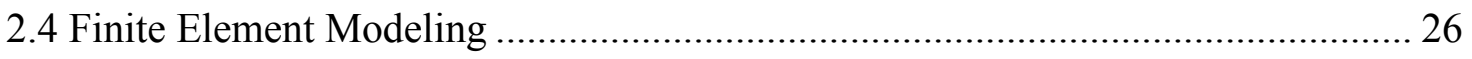

2.4.1 Volume Fraction correction for Ito-Chou models ...................................... 27

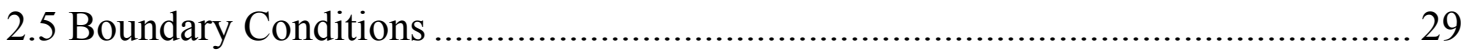

2.6 Linear Solution and Post Processing: ........................................................... 30

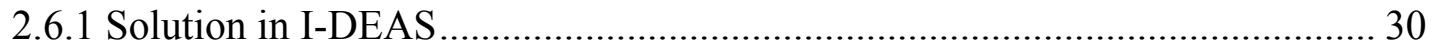

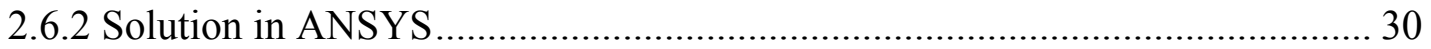

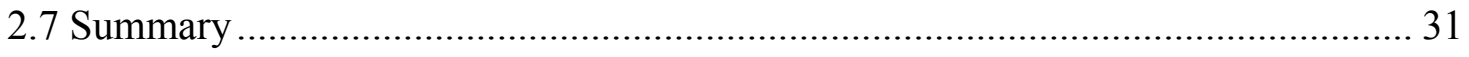

CHAPTER 3: DAMAGE MODEL FOR POLYMER MATRIX COMPOSITES ... 43

3.1 Introduction 


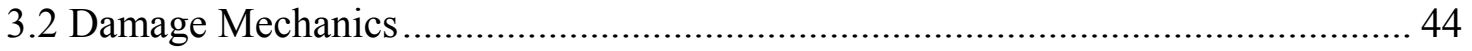

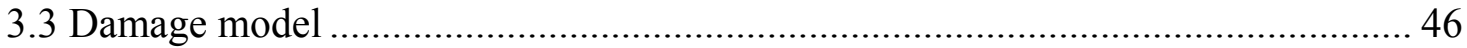

3.3.1 Procedure for calculating the internal material constants ................................. 48

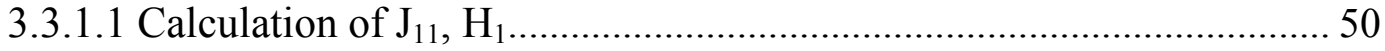

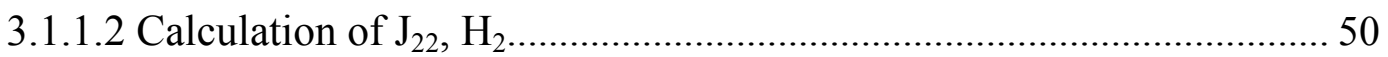

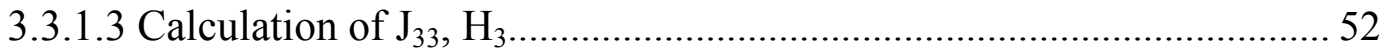

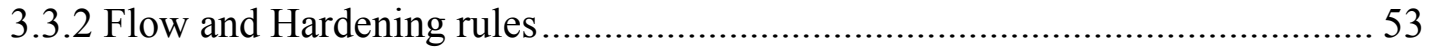

3.3.3 Adjusting the hardening parameters $\left(\mathrm{c}_{1}, \mathrm{c}_{2}\right)$ and damage threshold $\left(\gamma_{0}\right) \ldots \ldots \ldots . . .55$

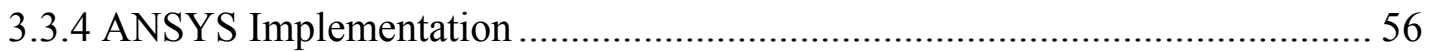

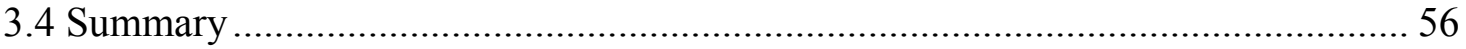

CHAPTER 4: RESULTS AND DISCUSSION ........................................................ 61

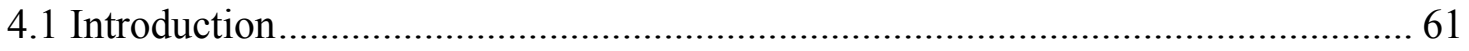

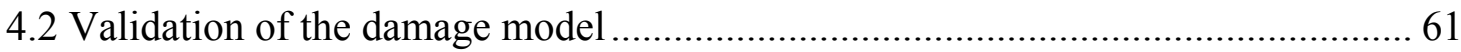

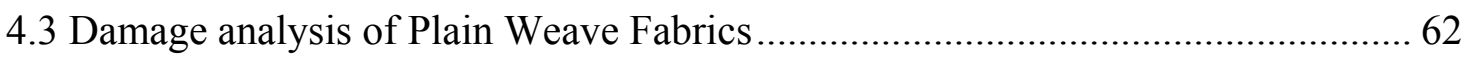

CHAPTER 5: SUMMARY AND CONCLUSIONS ......................................................... 78

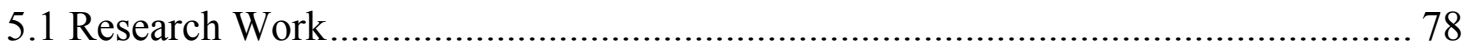

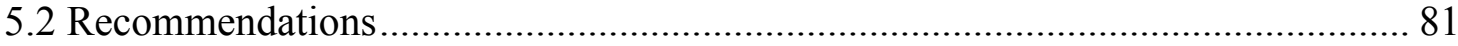

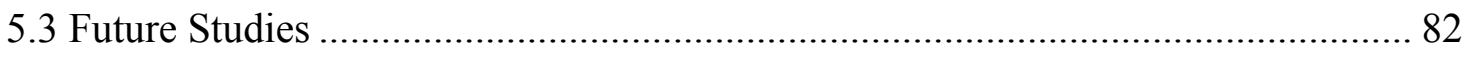

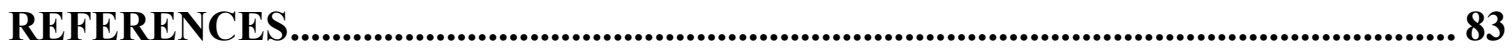

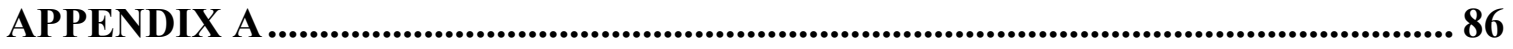

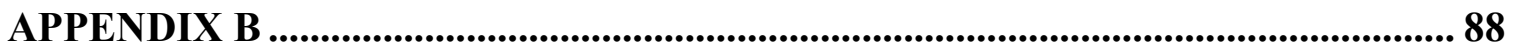

APPENDIX C …….................................................................................................................. 91

APPENDIX D ..................................................................................................................... 93 


\section{LIST OF FIGURES}

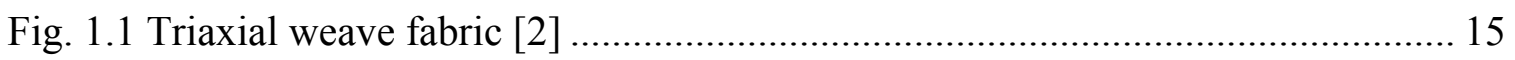

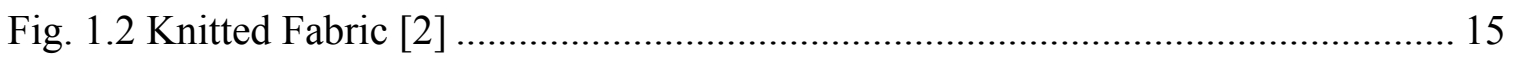

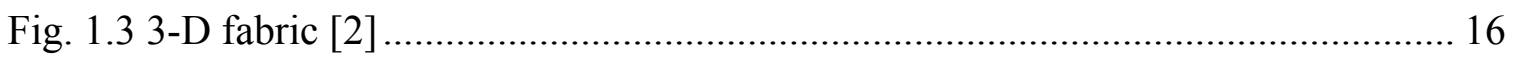

Fig. 1.4 Shedding Process for a Plain Weave Fabric [2] ........................................... 16

Fig. 1.5 Picking Process for a Plain Weave Fabric [2] ................................................ 17

Fig. 1.6 Beating Process for a Plain Weave Fabric [2] .............................................. 17

Fig. 1.7 Model of a Single Lamina without matrix.................................................... 18

Fig. 1.8 Model of a Single Lamina with matrix.......................................................... 18

Fig. 1.9 RVE of a single lamina (quarter model) .................................................... 19

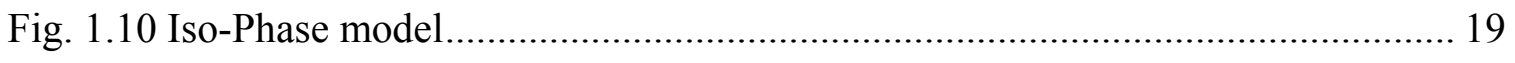

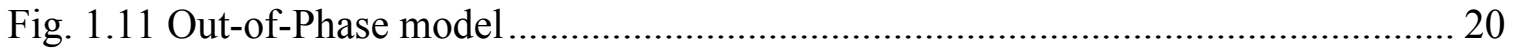

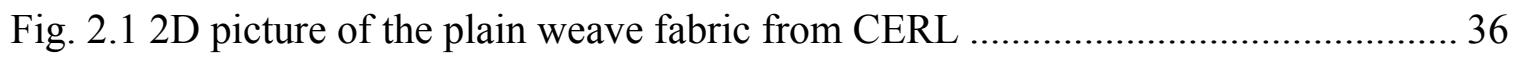

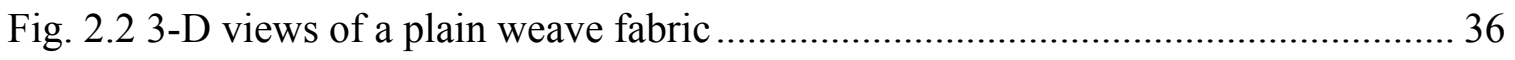

Fig. 2.3 Yarn parameters measured by CERL .......................................................... 37

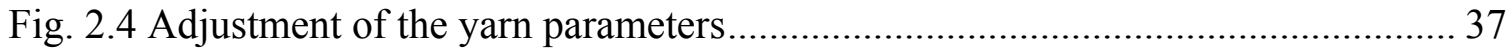

Fig. 2.5 Yarn parameters measured by Ito and Chou .............................................. 38

Fig. 2.6 Description of yarn path and cross-section curves ........................................ 38

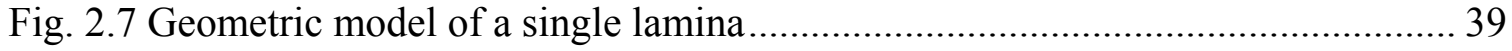

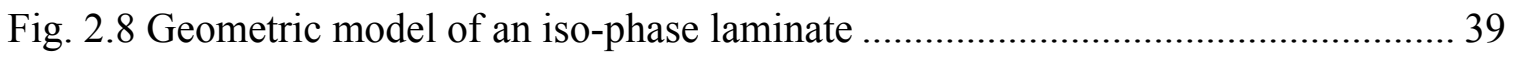

Fig. 2.9 Geometric model of an out-phase laminate ............................................ 40

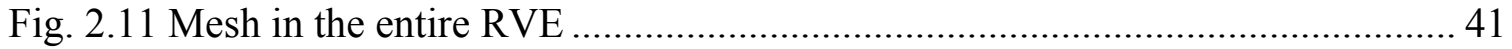

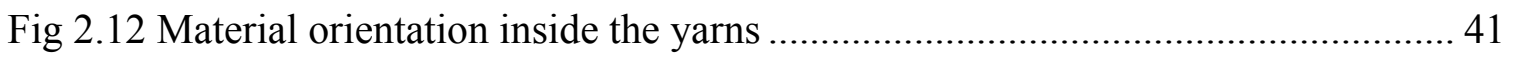

Fig. 2.13 Boundary conditions for plain weave laminates....................................... 42

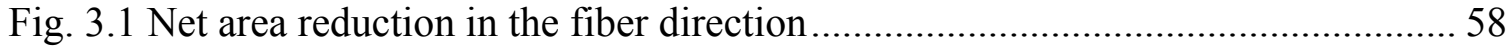

Fig. 3.2 Net area reduction in the transverse direction ............................................ 58

Fig. 3.3 Net area reduction in the inter-laminar direction.........................................5 59

Fig. 3.4 Damage surface in the thermodynamic space ............................................. 59

Fig. 3.5 Boundary conditions for pure shear in a composite lamina ............................ 60

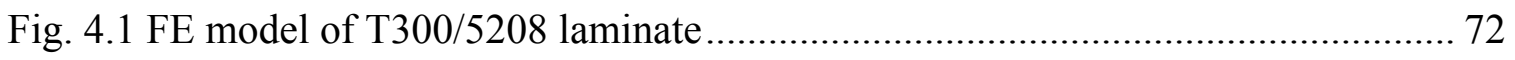

Fig. 4.2 Matching of shear response of T300/5208 with the experimental data.............. 72 
Fig. 4.3 Experimental and damage model results for T300/5208 laminate.

Fig. 4.4 Matching the shear response of AS4/Vinyl Esther with experimental data ........ 73

Fig.4.5 Loading direction and origin of the FE model .............................................. 74

Fig. 4.6 Damage analysis for the iso-phase laminate............................................... 74

Fig. 4.7 Damage evolution in the iso-phase model at location indicated in the parenthesis 75

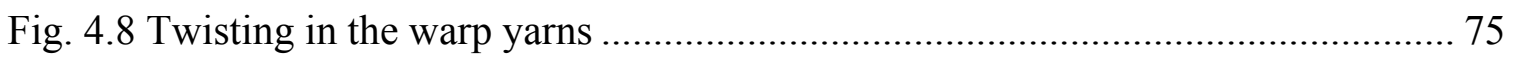

Fig. 4.9 Damage analysis of the out-of-phase laminate .............................................. 76

Fig. 4.10 Normalized stress plot for an element in the out-of-phase model................... 76

Fig. 4.11 Damage evolution in the out-of-phase laminate at location indicated in the

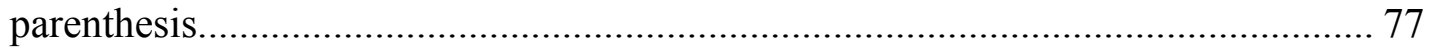




\section{LIST OF TABLES}

Table 2.1 Mathematical Parameters of a single lamina measured by CERL................... 32

Table 2.2 Mathematical Parameters measured by Ito and Chou .................................... 33

Table 2.3 Overall, Mesoscale, Microscale fiber volume fraction for all experimental

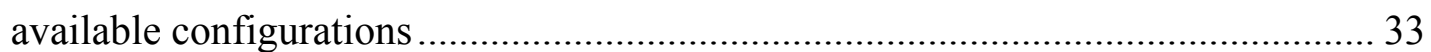

Table 2.4 Elastic properties of the Fiber, Yarn and Matrix ........................................... 34

Table 2.5 Comparison of Results from PMM models $[16,18]$...................................... 35

Table 2.6 Comparison of Results of the stiffness Ex for CERL Model .......................... 35

Table 2.7 Comparison of Results of the stiffness Ex for Ito and Chou Model................ 35

Table 4.1 Elastic properties and Damage parameters for T300/5208 material................ 69

Table 4.2 Elastic properties of AS4/Vinyl Ester material............................................. 70

Table 4.3 Damage parameters of AS4/ Vinyl Ester Material ...................................... 71 


\section{CHAPTER 1: INTRODUCTION AND LITERATURE REVIEW}

\subsection{Composites}

A composite material is a combination of two or more materials that provide better structural properties than its constituents. They exist in nature in the form of wood, human bone, etc. In the present world, composites generally refer to polymers (matrix) reinforced with fibers. The main advantages of composites are improved stiffness and strength properties, high strength to weight and stiffness to weight ratios, resistance to corrosion and wear, excellent fatigue performance etc. Both fibers and matrix are responsible for bearing the mechanical loads and the matrix protects the fibers from environmental attacks [1]. Due to these factors, composites find a wide variety of application in the mechanical, aerospace, and chemical industry.

A lamina is a thin plate that is formed by aligning a large number of fibers as continuous reinforcements. The lamina has a maximum stiffness and strength in the fiber direction and is weak in other directions [1]. Laminated composites are formed by several layers of lamina having similar or different fiber orientation and material.

Alternative to unidirectional reinforcements are fabrics. A fabric is a collection of fibers arranged in a given pattern. They are classified as woven, non-woven, knitted, or braided fabrics [2]. Further, they can also be classified into 2-D (two-dimensional reinforcement) and 3-D fabrics (three-dimensional reinforcement). Some examples of fabrics are plain weave fabrics, satin weave fabrics, weft knitted and warp knitted fabrics, and orthogonal fabrics. Some basic kinds of fabrics are shown in Figs. 1.1-1.3. 


\subsection{Purpose and Scope}

Unidirectional laminated composites are used where the in-plane properties are important. However, the laminated composites have poor inter-laminar properties, as there are no reinforcements in the thickness direction. As a result, the stiffness and strength in the thickness direction are greatly reduced. This leads to poor damage tolerance and impact resistance when out-of-plane stresses are present. Also, the handling and fabrication cost of such composites are high. To overcome these problems, woven fabrics are used as reinforcements in composites in order to obtain balanced ply properties and improved inter-laminar properties. Also, their ability to drape and conform to irregularly shaped structures makes woven fabrics easier to handle. Other advantages of such fabrics are low fabrication cost, handling cost, and improved de-lamination resistance. But these advantages are at the cost of reduced stiffness and strength in the inplane direction. Thus, it is important to study the mechanical behavior of such composites in order to fully realize the potential of woven fabric composites. The stiffness and strength depends upon the fabric architecture and material properties of fiber and matrix. The fabric architecture depends upon the undulation of the yarns, yarn crimps, density of the yarns, etc. A yarn is a twisted strand of fibers. The undulation or waviness of the yarns causes crimps (bending) in the yarns, which significantly reduces the mechanical properties of the composite. The geometry of the woven composites is complex and the choice of possible architectures is unlimited. The present thesis work concentrates on the modeling the in-elastic behavior of simplest of the woven fabrics - plain weave fabrics, using finite element methods. 


\subsubsection{Plain Weave Fabrics}

Plain weave fabrics are formed by interlacing (weaving) of yarns (twisted strand). The yarns in the longitudinal direction are known as warp yarns. The yarns in the transverse direction are known as the fill yarns or weft. The interlacing causes bending in the yarns, called yarn crimp. The weaving process is illustrated in Figs. 1.4-1.6. The process consists of three operations [2].

- Shedding: The operation is performed in order to separate the warp yarns into two or more layers. One yarn is lifted up and the other is lowered down creating a space between the warp yarns.

- Picking: The fill yarn is inserted through the space between the warp yarns thus interlocking the yarns together.

- Beating: The fill yarn is pushed against the fabric to give a compact structure.

The plain weave fabrics are available in different laminate stacking configurations. The single lamina consists of warp and fill yarns surrounded by matrix in a single layer as shown in Figs. 1.7-1.9. The iso-phase configuration consists of plain weave laminates arranged one above the other so that the undulations are in phase with one another as shown in Fig 1.10. The out-of-phase configuration consists of plain weave laminates arranged in a symmetric manner as shown in Fig. 1.11, so that the undulation are out of phase by $\mathrm{P} / 2$ where $\mathrm{P}$ is the pitch of the undulation. In order to model the single lamina, iso-phase and out-of-phase laminates using finite element methods, only the representative volume elements (RVE) of the respective configurations are considered. The RVE is the repeating element (unit cell) of the whole composite fabric structure. 
Though theories to model the elastic behavior of plain weave fabric composites are well understood, theories to predict the non-linear behavior of such fabrics due to plasticity or damage mechanics have been rare. Therefore, the objectives of this research are

(a) To develop 3-D finite element models of plain weave laminated composites in order to predict their in-plane elastic moduli under tensile loading.

(b) To predict the in-elastic behavior of plain weave laminated composites under tensile loading with a user defined damage model using finite element methods.

\subsection{Thesis Overview}

The thesis consists of five chapters. Chapter 1 gives a brief description regarding the basic concepts involved with plain weave fabrics. It explains why we need to study the behavior of plain weave fabrics. Also, a literature survey on the modeling and analysis of plain weave laminates is presented in Chapter1.

Chapter 2 gives a detailed description on the 3-D geometric and finite element modeling of single, iso-phase and out-of-phase plain weave laminates. A procedure to determine the elastic moduli of the laminates is presented. Experimental correlations are provided in order to support validity of the proposed models.

Chapter 3 explains the formulation of the damage model that is used for predicting the inelastic behavior of the plain weave laminates. The parameters required for the damage model are explained in Chapter 3. A user subroutine is developed based on the damage model in FORTRAN [3] and is linked to finite element software for predicting the damage behavior of composites. 
Chapter 4 explains the procedure for analyzing the plain weave laminates with the damage model. The damage model is validated for the tensile response of unidirectional laminates using finite element methods and then the plain weave fabrics are analyzed.

The results obtained are compared with the experimental data available. The root cause of the non-linearity is identified and discussed. Chapter 5 gives a brief summary of the research, conclusions and, recommendations for future work.

\subsection{Literature Review}

Numerous methods are available for modeling and analyzing plain weave fabric composites. There are two main categories: analytical models and numerical models. A literature review of the available methods is summarized in this section.

\subsubsection{Analytical Models}

Most analytical models are the based on micromechanical study of the fabrics. Huang [4] developed a micromechanical bridging model to predict the elastic properties and strength of woven fabric composites. The geometric models of the fabrics (RVE) are well described. The yarn cross-section is taken as elliptical and a yarn undulation is described by a sinusoidal function. A discretization procedure is applied to the RVE of the fabric composite. The RVE is divided into a number of sub-elements, with no divisions in the thickness direction as shown in Fig. 7 of [4]. Each sub-element consists of the yarn segments and the pure matrix. The yarn segments are considered as unidirectional composites in their material co-ordinate system. The elastic response (compliance) of the yarn segments and the matrix are assembled in order to get the effective stiffness of the sub-element using classical laminate theory (iso-strain condition). The overall elastic 
property of the RVE is calculated by assembling the compliance matrix of the subelements under iso-stress assumption. In order to calculate the strength, the fiber is assumed to be elastic until failure and the matrix is considered as elasto-plastic. The overall stress applied to the sub-element is used to obtain the global stress sustained by each yarn segment and the matrix. These stresses are then transformed to the material coordinate system for the yarn segments. Huang [4] established a relation between the stresses in the matrix and fiber in the yarn using a bridging matrix, which indicates the load share capacity of fiber with respect to matrix. Using such relation, average stresses in the fibers and matrix are calculated and compared with the individual strengths. Only the stiffness of the matrix material is refined as it is elasto-plastic. The tensile strength of the fabric is predicted when the fiber stress in the yarn reaches a present value of fiber strength.

Naik et. al. [5] developed 2-D micro-mechanical models of plain weave fabrics to determine the elastic properties of the fabrics. The models take the warp and weft yarn undulations into considerations. In the case of the Slice Array Model (SAM), the RVE is divided into number of slices. These slices are idealized in the form of four-layered laminate (asymmetrical cross ply sandwiched between matrix layers at top and bottom). The properties of each slice are calculated from the individual layers (considering the undulation), which in turn are used for calculating the elastic constants of the RVE. The limitation of the model is that it approximates the stiffness contribution from the warp strand. This is because the undulation angle for the warp strand is approximated. In order to overcome these limitations, Naik et. al. developed the Element Array Model (EAM). It is further divided into series-parallel (SP) and parallel series (PS) models. In the SP 
model, the slicing is made in the warp direction. Each slice is further divided into elements of infinitesimal thickness. Then, the elastic constants of the warp and fill yarns are calculated within each element (considering the undulation angle), and then the stiffness of the element is calculated using the classical laminate theory. The compliance of the slices is calculated from the element stiffness matrix using iso-stress conditions. Finally, the overall stiffness of the RVE is calculated from stiffness of the slices using iso-strain condition.

In the PS model, the slicing is made in the fill direction. So, the elements in the slices are assembled using the iso-strain condition to get the slice stiffness and then the slices are assembled assuming iso-stress condition in order to obtain the overall stiffness of the RVE. Although these models show good correlation with the experimental data, they are very complicated.

Vandeurzen et. al. [6,7] developed analytical 3-D geometric and elastic models for 2-D "hybrid" woven fabrics. The first part of his work explains the geometric analysis of the woven fabrics in detail. Three groups of geometric parameters are identified for describing the 2-D weave geometry. The first group is the "know" group, which contains the data supplied by the weaving company- number of fibers, diameter of the fiber and yarn spacing. The second group is called the "measure group", which contains quantities that can be obtained from microscopic observations and calculations- aspect ratio of the yarns, thickness of the fabric laminate, yarn-packing factor, etc. The third group is called the "calculate group", which contains the parameters that can be calculated from the know and measure groups- fiber volume fraction, orientation of the yarns, etc. A partitioning procedure is used for discretizing the woven fabric unit cell. First, a macro 
partition is done to the checkerboard pattern of the woven fabric RVE. Each square of the pattern is divided into four macro cells with two cells in the upper layer and two cells in the lower layer. Then each macro cell itself is partitioned into small micro cells. There are two schemes involved in micro-partitioning - 1-D and 2-D micro-partition. In the 1-D scheme each macro cell is partitioned into four micro cells and does not consider the partitioning in the second direction whereas in the 2-D scheme, a two-dimensional approach is used to partition the macro cells. Using the partitioning scheme, the parameters in the "calculate" group are obtained. The important parameters calculated from the partitioning scheme include the yarn orientation and fiber volume fraction for each micro cell. Then, these micro cells are assembled to get the parameters of the macro cells, which in turn is assembled to get the parameters of the RVE or unit cell. The geometric analysis explained above is implemented using TEXCOMP, a custom application software for Microsoft Excel. Using the software, a parametric study is done on the yarn spacing limit based on the aspect ratio and crimp of the yarns, as well as studies are carried out on the fiber volume fraction, laminate thickness, and maximum yarn orientation as a function of yarn spacing for different aspect ratios. In order to determine the elastic constants of the fabric geometry model, Vandeurzen et. al. [6,7] developed two models- mixed yarn system model and non-mixed yarn system model . Each rectangular micro-cell is considered to be a mixed yarn system. First, the stiffness matrix for each micro-cell is calculated in the yarn coordinate system, assuming each micro-cell as a unidirectional lamina. Then, the local stiffness matrix is transformed to global coordinates. The overall stiffness matrix of the RVE or unit cell is obtained by assembling the elastic response of each micro-cell using iso-stress or iso-strain 
assumption. In the non-mixed yarn system, yarns and matrix are modeled discretely. Further, the yarns are split into different cells. The same procedure as for mixed-yarn system is repeated for calculation of elastic constants. The models works well for prediction of elastic modulus but the prediction of in-plane shear modulus is not good.

Hahn et. al. [8] developed a simple analytical model to predict the elastic properties of plain weave fabrics. The mathematical functions describing the yarn profiles and geometry are provided in detail. The cross-sectional and the undulation are assumed to be sinusoidal. Further, the undulation shape of a yarn determines the cross-section shape of a perpendicular yarn. Also, the volume fraction of voids is taken into consideration while calculating the volume fraction of fibers, which is neglected by previous investigators. The iso-strain condition is used for calculating the stiffness matrix of the woven fabric. First, the yarn stiffness components in material coordinate system are calculated using micromechanics equations. Then the overall stiffness is obtained by averaging the stiffness matrix of yarn and matrix over their thickness.

Scida et. al.[9] developed an analytical model called MESOTEX (MEchanical Simulation Of TEXtiles) based of classical laminate theory to predict the 3-D elastic properties, damage evolution, and strength of woven fabric composites. The properties are calculated by discretization process of the yarns and matrix in the unit cell as done by the previous investigators. The calculated stiffness is compared with experimental data and other models. Failure analysis is carried out using the Tsai-Wu criteria. The local stress in each dicretized yarn element of the unit cell is compared with the permissible values using the criteria. The Von-Mises criterion is used for predicting failure in matrix. Once the first ply failure occurs, the ply-discount method is used to reduce the stiffness, i.e., the 
stiffness of the element that is subjected failure is reduced to zero. The limitation of this model is that only the in-plane stresses of the fabrics are used in the calculation of the failure in a yarn whereas inter-laminar effects are important in fabrics. Also, the plydiscount method used for stiffness reduction scheme is very approximate.

Chou et. al. [10] developed 1-D analytical models of the plain weave laminated composites for determining their stiffness and strength. The undulation of the fill yarn is not considered for the analysis. Three different laminate stacking configurations are considered for the analysis: Iso-phase, out-of-phase and random phase laminates. Mathematical models of the configurations are explained very well and are evaluated experimentally for all three configurations. The undulation of warp yarn is assumed to be sinusoidal and two types of cross-section are assumed for the fill yarns: sinusoidal and elliptical. The iso-strain condition is used for evaluating the stiffness of the plain weave laminates. In case of the strength analysis, the maximum stress criterion is used for prediction of failure strength of the laminates. The predictions relate well with experimental results for the in-plane Young's modulus and strength values when elliptical cross-section is assumed for fill yarns.

Also, Chou et. al. [28,29] have developed three models to predict the elastic properties of woven fabric laminates. The mosaic model [28] is used to predict the stiffness of satin weave fabric composites. The model neglects the yarn crimp and idealizes the composite as an assemblage of asymmetric cross-ply laminates. Then, iso-stress or iso-strain condition is used to predict the stiffness of the laminate depending on whether the laminates are assembled in series or parallel. Since the model neglects the yarn crimp, the prediction of stiffness is not accurate. The fiber undulation model [28] or the 1-D model 
considers fiber undulation in the longitudinal direction and is neglected in the transverse direction. The bridging model [29], combination of mosaic and fiber undulation model, is developed for satin weave fabrics. The model reduces to crimp model [28] for the plain weave fabrics and hence the stiffness prediction is not accurate.

\subsubsection{Finite Element Models}

The closed form solutions provide simplified stress-strain distributions whereas numerical models provide detailed stress-strain distributions. The geometrical description of the unit cell architecture with the yarns and matrix is the most important aspect in finite element analysis. Mathematical models have been developed describing the geometry of a unit cell. Averill et. al. [11] developed a simplified analytical/numerical model for predicting the elastic properties of plain weave fabrics. The unit cell of the fabric is discretized with brick elements, with one element through the thickness of the cell. The tow volume fraction and tow inclination are calculated based on the assumed unit cell geometry. The stiffness properties of each element are calculated from the fiber volume fraction, orientation of fibers, and fiber and matrix properties using effective moduli theory. These properties are given as input to the finite element model and the overall properties of the unit cell are obtained by applying necessary boundary conditions. The model is simple in the sense that 3-D modeling of tows is not required. Therefore, a fewer number of elements are required for the model and hence the computational time is small. The model yields good results for the stiffness values except for inter-laminar shear modulus $\mathrm{G}_{13}$.

Blackletter et. al. [12] developed a 3-D finite element model of a plain weave fabric and studied the damage propagation in the fabric under tensile and shear loading. The yarns 
and matrix are modeled using PATRAN. Hexahedral elements are used for generating the mesh. The yarns are modeled as unidirectional composite materials. The yarn properties are calculated using two-dimensional generalized plane strain micromechanics analysis. The properties of individual fibers and matrix are used for predicting the damage behavior of the yarns used in the failure analysis. In the in-elastic analysis, the damage is tracked at each Gaussian integration point. The maximum normal stress criterion is used for the matrix elements, i.e., when the principal stresses exceed the strength values; the tensile modulus and shear modulus are degraded by a fudge factor in the range 0.01-0.1. Maximum stress criterion is used for the yarn elements, i.e., when the stress in the material coordinate exceeds the ultimate strengths; the stiffness is reduced in the appropriate direction at each integration point. The damage model is then used in finite element analysis to predict the in-elastic behavior of plain weave fabrics. Transverse failure is observed prior to catastrophic failure of the fabric in the tensile test. The model over-predicts the failure strength of the fabric. In the case of the shear test, transverse tensile failure of the yarns is observed which, according to the model, results in reduction of transverse tensile modulus and in-plane shear modulus to essentially zero. But, the analysis greatly under predicts the failure strength. Therefore, the degradation factor of in-plane shear modulus is assumed as 0.2 instead of 0.01 so as to match the experimental shear response. Therefore, the damage model employed is similar to the degradation factor method [1] and it is therefore approximate.

Sridharan et. al. $[13,14]$ developed two types of finite element model for plain weave fabrics. The first type is similar to the previous finite element models where the quarter model of the RVE, containing the yarns and matrix, is meshed using 3-D solid elements. 
The second type is different from the usual models. Here the model consists of plate elements representing the yarns and 3-D solid elements representing the matrix sandwiched between the yarns. Thus, the unit cell consists of four plate elements representing fill and warp yarns. The thickness variations in the yarns are incorporated in the plate elements. Elastic responses of the two models match well with the experimental data. The in-elastic analysis of the models is carried out by assuming material nonlinearity in the yarns and matrix. A micromechanical model is proposed in order to describe the stress state of fiber and matrix within the yarns. The fibers are assumed to be elastic until failure. The micromechanical model is installed at each integration point. The non-linearity of the matrix is modeled using Ramberg-Osgood relations. Also, non-linear geometry is considered for the analysis. The in-elastic behavior of plain weave fabrics is analyzed when subjected to in-plane tensile, compressive, and shear loads applied in the fill direction. The model identifies the failure modes for each loading. The model is simple in formulation and the computation time required for the analysis is low. The model gives a good strength prediction for plain weave laminates subjected to tension and shear.

\subsubsection{Summary}

Though a number of plain weave fabric models are available for predicting stiffness and strength, each model has their limitations.

- Some models have not been able to incorporate the yarn crimp of fill and warp yarns which lead to approximate prediction of fabric properties

- Some models assume the cross-section of yarns to be semicircular which does not represent the true geometry. 
- Progressive damage analysis, which predicts accurate in-elastic response, is not used in most of the models. Instead, a ply degradation technique is adopted for predicting strength, which is a very rough estimate.

- Also, most of the models consider the effect of in-plane stresses only, neglecting the inter-laminar effects.

The aim of this thesis is to develop accurate finite element models of plain weave fabrics and determine the stiffness and strength properties without these limitations. 


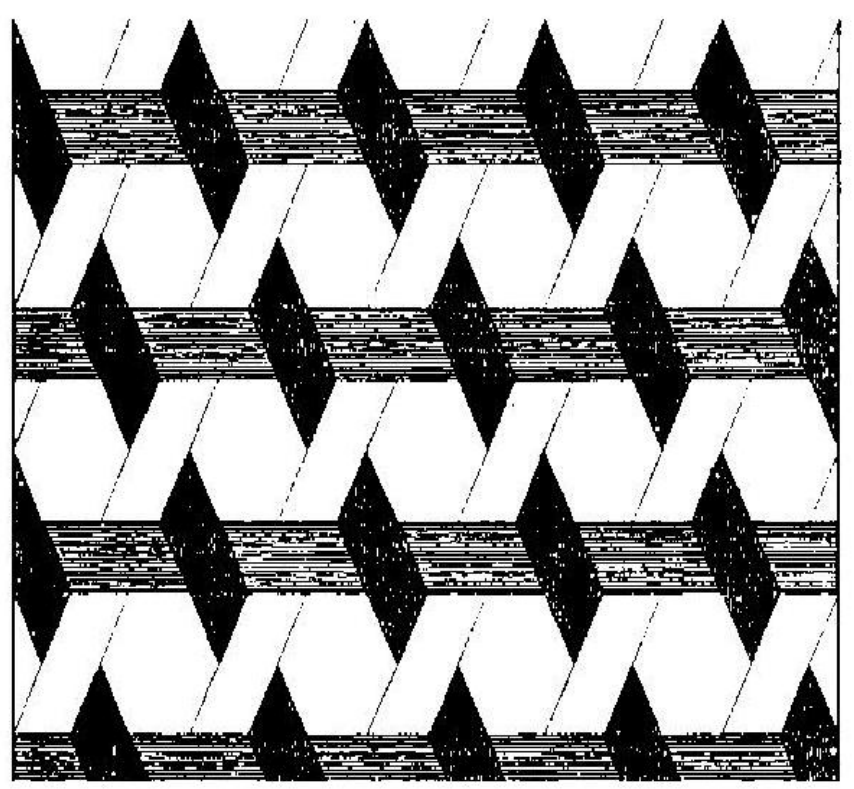

Fig. 1.1 Triaxial weave fabric [2]

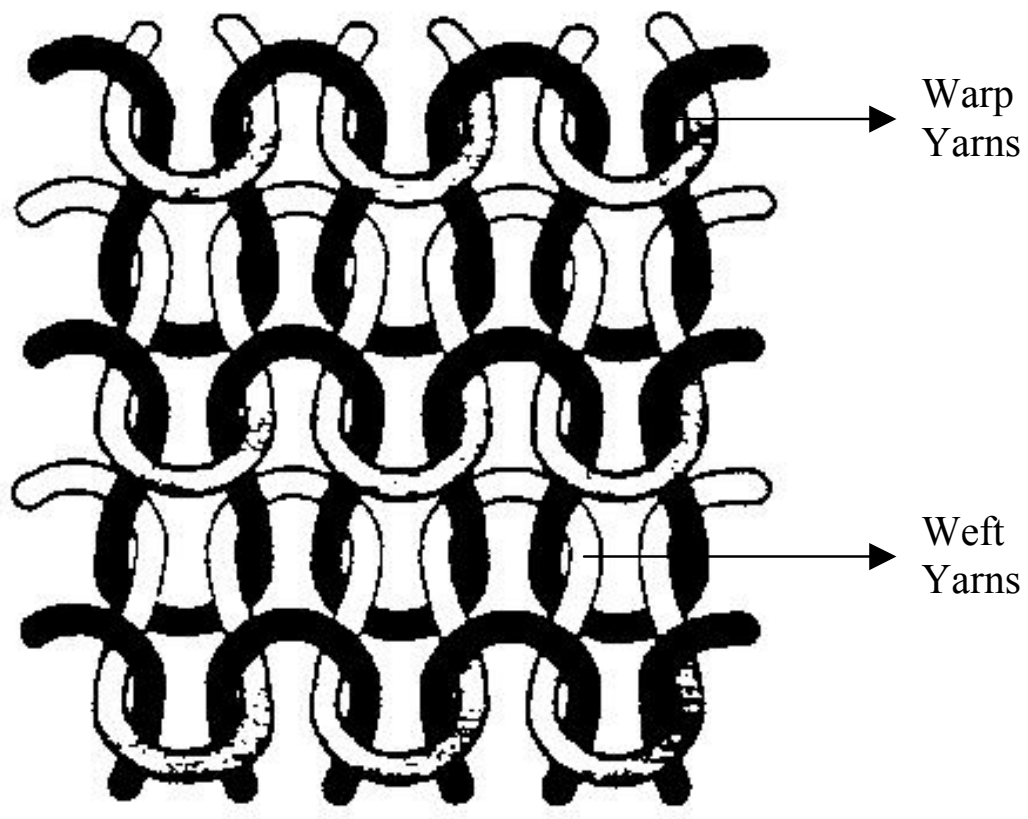

Fig. 1.2 Knitted Fabric [2] 


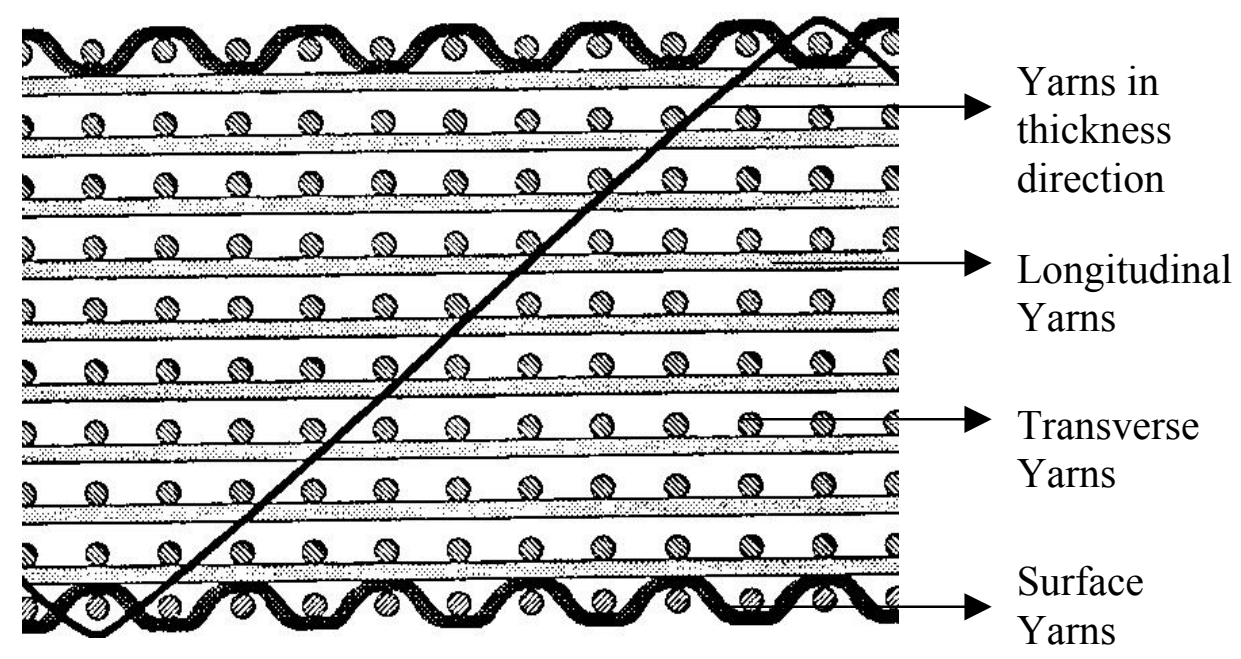

Fig. 1.3 3-D fabric [2]

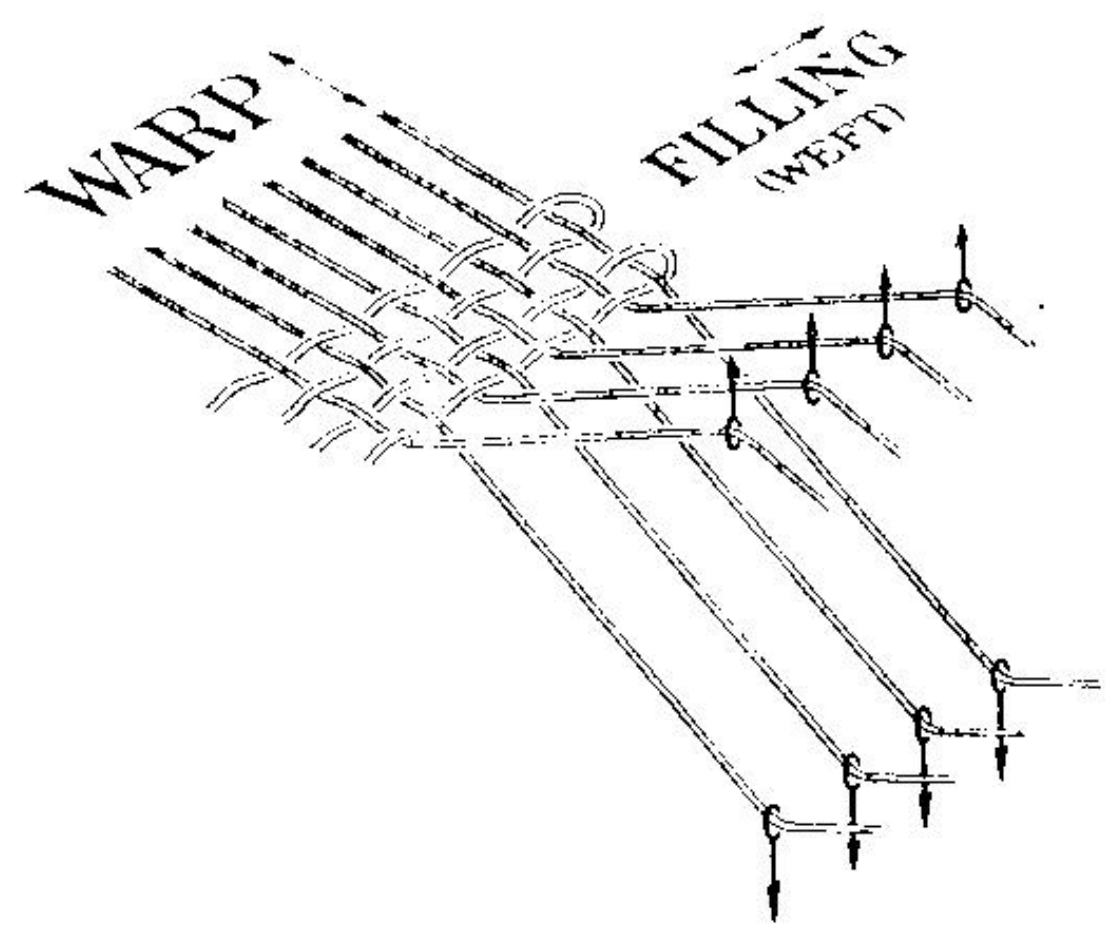

Fig. 1.4 Shedding Process for a Plain Weave Fabric [2] 


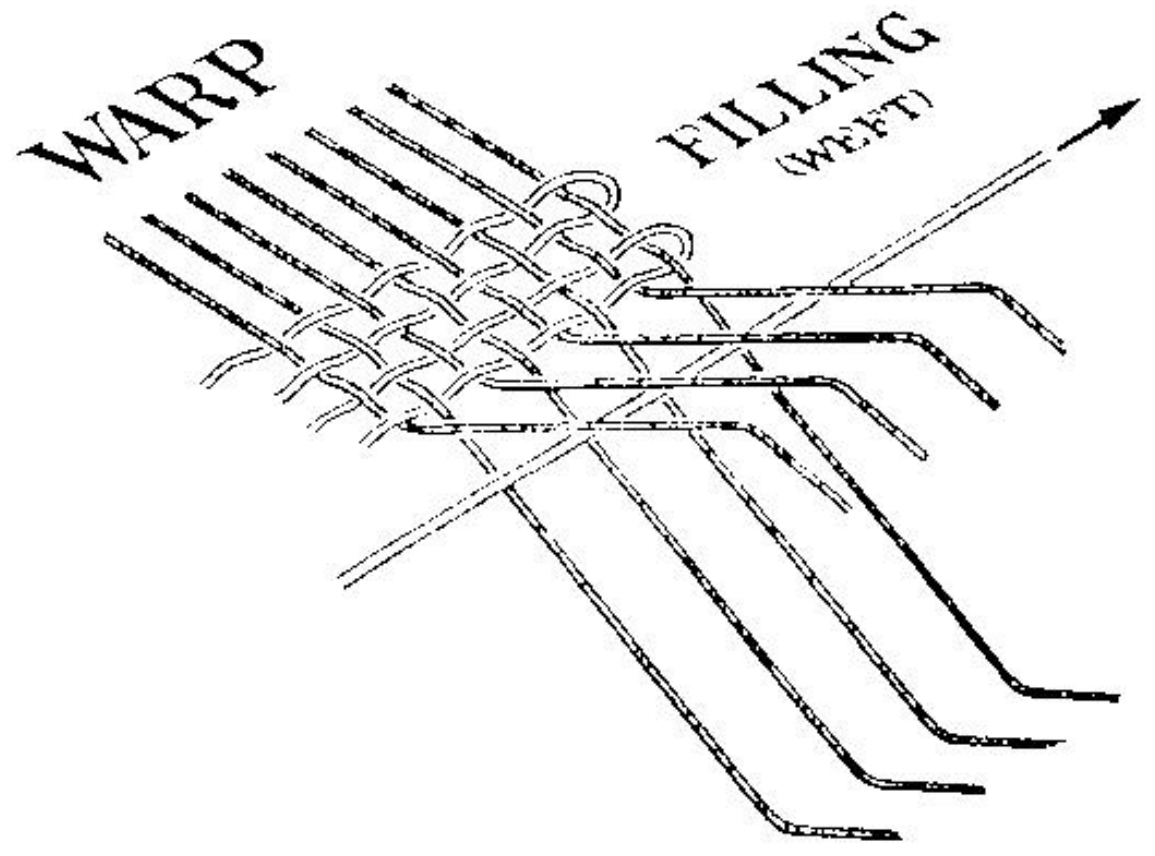

Fig. 1.5 Picking Process for a Plain Weave Fabric [2]

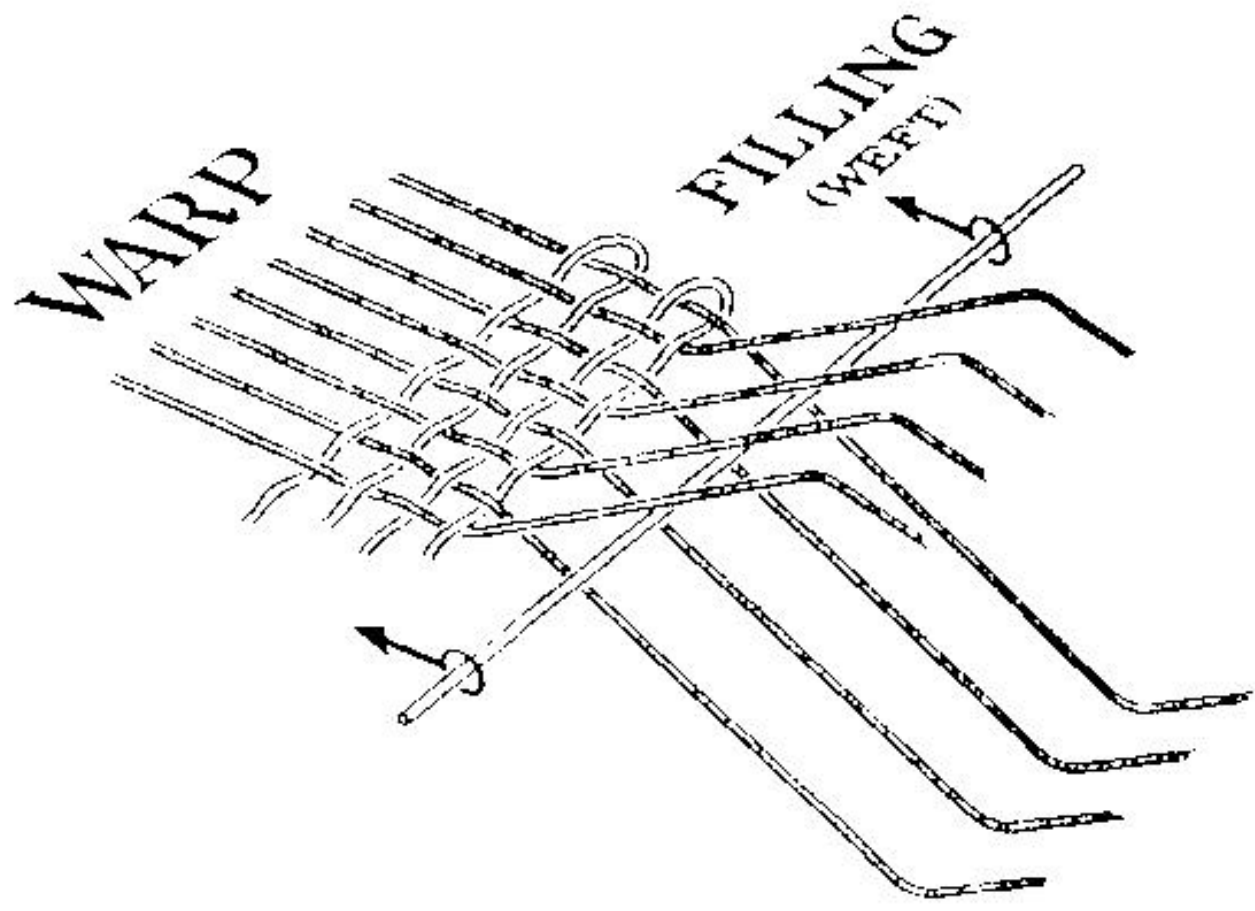

Fig. 1.6 Beating Process for a Plain Weave Fabric [2] 


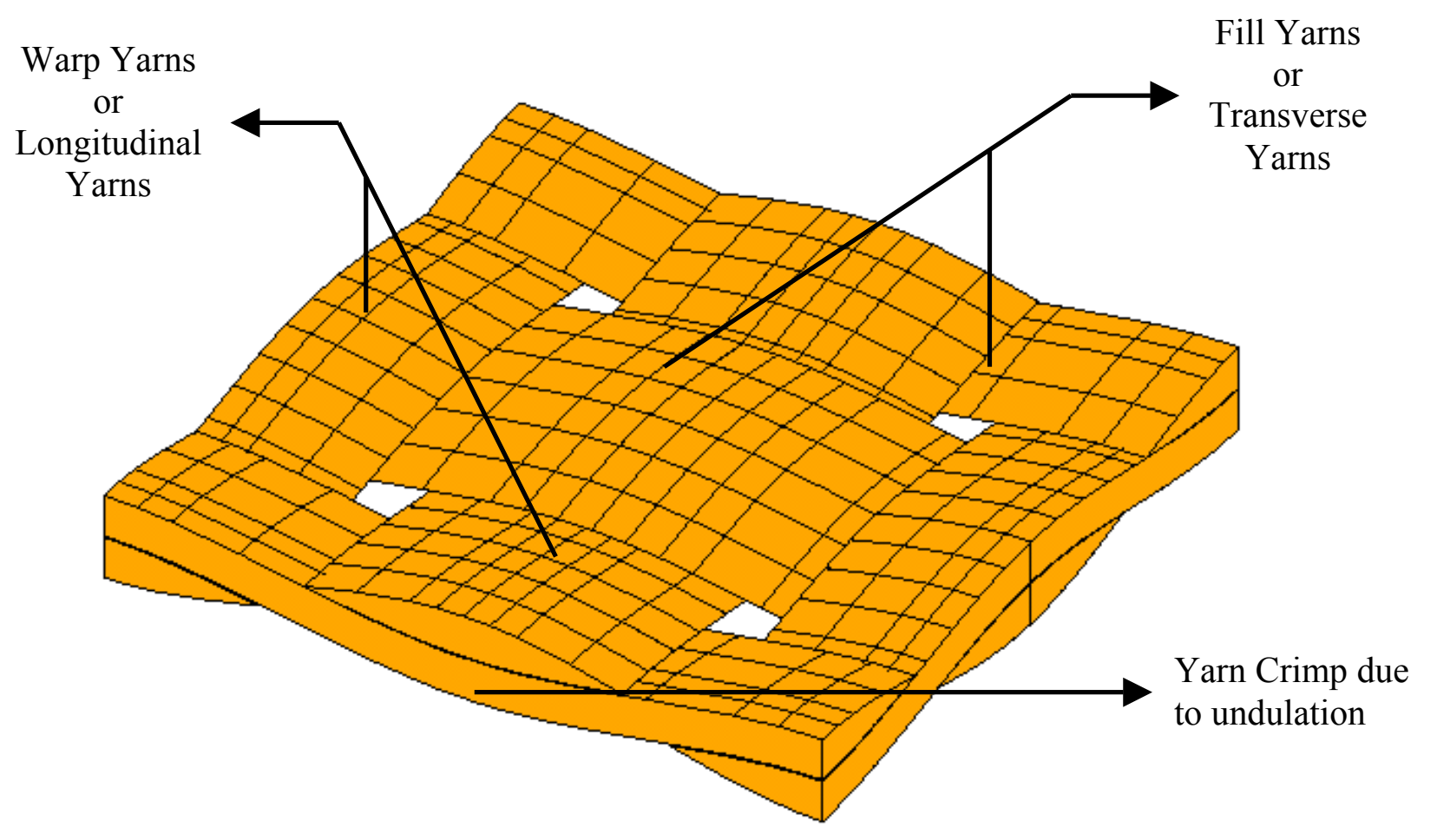

Fig. 1.7 Model of a Single Lamina without matrix

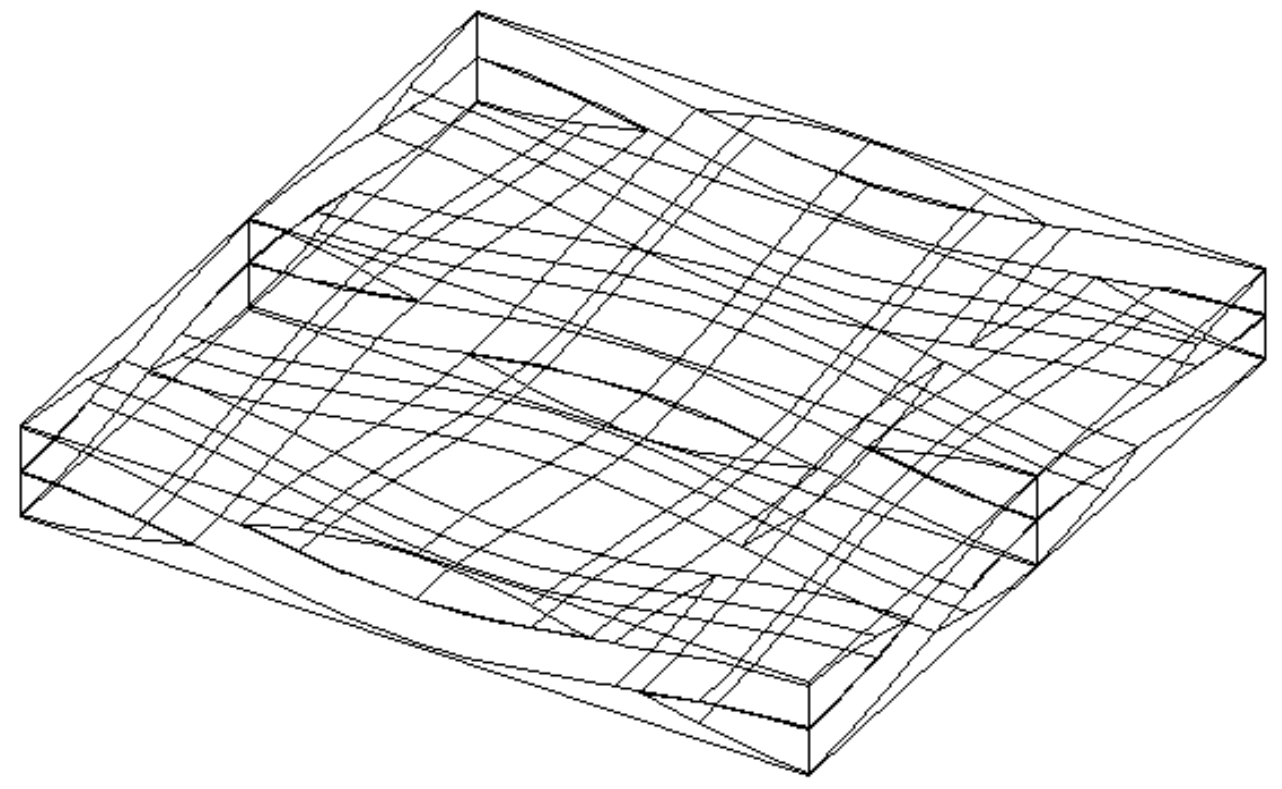

Fig. 1.8 Model of a Single Lamina with matrix 


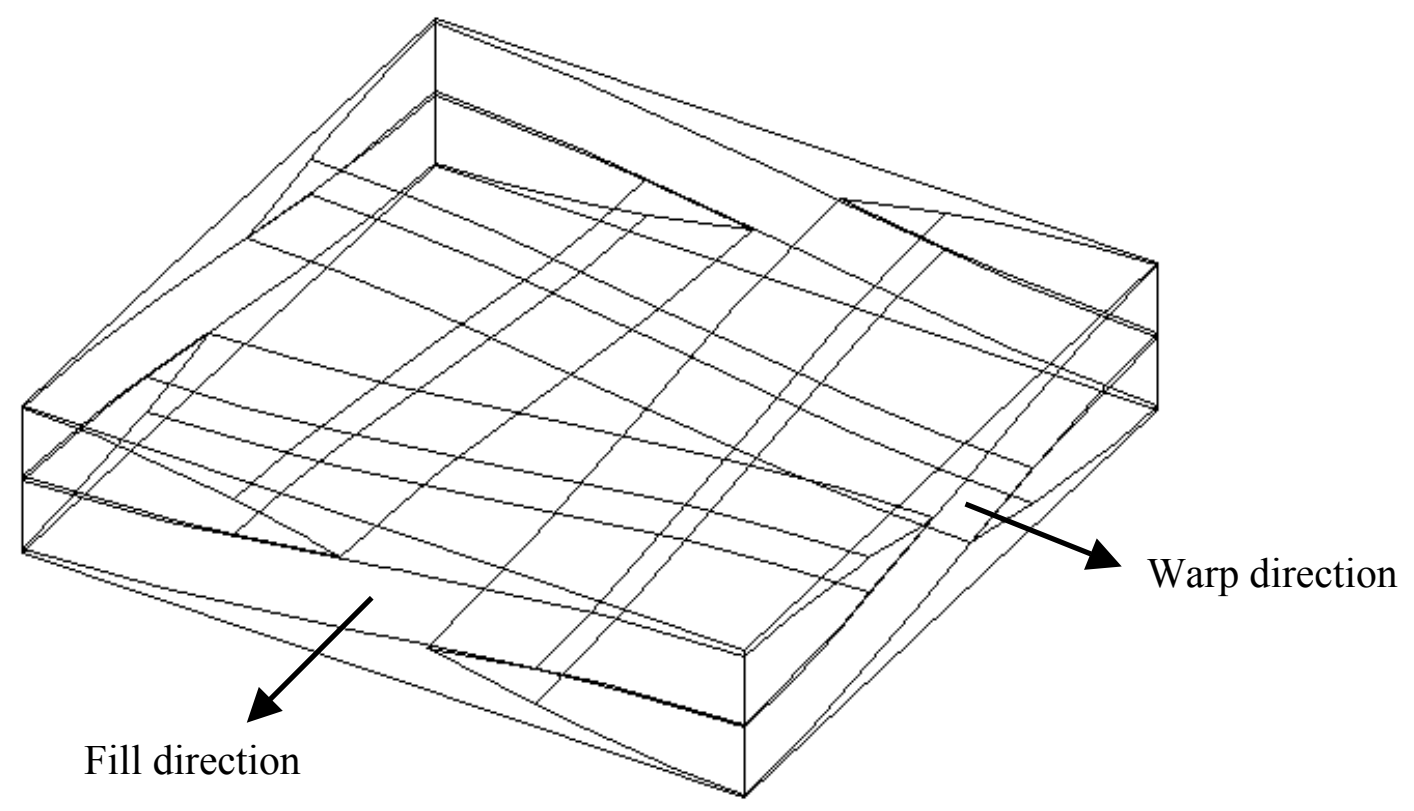

Fig. 1.9 RVE of a single lamina (quarter model)

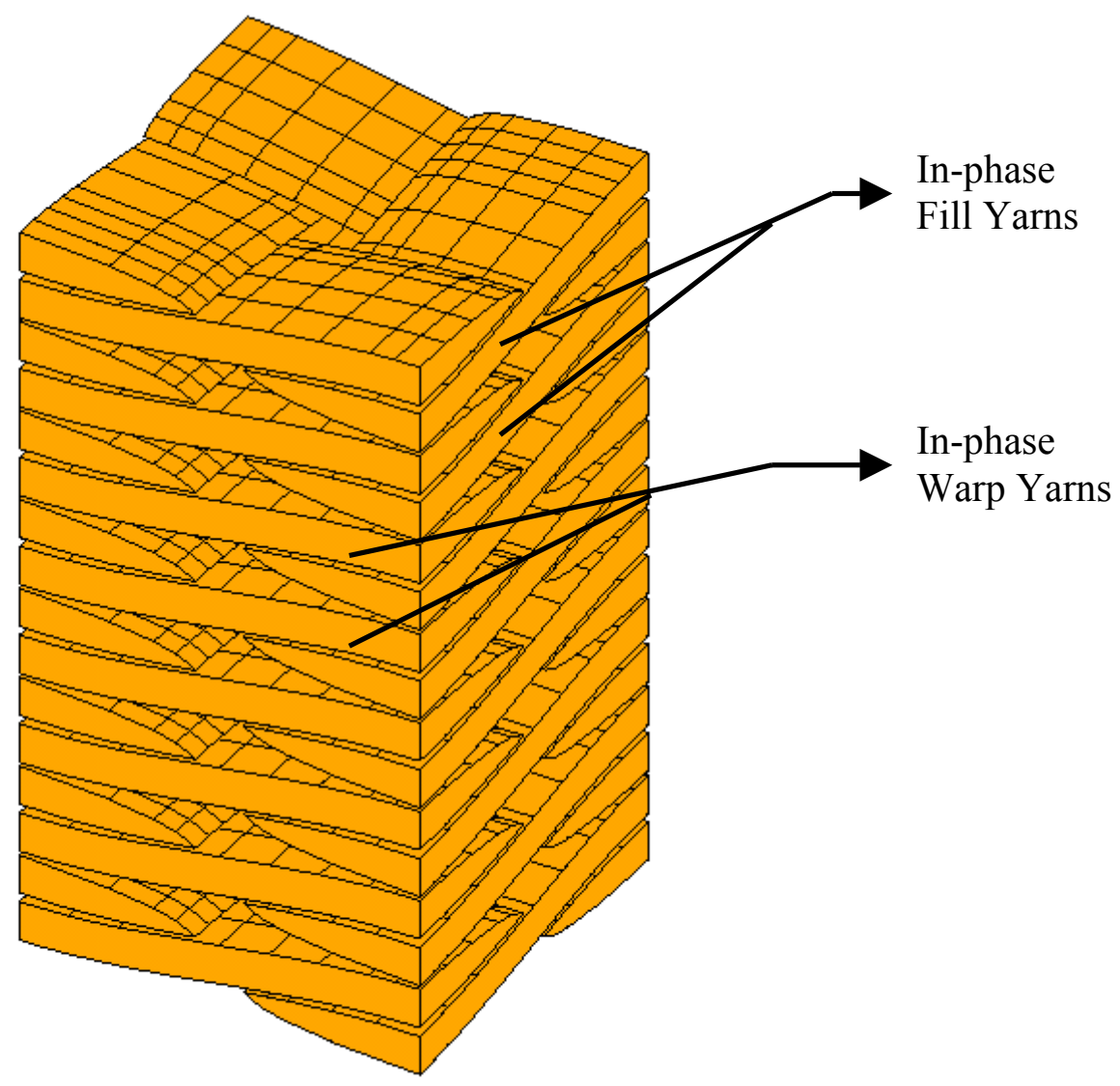

Fig. 1.10 Iso-Phase model 


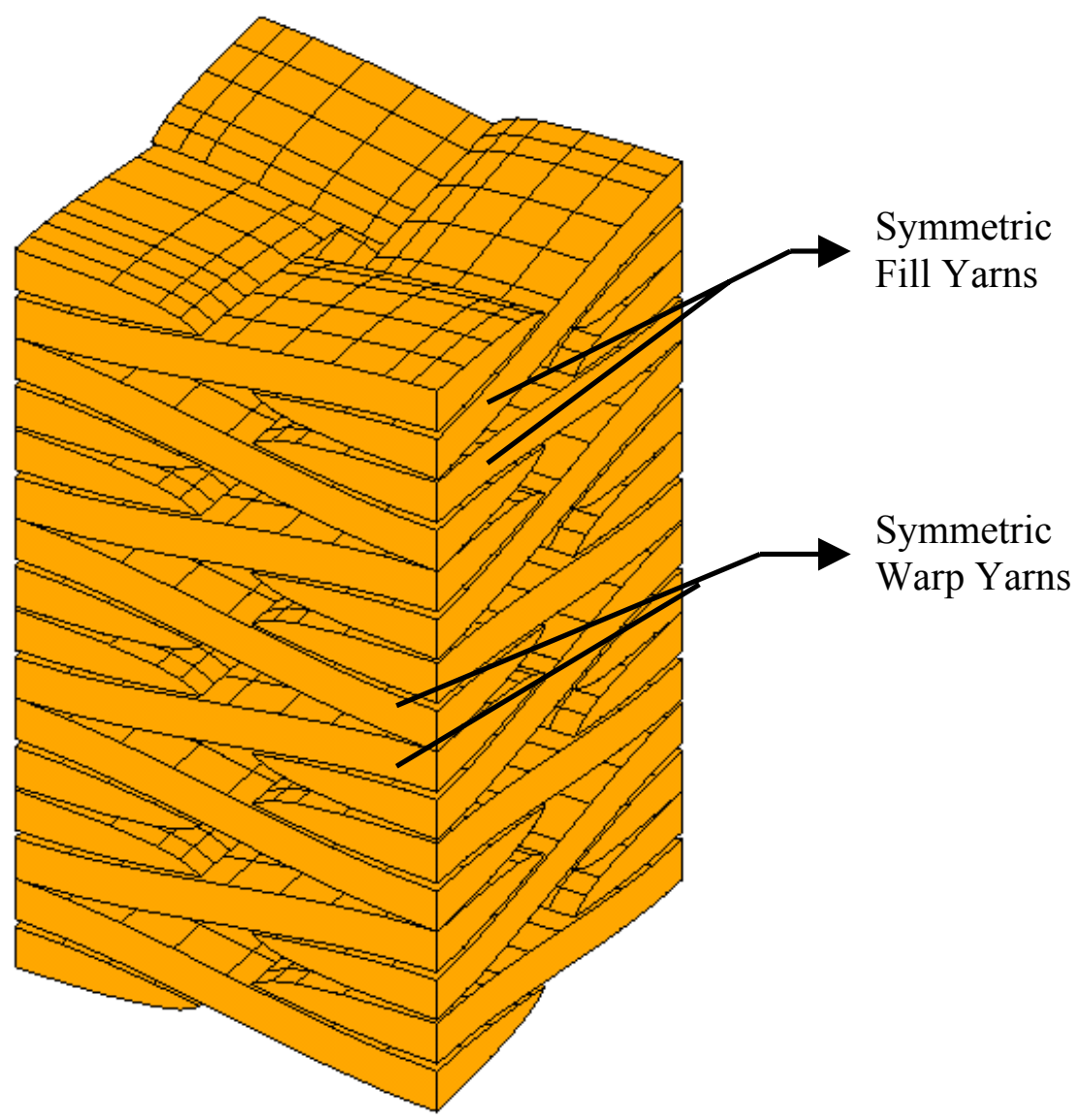

Fig. 1.11 Out-of-Phase model 


\section{CHAPTER 2: 3-D GEOMETRIC AND FINITE ELEMENT MODELS OF PLAIN WEAVE FABRICS}

\subsection{Introduction}

The various stages involved in geometric and finite element modeling of the plain weave fabrics are explained in this chapter, which is divided into two parts. The first part explains the geometric modeling of plain weave fabric laminates based on optical measurements of the plain weave pattern $[15,10]$. The second part explains the development of finite element models of the laminated plain weave fabrics for predicting the longitudinal stiffness and comparing it with experimental results [10].

\subsection{Geometrical Models}

The geometrical model for the representative volume element (RVE) and the yarns for plain weave fabrics were developed using the geometrical parameters measured by CERL [15] and Ito and Chou [10]. The RVE consists of four intertwined yarns surrounded by the matrix (isotropic). There are two warp yarns in the longitudinal direction and two fill yarns in the transverse direction. Each yarn is a unidirectional composite in the material coordinate system with orthotropic properties. 2-D and 3-D views of the fabric are shown in Fig. 2.1 and 2.2.

\subsubsection{2-D Geometrical model based on measurements by CERL}

The 2-D geometrical model describing the internal geometry of the RVE of a single lamina is developed from the measured values of the yarn parameters. The measured 
values are given in Appendix A. The parameters describing the geometry are shown in Fig. 2.3. The boundaries of the yarns on the faces of the RVE are given by the equation:

$$
\begin{gathered}
\mathrm{y}=\mathrm{P} 1 \sin (\mathrm{P} 2 \mathrm{x}+\mathrm{P} 3)+\mathrm{P} 4 \\
\mathrm{P} 4=\frac{\mathrm{b}}{2} \\
\mathrm{a}=\frac{\pi}{\mathrm{P} 2} \\
\mathrm{~h}=2 \mathrm{~b}
\end{gathered}
$$

where

$\mathrm{P} 1=$ Amplitude of the yarn path curve

$\mathrm{P} 2=$ Period of the yarn path curve

P3= Phase adjustment factor

$\mathrm{P} 4=$ Offset

$\mathrm{b}=$ Yarn thickness in $\mathrm{mm}$

$\mathrm{a}=$ Length and Width of the RVE in mm

$\mathrm{h}=$ Height of the RVE in $\mathrm{mm}$

These values are measured in longitudinal and transverse directions since the shape and size of the yarns are different in these two directions. The above equations are plotted using Microsoft Excel to verify whether the curves from the longitudinal and transverse directions match (do not overlap nor gap exists). The plot spans the thickness and the period of the RVE. The curves in the longitudinal direction did not match with the curves in the transverse direction, as shown in Fig. 2.4. This is due to error in the measurement of amplitude of the fill yarn curve in the transverse direction. Hence, the amplitude of the curve (P1) is adjusted in the transverse direction so that the curves in the two directions 
match as in Fig. 2.4. (P1 of the transverse yarn path curve is changed from $0.1367 \mathrm{~mm}$ to $0.1165 \mathrm{~mm}$ so as to match the geometry of the yarns in longitudinal direction). The measured parameters for developing the mathematical model of the RVE are shown in Table 2.1. The geometrical model was developed using this set of equations.

\subsubsection{2-D Geometrical model based on measurements by Ito and Chou}

2-D Geometrical models of the RVE for single lamina, iso-phase, and out-of-phase laminates are developed from the yarn parameters measured in [10]. The parameters measured [10] are different from those measured by CERL [15]. Equations proposed by Ito and Chou [10] are used as a starting point for developing the geometrical model of the yarns for each kind of laminate. The parameters used are illustrated in Fig 2.5.

\section{Yarn path curve:}

$$
\mathrm{y}=\frac{\mathrm{hy}}{2} \sin \left(\frac{2 \pi \mathrm{x}}{\mathrm{a}}\right) \text { where }-\frac{\mathrm{a}}{4}<\mathrm{x}<\frac{\mathrm{a}}{4}
$$

\section{Yarn cross-section curve:}

$$
\begin{gathered}
y=\left(\frac{2 h c}{a-2 a g}\right) \times \sqrt{(2 x-a g)(a-a g-2 x)}+h y-h c \text { where } \frac{a g}{2}<x<\frac{a}{4} \\
h c=\frac{h y}{2}\left(\sin \left(\frac{\pi a_{g}}{a}\right)+1\right)
\end{gathered}
$$

where

hy $=$ yarn thickness

$a=$ length and width of the RVE

$\mathrm{a}_{\mathrm{g}}=$ gap width between two adjacent yarns 
The values of the parameters measured by [10] are shown in Table 2.2. These equations are used to develop the geometric models of the plain weave fabrics with different laminate stacking configurations.

\subsection{3-D Geometric Modeling}

The 3-D geometric models are created using modeling software. I-DEAS, Version.8, is chosen to model the RVE of the plain weave fabrics as it was simple, had interactive GUI menus that was easy to work with, and offered features like creating volume from set of curves, partitioning of solids, material orientation features, etc.

\subsubsection{Geometric modeling of a Single Lamina}

The procedure for developing 3-D geometric models of single lamina based on both of the 2-D geometrical models $[15,10]$ is the same. First, the yarn path curves and the yarn cross-section curves in the warp and fill direction are drafted from the measured parameters (Table 2.1, Table 2.2) and equations (Eqs. 2.1-2.7) in the 2-D geometrical model using the function spline option in I-DEAS. Sweeping operation could not be performed with the curves because the warp (and fill) yarn cross-section curves did not match the fill (and warp) yarn path curves in the faces of the RVE. This is due to the fact that the cross-section and path curves have different shape. So, the cross-section curves need to be blended with the path curve. For this purpose, the cross section curves are flipped (rotated by $180^{\circ}$ ) in the faces of the RVE where the cross-section curves do not match the path curves. Then, the surfaces are formed from the cross-section and path curves that define the yarn surfaces in the warp and fill directions. In order to define the surfaces of warp or fill yarns, 3 path curves and 4 cross-section curves are required as shown in Fig. 2.6. Surfaces related to the warp (and fill) are stitched together to get a 
solid model of the yarns. In total, the four intertwined yarns are formed with two of them in warp direction and two in fill direction. But there is a problem of yarns intersection when the surfaces are stitched together. This is due to interpolation of I-DEAS software when the surfaces are formed from the (analytical) spline curves. So, the fill yarns are slightly rotated about warp axis to make the four yarns non-intersecting, which resulted in a small gap between them. This small gap is modeled as matrix. The yarns are then partitioned from a rectangular prism having the dimensions the RVE, which indicates to the software that there are four yarns inside the prism. This is visualized as four yarns surrounded by matrix as shown in Fig. 2.7.

\subsubsection{Geometric Modeling of Iso-phase and Out-of-Phase Lamina}

In addition to measurement of yarn parameters of a single lamina, Ito and Chou also measured the parameters for iso-phase and out-of-phase laminate configurations [10]. In the case of the iso-phase laminate, the same procedure is followed as that for the single lamina. The number of plies is taken as eight for the iso-phase laminate configuration as done in the experiment [10]. So, copies of the single lamina are made and moved by an amount equal to the thickness of the lamina (Table 2.2). Then, the join operation is used to join the eight laminates as shown in the Fig. 2.8.

For the out-of-phase laminate, the geometric model consists of eight plies, with the single lamina arranged in a symmetric manner as shown in Fig. 2.9. The parameters for obtaining the solid model of the out-of-phase laminate are reported in Table 2.2. The Finite Element models are developed from the geometric models. 


\subsection{Finite Element Modeling}

A simple method is used to create the FE models. The geometric models (Sect. 2.2.1, 2.2.2) are meshed using 10 noded solid parabolic tetrahedral elements under the free mesh option in I-DEAS (Fig. 2.10-2.11). Each node has 3 degrees of freedom, $\mathrm{u}_{\mathrm{x}}, \mathrm{u}_{\mathrm{y}}$ and $\mathrm{u}_{\mathrm{z}}$. The elements exhibit a quadratic displacement behavior, which is well suited for modeling the complex and irregular structure of the plain weave fabric. The mesh is checked for distortion. A mesh sensitivity analysis is performed in order to get accurate results. The material property of the yarns varies along the orientation of the yarn curve.

Therefore, the material orientations of yarn elements are made to follow the yarn curve using the material orientation option. The local X-direction of co-ordinate system for each element follows the path curves of the warp or fill yarns (depending on the yarns for which material orientation is being defined) using the option. The X-direction of the yarn elements indicates the fiber direction, the $\mathrm{Y}$-direction indicates the transverse direction of the RVE (Figs. 2.7 and 2.12) and the Z-direction indicates the thickness direction. The meshing and material orientation is illustrated in Fig 2.10, 2.11 and Fig 2.12 .

Transversely isotropic material properties are assigned to the yarn elements and isotropic properties are assigned to the matrix elements. The material properties of the yarns are calculated using micromechanics [16]. The volume fraction and elastic properties of fiber and matrix differed for the CERL [1] and Ito and Chou's [10] models. In addition, a volume correction had to be done for the Ito and Chou models as explained next. 


\subsubsection{Volume Fraction correction for Ito-Chou models}

The overall volume fraction (Vo) is obtained from experimental data [10] for the three laminate stacking configurations and it is reported in Table 2.3. Experimental values of Vo can be obtained from ignition loss method (ASTM D2854-68). Vo is the product of the mesoscale volume fraction Vmeso and yarn volume fraction $\mathrm{Vf}$

The mesoscale volume fraction can be obtained from the solid model as the ratio of yarn volume to RVE volume.

$$
\text { Vmeso }=\frac{\text { Vy }}{\text { Vrve }}
$$

Therefore, the microscale (yarn) volume fraction can be obtained as

$$
V f=\frac{\text { Vo }}{\text { Vmeso }}
$$

where

Vmeso $=$ mesoscale volume fraction obtained from the geometric model

$\mathrm{Vf} \quad=$ microscale fiber volume fraction used for calculating the material properties of yarns.

$\mathrm{Vy}=$ total volume of the yarns calculated from the geometric model

Vrve = volume of the RVE obtained from the geometric model.

The yarn fiber volume fraction Vf calculated from above equations did not match the Vf reported in [10]. Vmeso from our model is too high because the rotation of the yarns [Sect. 2.2.1] results in an increase in thickness of the RVE. This is accounted for by calculating the correct mesoscale volume fraction Vmeso' using the original dimensions of RVE, as follows

$$
\text { Vmeso' }^{\prime}=\frac{\text { Vy }}{\text { Vrve' }^{\prime}}
$$


and recalculating the yarn fiber volume fraction

$$
\mathrm{Vf}^{\prime}=\frac{\mathrm{Vo}}{\text { Vmeso' }^{\prime}}
$$

where

$\mathrm{Vmeso}^{\prime}=$ corrected meso scale volume fraction from measured data [10]

Vrve' $^{\prime}=$ corrected volume of RVE from measured data [10]

$\mathrm{Vf}^{\prime}=$ corrected fiber volume fraction of fiber.

Using $\mathrm{Vf}^{\prime}$ the material properties of the yarns is calculated using micromechanics [16]. The microscale fiber volume fraction for the CERL model [15] is $\mathrm{Vf}=0.5$. The elastic properties of constituent materials for CERL are obtained from [1] and for Ito and Chou models from [10]. The yarns are transversely isotropic and require only five properties $\left(E_{1}, E_{2}, G_{12}, v_{12}, v_{23}\right)$ since

$$
\begin{aligned}
\mathrm{E}_{2} & =\mathrm{E}_{3} \\
\mathrm{G}_{12} & =\mathrm{G}_{13} \\
v_{12} & =v_{13} \\
\mathrm{G}_{23} & =\frac{\mathrm{E}_{2}}{2\left(1+v_{23}\right)}
\end{aligned}
$$

Since AS4 carbon fiber is transversely isotropic, the elastic properties are calculated using periodic microstructure micromechanics for isotropic fibers (PMM) [18] in Microsoft Excel. Most micromechanics models assume the transversely isotropic fibers to be isotropic (e.g. [16]). As an alternative to [18] and to validate the predictions we also implemented the following procedure to account for transversely isotropic fibers with a simple model [16].

1. $E_{1}$ is calculated by using the longitudinal fiber modulus $E_{f 1}$ and $v_{12 f}$ of the fiber, and elastic properties of matrix. 
2. $E_{2}$ is calculated by using the radial fiber modulus $E_{\mathrm{f} 2}$ and $v_{12 \mathrm{f}}$ of the fiber, and elastic properties of matrix.

3. $G_{12}$ is calculated by using the value of $G_{12 f}, v_{12 f}$ of the fiber and elastic properties of matrix.

4. $\mathrm{G}_{23}$ is calculated by using $\mathrm{E}_{\mathrm{f} 2}, v_{23 \mathrm{f}}$ of the fiber and elastic properties of matrix, where $v_{23 f}$ is calculated from Eq. 2.13, which is valid for a transversely isotropic material.

The properties are checked for the restrictions on elastic constants [17]. The results are compared with the PMM model that assumes fibers to be transversely isotropic material [18] and with [16] using only longitudinal fiber properties $E_{f 1}$ and $v_{12 f}$. The results obtained from the procedure show good correlation with the PMM model for transversely isotropic fibers (Table 2.5). The elastic properties of the constituent materials and the overall properties of the yarn (composite) are reported in Table 2.4. Then, the properties are assigned to the yarn and matrix elements in I-DEAS. The next step is to apply the boundary conditions and analyze the results.

\subsection{Boundary Conditions}

In case of all laminated configurations, the RVE represents the quarter of a full model of the laminated plain weave fabrics. So, symmetric boundary conditions are assigned to the nodes in the back surfaces in the warp direction (YZ plane) and to the nodes in the right surfaces in the fill direction of the RVE (XZ plane, Fig. 2.7). Then, nodes in the left surfaces are coupled to move along a straight line the $\mathrm{Y}$ direction to enforce periodicity compatibility conditions (Fig. 2.13). This simulates the full model. Then, a one percent strain $(\varepsilon=1 \%)$ is assigned to the nodes in the $\mathrm{X}$ direction at the front surfaces in the fill 
direction as illustrated in Fig. 2.13. The conditions are given in order to predict the stiffness value in longitudinal direction $(\mathbf{E x})$.

\subsection{Linear Solution and Post Processing:}

\subsubsection{Solution in I-DEAS}

A linear static analysis is performed on the FE models with the necessary boundary conditions in I-DEAS. The following procedure is used for calculating the stiffness of the single lamina, iso-phase, and out-of-phase laminates for CERL and Ito and Chou models. During the post processing stage, the results of the reaction forces in the $\mathrm{X}$ direction are obtained. For calculating the value of stiffness $(\mathrm{Ex})$, the sum of the reaction forces $\left(\mathrm{F}_{\mathrm{x}}\right)$ in the $\mathrm{X}$ direction, in the loading surface of the RVE, was obtained. Taking $\mathrm{F}_{\mathrm{x}}$ and dividing it by the cross-section area of the RVE, the average stress acting on the surface is calculated $\left(\sigma_{\mathrm{x}}\right)$. Finally, Ex was obtained by dividing $\sigma_{\mathrm{x}}$ with the strain $(\varepsilon)$. But the value has to be adjusted due to the volume fraction correction described in Eqs.(2.10-2.11). The actual stiffness is calculated as follows

$$
\mathrm{Ex}^{\prime}=\mathrm{Ex}\left(\frac{\mathrm{Vmeso}^{\prime}}{\mathrm{Vmeso}^{\prime}}\right)
$$

Experimental results for the CERL model are not available. The results obtained for the Ito and Chou models are compared with the experimental stiffness [10] in Table 2.6 and 2.7 .

\subsubsection{Solution in ANSYS}

As a preamble for future work including damage, it was desired to recalculate the models in ANSYS. This is because the damage constitutive equation can be modeled in ANSYS but not in I-DEAS (Chapter 3). The FE models of the plain weave fabric are exported to 
ANSYS, Version 6.1 as a data file. While exporting, the element type is changed to Solid 92, which is an equivalent for parabolic element in ANSYS. There were several errors encountered while opening the file in ANSYS. The ANSYS software supports two types of Poisson's ratio, major Poisson's ratio and minor Poisson's ratio, for orthotropic material model. The major Poisson's ratio (PRXY, PRYZ, PRXZ) corresponds to $v_{\mathrm{xy}}$, $v_{\mathrm{yz}}, v_{\mathrm{xz}}$ as input. The minor Poisson's ratio (NUXY, NUYZ, NUXZ) corresponds to $v_{\mathrm{yx}}$, $v_{z y}, v_{z x}$ as input. When the file is exported from I-DEAS, ANSYS interpreted $v_{x y}, v_{y z}, v_{x z}$ as minor Poisson's ratio instead of major Poisson's ratio. This resulted in error when the software verified for the restrictions on elastic constants. This is corrected by substituting PR for NU in ANSYS command lines.

Once the errors are corrected, the model is solved and the results obtained are in good agreement to that obtained from I-DEAS.

\subsection{Summary}

The FE models of the laminated plain weave composites are developed and analyzed using I-DEAS and ANSYS. The laminates are subjected to uniaxial tensile load. The longitudinal stiffness of the laminates are determined and compared with results of Ito and Chou [10]. The experimental values are close to that obtained from finite element analysis. Also, the stiffness of the CERL model is predicted using Finite Element Analysis. 
Table 2.1 Mathematical Parameters of a single lamina measured by CERL

\begin{tabular}{|c|c|c|c|c|c|c|}
\hline $\begin{array}{c}\text { Direction of } \\
\text { Measurement }\end{array}$ & $\begin{array}{c}\text { Type } \\
\text { of } \\
\text { curve }\end{array}$ & $\begin{array}{c}\text { Domain } \\
\text { where valid }\end{array}$ & P1 (mm) & P2 $\left(\mathrm{mm}^{-1}\right)$ & P3 (rad) & P4 (mm) \\
\hline \multirow{3}{*}{$\begin{array}{l}\text { Longitudinal } \\
\text { or Warp } \\
\text { direction (XY } \\
\text { plane, } y=f(x))\end{array}$} & $\begin{array}{l}\text { Warp } \\
\text { path }\end{array}$ & $0<x<1.84$ & 0.07442 & 1.71 & 1.5707 & 0.1013 \\
\hline & $\begin{array}{l}\text { Fill } 1 \\
\text { cross } \\
\text { section }\end{array}$ & $0<x<0.77$ & 0.26361 & 1.296 & 1.5707 & 0.05807 \\
\hline & $\begin{array}{l}\text { Fill } 2 \\
\text { cross } \\
\text { section }\end{array}$ & $1.11<\mathrm{x}<1.84$ & 0.26361 & 1.296 & -0.8138 & -0.05807 \\
\hline \multirow{3}{*}{$\begin{array}{l}\text { Transverse or } \\
\text { Fill direction } \\
\text { (YZ plane, } z= \\
f(y))\end{array}$} & $\begin{array}{l}\text { Fill } \\
\text { path }\end{array}$ & $0<y<1.84$ & 0.11657 & 1.726 & 1.5707 & 0.08967 \\
\hline & $\begin{array}{l}\text { Warp } \\
1 \text { cross } \\
\text { section }\end{array}$ & $0<y<0.63$ & 0.24177 & 1.68 & 1.5707 & 0.06604 \\
\hline & $\begin{array}{c}\text { Warp } \\
2 \text { cross } \\
\text { section }\end{array}$ & $1.19<\mathrm{y}<1.84$ & 0.24177 & 1.68 & -1.5535 & -0.06604 \\
\hline
\end{tabular}


Table 2.2 Mathematical Parameters measured by Ito and Chou

\begin{tabular}{|c|c|c|}
\hline Geometrical Parameters & $\begin{array}{c}\text { Single and Iso Phase } \\
\text { laminate (mm) }\end{array}$ & Out-Of-Phase laminate (mm) \\
\hline $\begin{array}{c}\text { Weave length in warp } \\
\text { direction, } \mathrm{a}^{\mathrm{w}}\end{array}$ & 6.432 & 6.408 \\
\hline $\begin{array}{c}\text { Gap width in warp } \\
\text { direction, ag }\end{array}$ & 0.392 & 0.391 \\
\hline $\begin{array}{c}\text { Weave length in fill } \\
\text { direction, a }\end{array}$ & 6.11 & 6.189 \\
\hline Gap width in fill direction, \\
ag
\end{tabular}

Table 2.3 Overall, Mesoscale, Microscale fiber volume fraction for all experimental available configurations

\begin{tabular}{|c|c|c|}
\hline Volume Fraction & $\begin{array}{c}\text { Single and Iso-phase } \\
\text { Laminate }\end{array}$ & \begin{tabular}{c} 
Out-of-phase laminate \\
\hline Overall
\end{tabular} \\
\hline Meso scale & 0.44 & 0.44 \\
\hline Micro scale & 0.65 & 0.65 \\
\hline
\end{tabular}


Table 2.4 Elastic properties of the Fiber, Yarn and Matrix

\begin{tabular}{|c|c|c|}
\hline \multirow{3}{*}{$\begin{array}{c}\text { Elastic properties for the } \\
\text { CERL model }\end{array}$} & Fiber (Carbon: AS4-D) & $\begin{array}{l}\mathrm{E}_{\mathrm{f}}=241 \mathrm{GPa} \\
v_{\mathrm{f}}=0.22\end{array}$ \\
\hline & Matrix (Epoxy: 9310/9360) & $\begin{array}{l}\mathrm{E}_{\mathrm{m}}=3.12 \mathrm{GPa} \\
v_{\mathrm{m}}=0.38\end{array}$ \\
\hline & $\begin{array}{l}\text { Yarn (Carbon/Epoxy) } \\
\qquad(\mathbf{V f}=\mathbf{0 . 5})\end{array}$ & $\begin{aligned} \mathrm{E}_{1} & =122.06 \mathrm{GPa} \\
\mathrm{E}_{2} & =11.7972 \mathrm{GPa} \\
\mathrm{v}_{12} & =0.29 \\
\mathrm{G}_{12} & =3.29 \mathrm{GPa} \\
\mathrm{G}_{23} & =1.130 \mathrm{GPa}\end{aligned}$ \\
\hline \multirow{3}{*}{$\begin{array}{l}\text { Elastic properties for the } \\
\text { Ito and Chou Model }\end{array}$} & Fiber (Carbon: AS4) & $\begin{array}{l}\mathrm{E}_{\mathrm{f} 1}=221 \mathrm{GPa} \\
\mathrm{E}_{\mathrm{f} 2}=16.6 \mathrm{GPa} \\
\mathrm{v}_{12 \mathrm{f}}=0.26 \\
\mathrm{G}_{12 \mathrm{f}}=8.27 \mathrm{GPa} \\
\mathrm{G}_{23 \mathrm{f}}=5.89 \mathrm{GPa}\end{array}$ \\
\hline & Matrix (Vinyl Ester) & $\begin{array}{l}\mathrm{E}_{\mathrm{m}}=3.4 \mathrm{GPa} \\
v_{\mathrm{m}}=0.3\end{array}$ \\
\hline & $\begin{array}{c}\text { Yarn (Carbon/Vinyl Ester) } \\
(\mathbf{V f}=\mathbf{0 . 6 8})\end{array}$ & $\begin{array}{l}\mathrm{E}_{1}=151.36 \mathrm{GPa} \\
\mathrm{E}_{2}=9.04 \mathrm{GPa} \\
\mathrm{v}_{12}=0.27 \\
\mathrm{G}_{12}=3.89 \mathrm{GPa} \\
\mathrm{G}_{23}=3.36 \mathrm{GPa}\end{array}$ \\
\hline
\end{tabular}


Table 2.5 Comparison of Results from PMM models [16,18]

\begin{tabular}{|c|c|c|c|c|c|}
\hline Model Type & $\mathbf{E}_{\mathbf{1}}(\mathbf{G P a})$ & $\mathbf{E}_{\mathbf{2}}(\mathbf{G P a})$ & $\boldsymbol{v}_{\mathbf{1 2}}$ & $\mathbf{G}_{\mathbf{1 2}}(\mathbf{G P a})$ & $\mathbf{G}_{\mathbf{2 3}}(\mathbf{G P a})$ \\
\hline $\begin{array}{c}\text { Approx. Transversely } \\
\text { Isotropic fiber [16] }\end{array}$ & 151.36 & 8.731 & 0.271 & 3.906 & 3.339 \\
\hline $\begin{array}{c}\text { Transversely } \\
\text { Isotropic fiber [18] }\end{array}$ & 151.36 & 9.041 & 0.272 & 3.89 & 3.365 \\
\hline Isotropic fiber [16] & 151.36 & 15.89 & 0.268 & 6.50 & 5.90 \\
\hline
\end{tabular}

Table 2.6 Comparison of Results of the stiffness Ex for CERL Model

\begin{tabular}{|c|c|c|}
\hline Model Type & Type of Laminate & FE results \\
\hline CERL Model & Single lamina & $23.2 \mathrm{GPa}$ \\
\hline
\end{tabular}

Table 2.7 Comparison of Results of the stiffness Ex for Ito and Chou Model

\begin{tabular}{|c|c|c|c|}
\hline \multirow{2}{*}{ Model Type } & Type of Laminate & $\begin{array}{c}\text { Ito and Chou } \\
\text { results }\end{array}$ & FE results \\
\hline \multirow{3}{*}{ Ito and Chou model } & Single lamina & - & $32.8 \mathrm{GPa}$ \\
\cline { 2 - 4 } & Iso-phase laminate & $42.8 \mathrm{GPa}$ & $41.5 \mathrm{GPa}$ \\
\cline { 2 - 4 } & $\begin{array}{c}\text { Out-of-phase } \\
\text { laminate }\end{array}$ & $51.8 \mathrm{GPa}$ & $49.5 \mathrm{GPa}$ \\
\hline
\end{tabular}




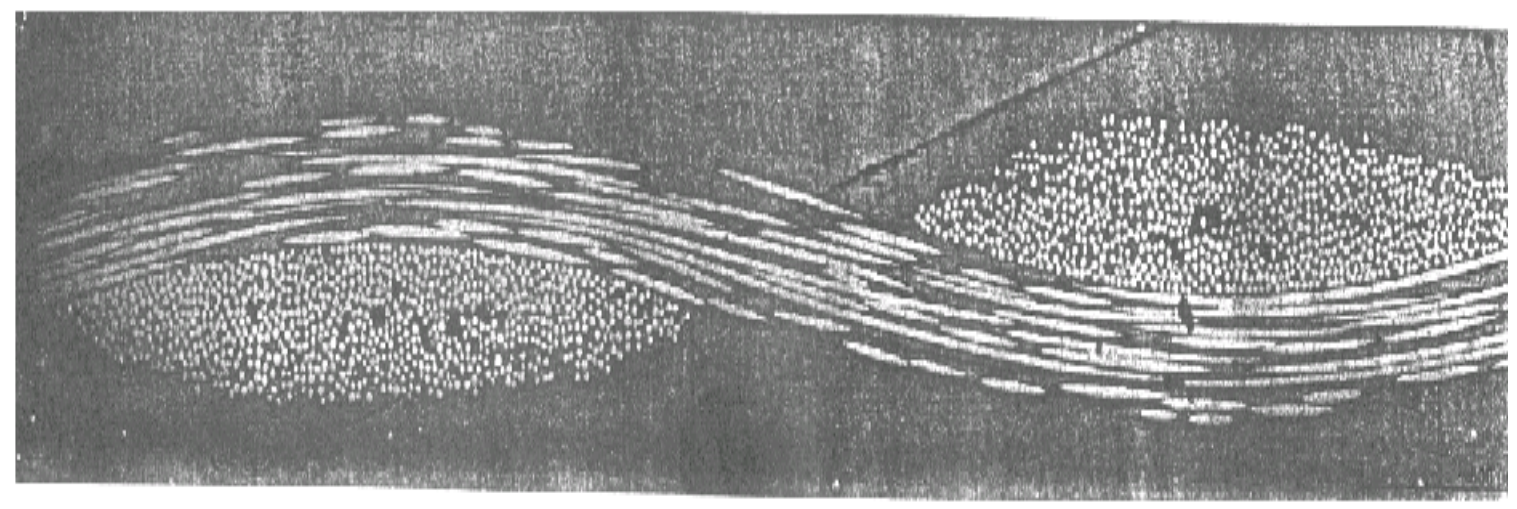

Fig. 2.1 2D picture of the plain weave fabric from CERL

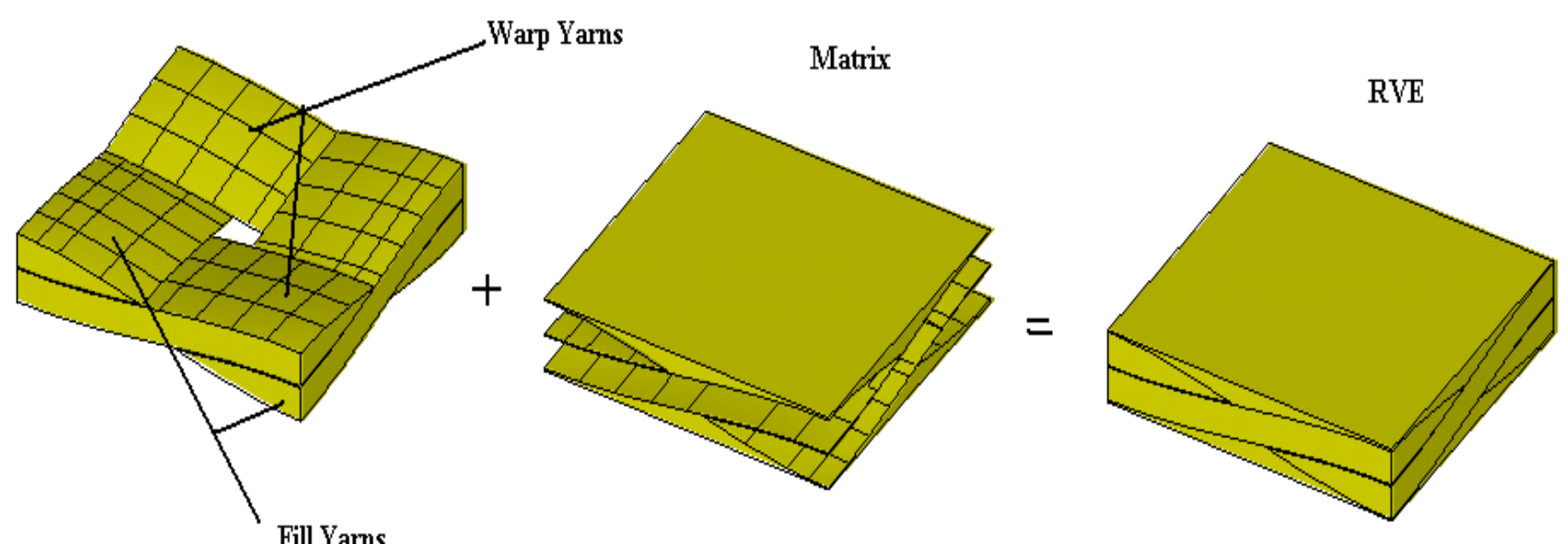

Fig. 2.2 3-D views of a plain weave fabric 


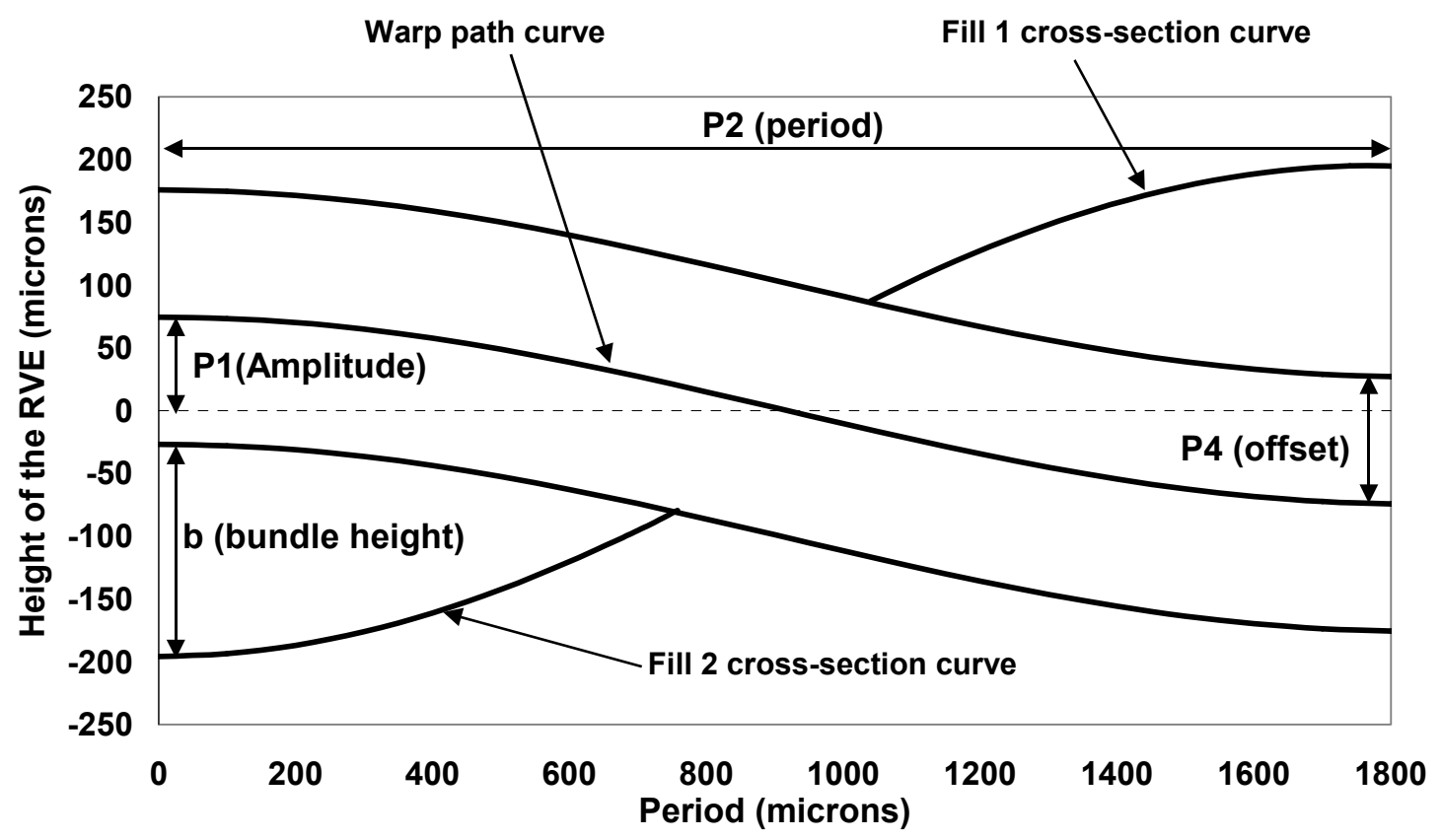

Fig. 2.3 Yarn parameters measured by CERL

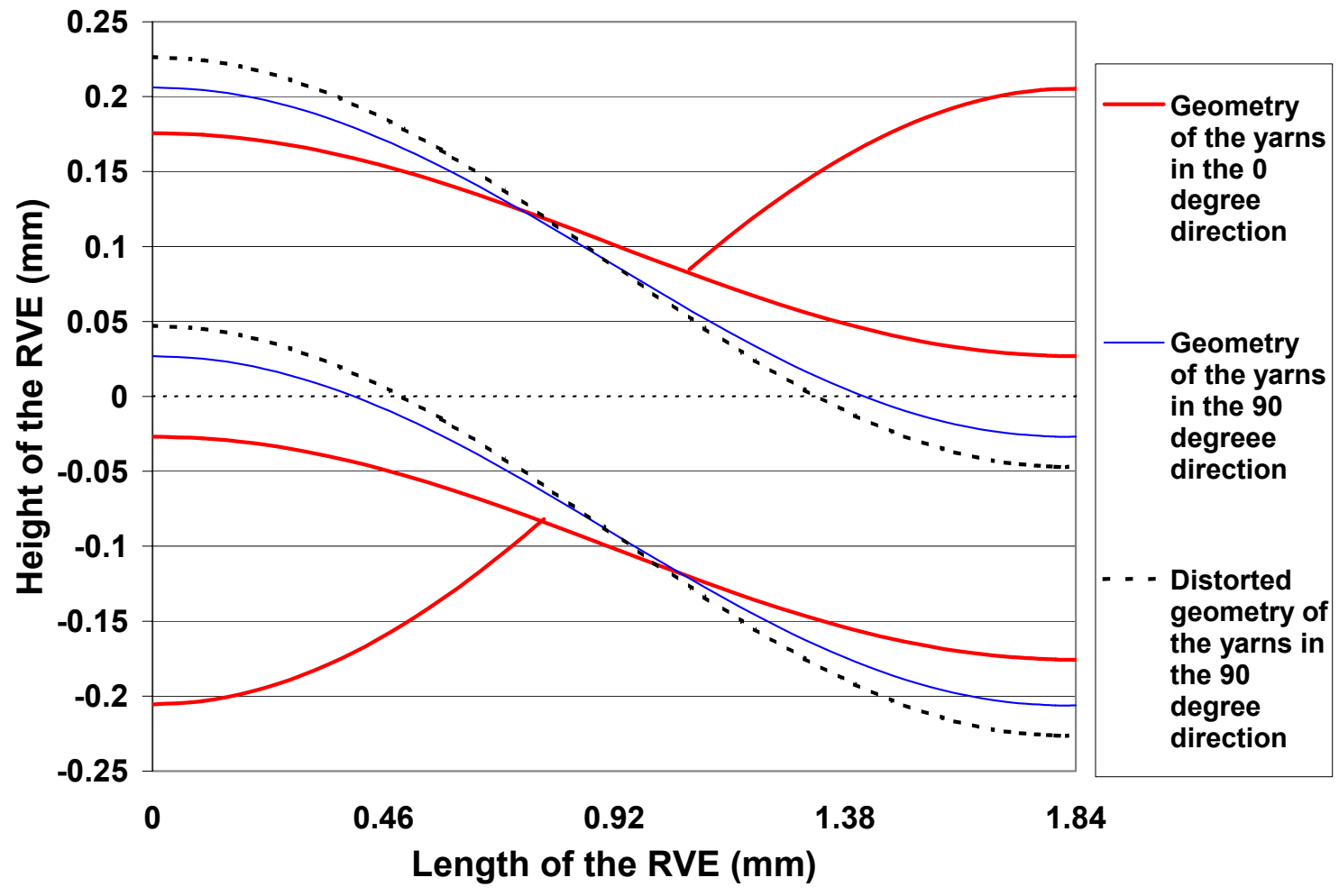

Fig. 2.4 Adjustment of the yarn parameters 


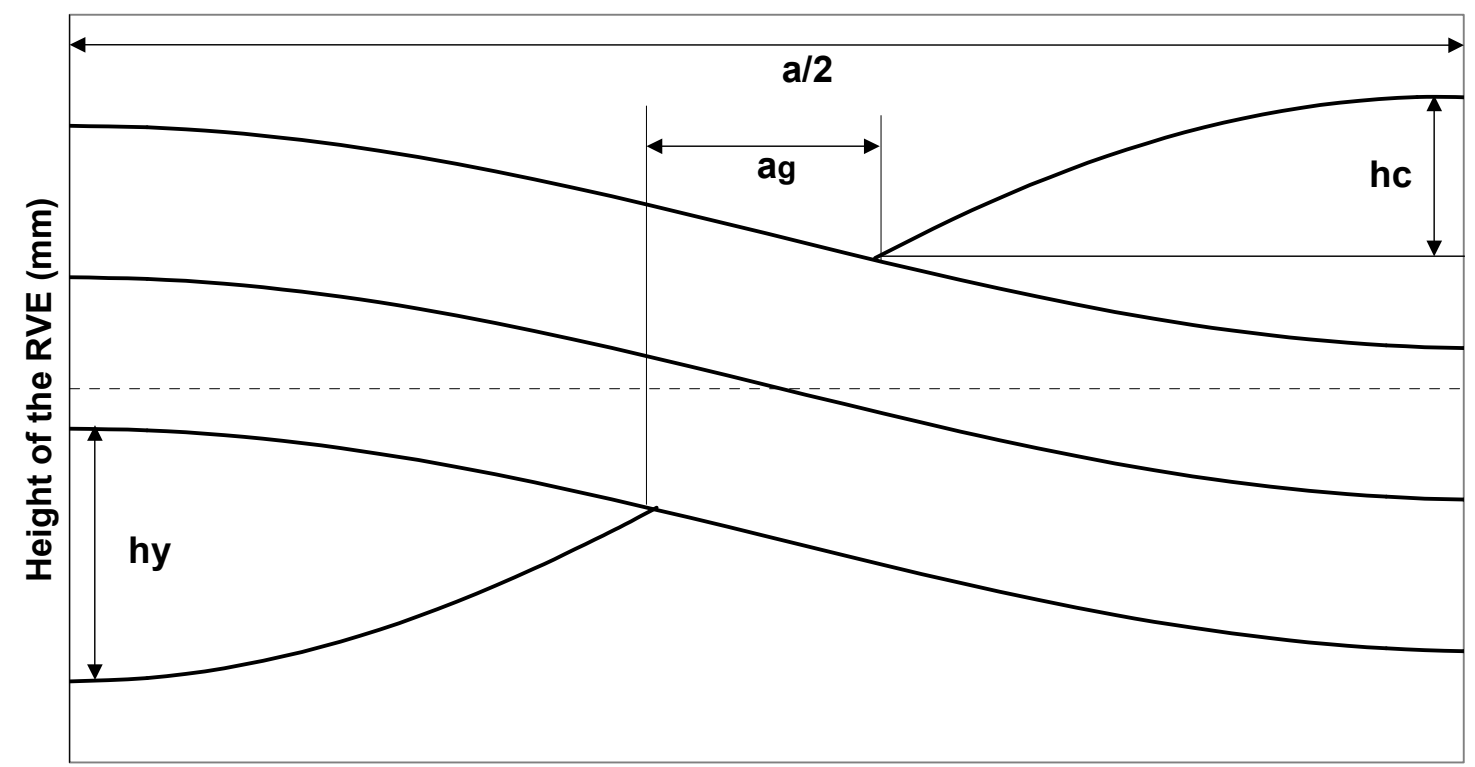

Length of the RVE (mm)

Fig. 2.5 Yarn parameters measured by Ito and Chou

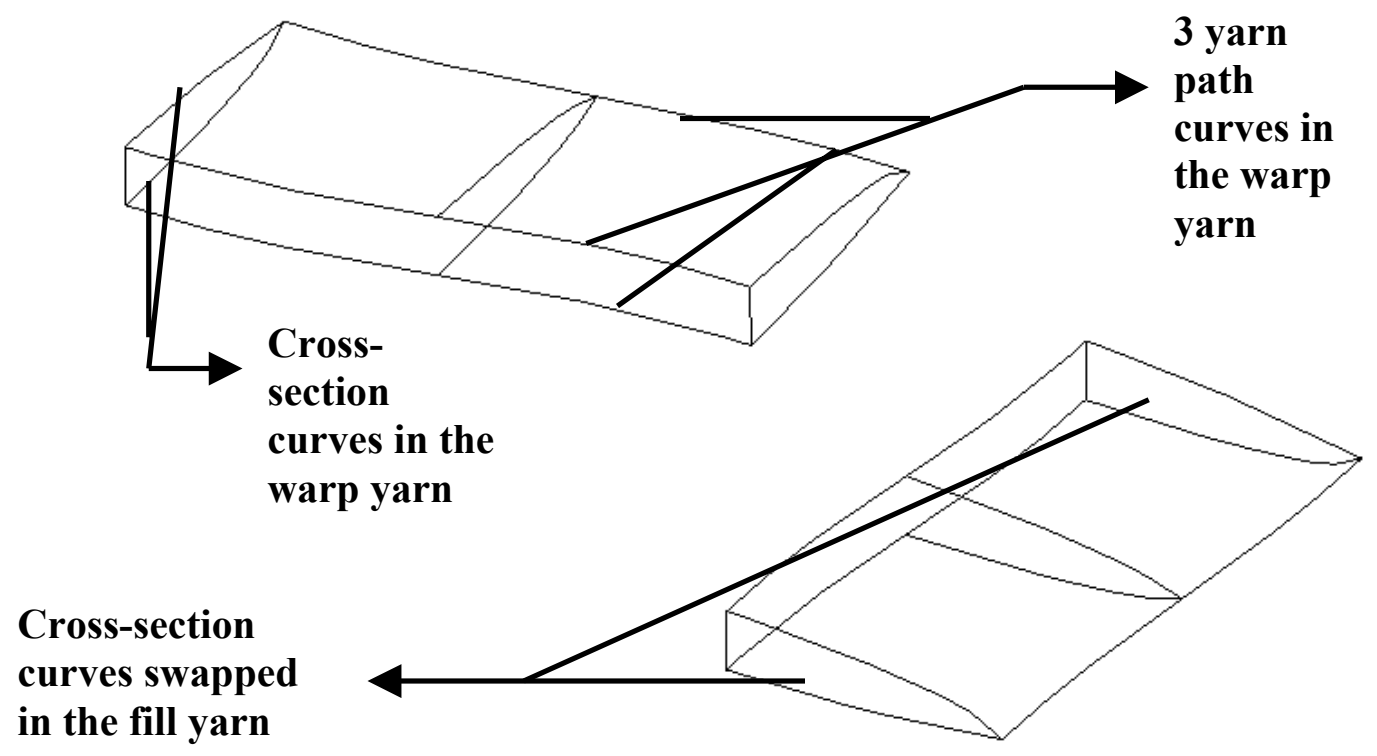

Fig. 2.6 Description of yarn path and cross-section curves 


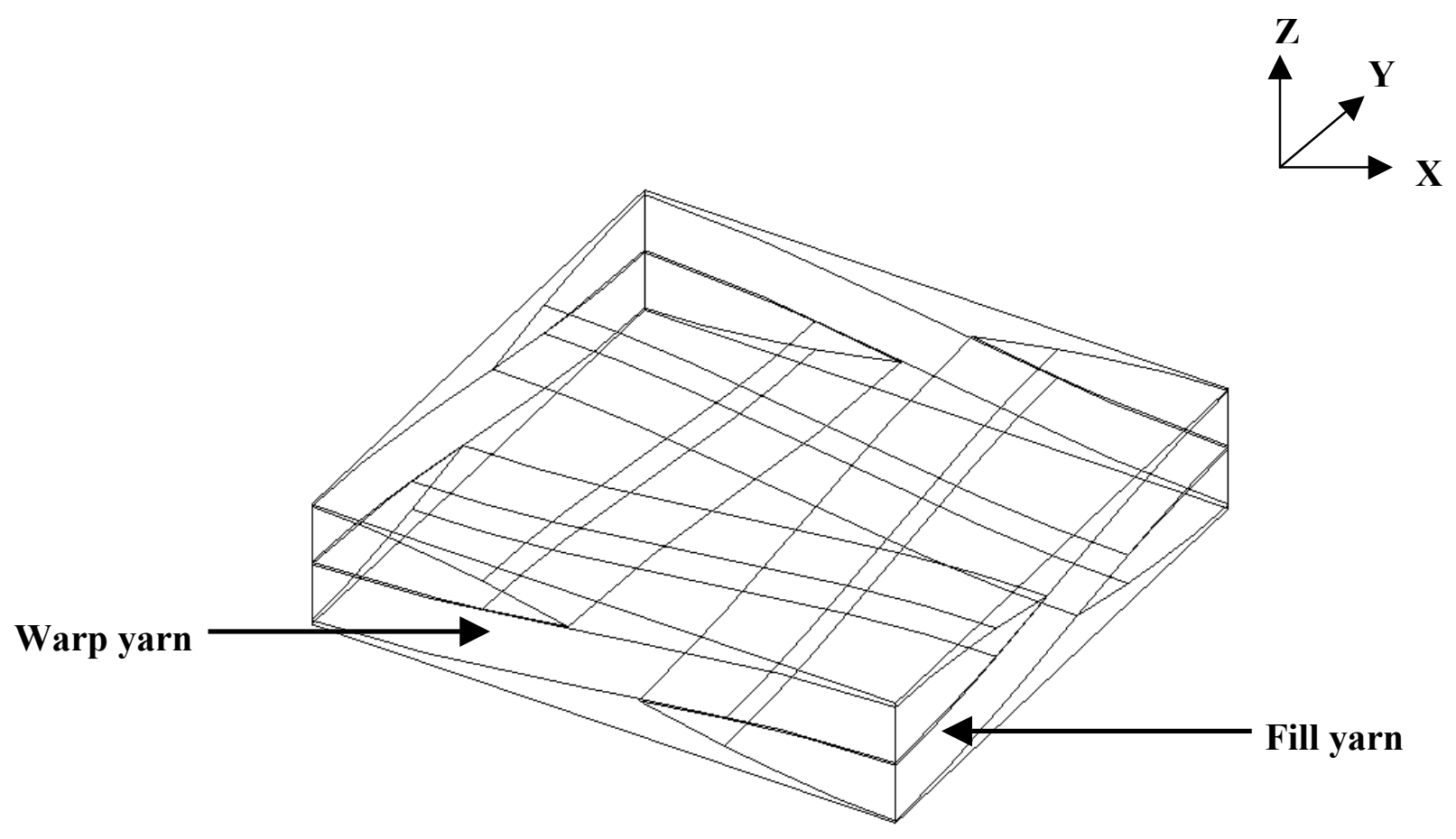

Fig. 2.7 Geometric model of a single lamina

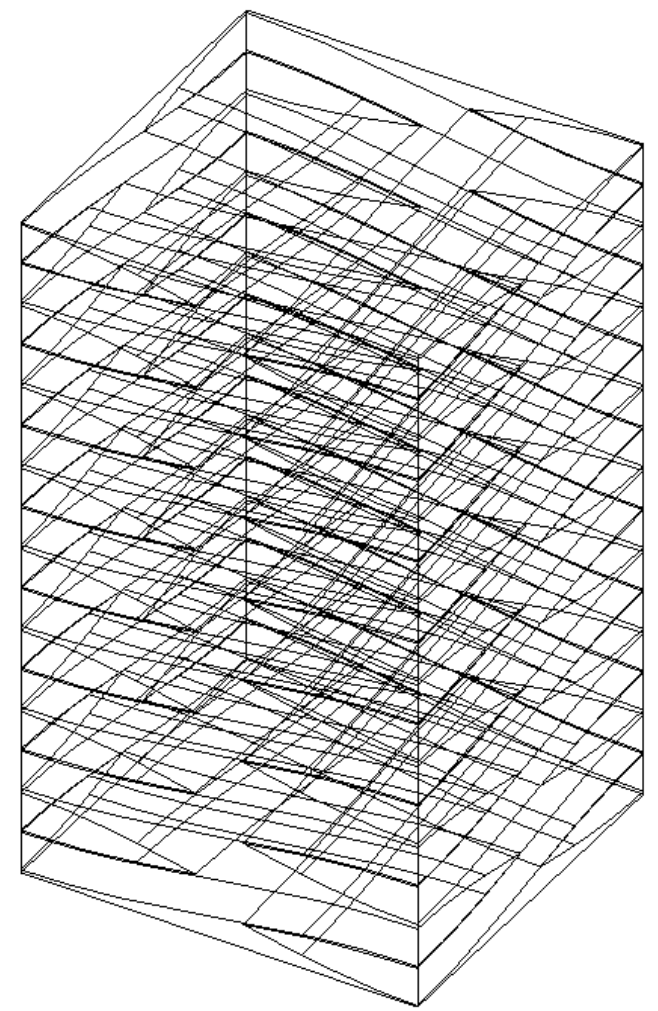

Fig. 2.8 Geometric model of an iso-phase laminate 


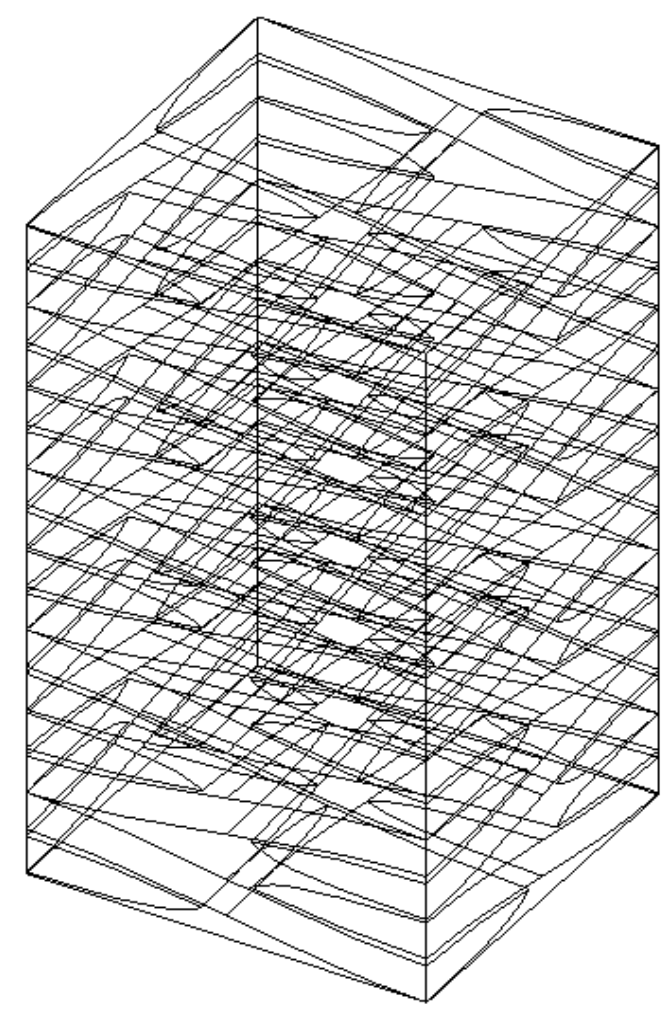

Fig. 2.9 Geometric model of an out-phase laminate
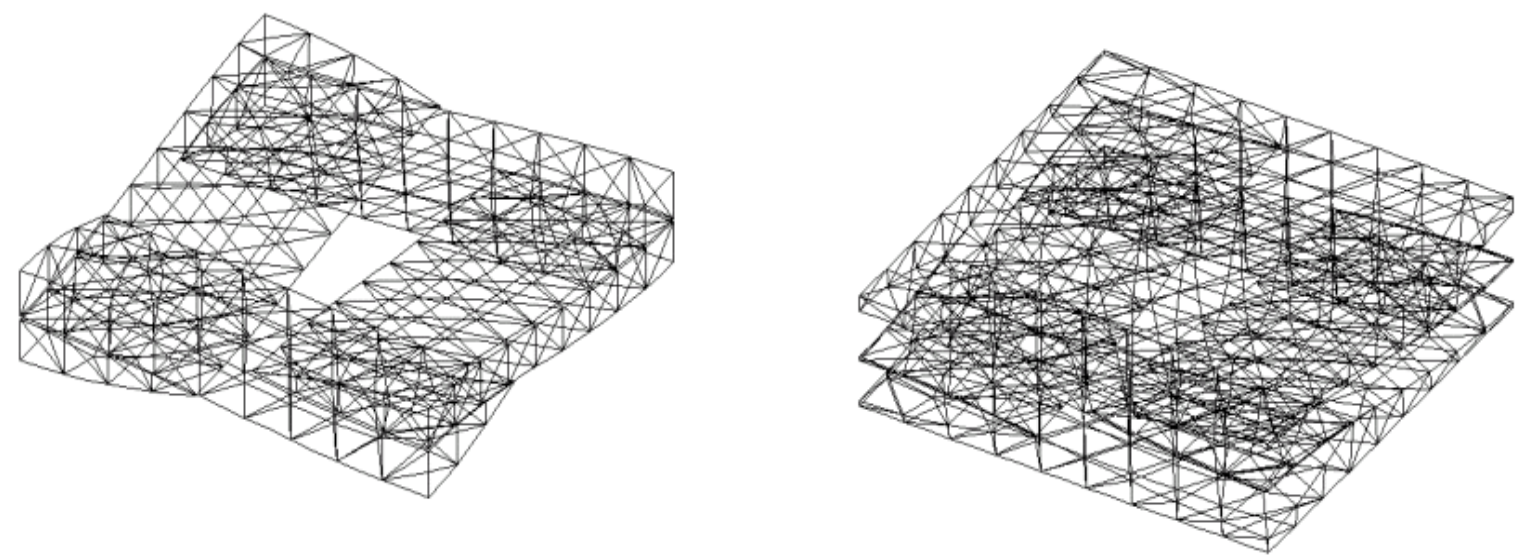

Fig. 2.10 Mesh in the yarns and matrix 


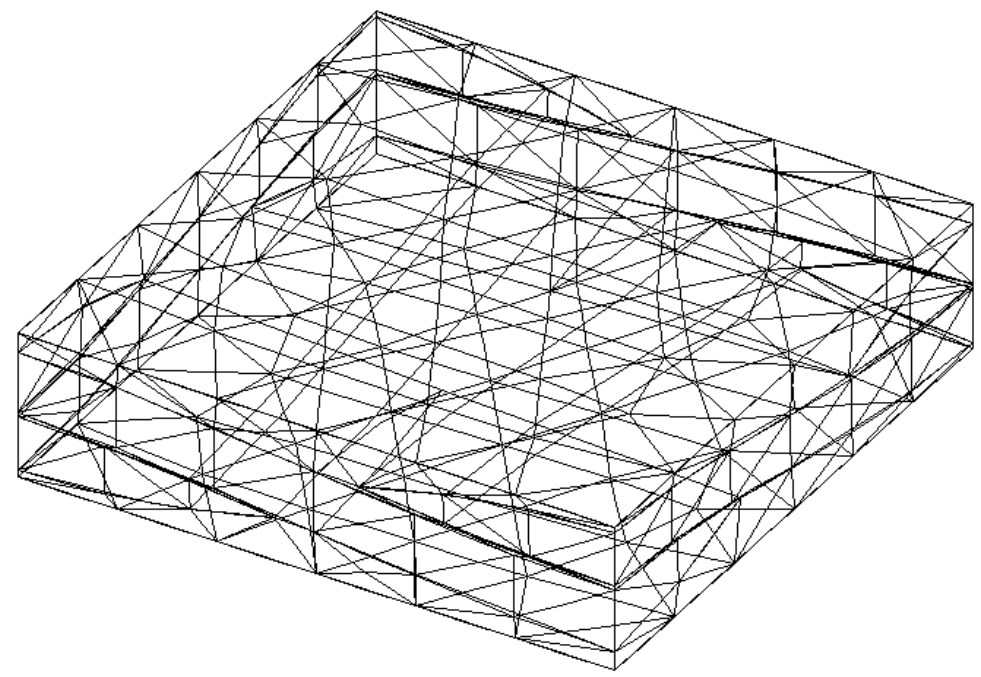

Fig. 2.11 Mesh in the entire RVE

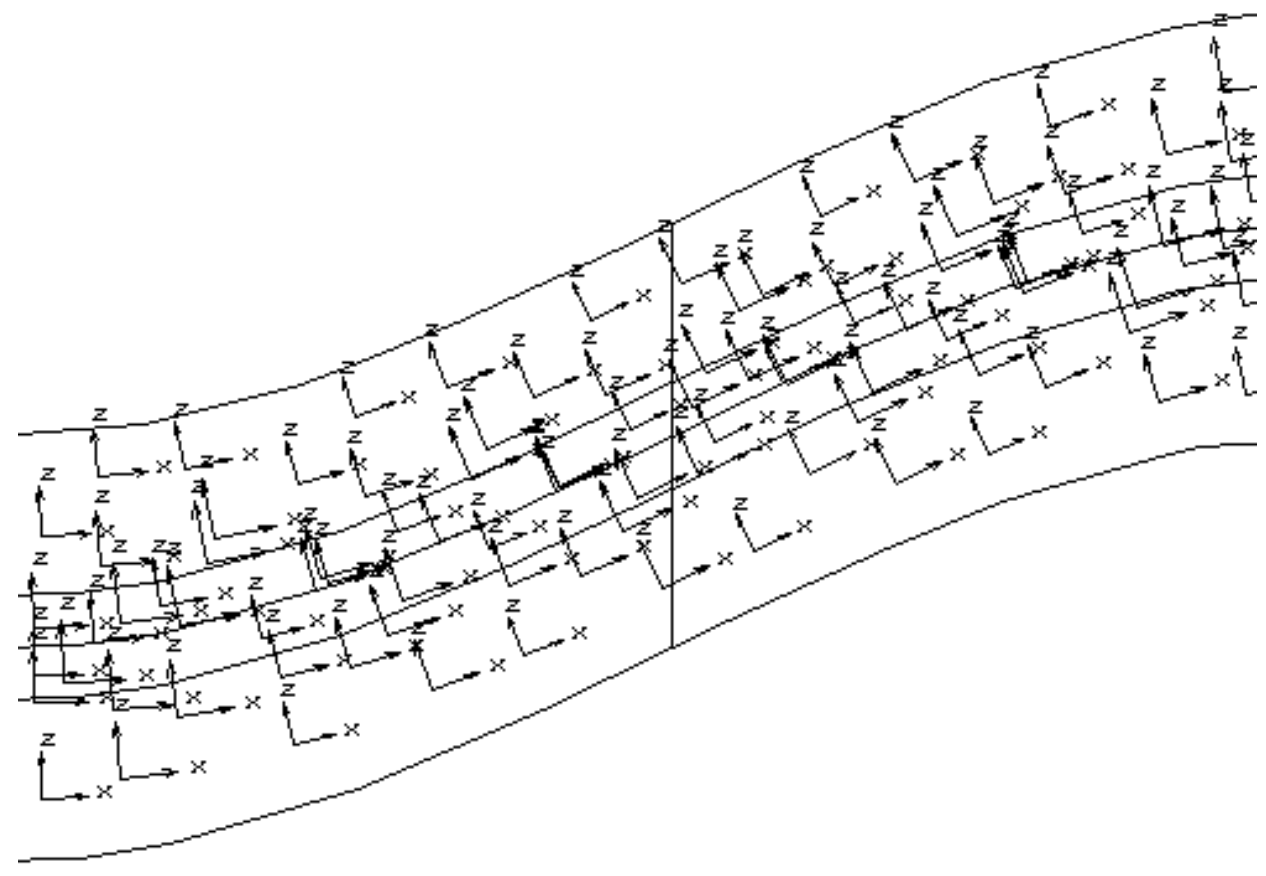

Fig 2.12 Material orientation inside the yarns 
Couple nodes to move in $\mathrm{Y}$ direction

(Left Surface)

Symmetric face (Back Surface)
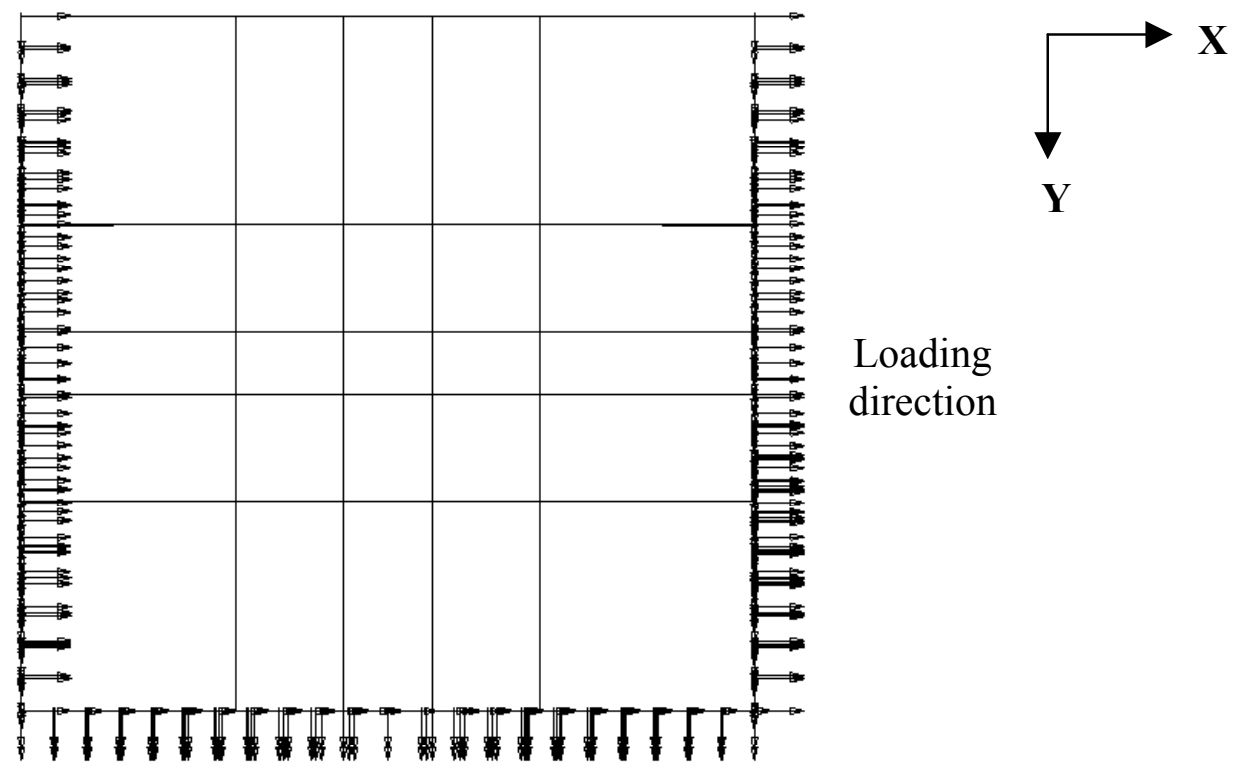

Symmetric face (Right Surface)

Fig. 2.13 Boundary conditions for plain weave laminates 


\section{CHAPTER 3: DAMAGE MODEL FOR POLYMER MATRIX COMPOSITES}

\subsection{Introduction}

The material model used for predicting the non-linear behavior of plain weave fabrics is discussed in this section. The elastic stiffness of a fiber-reinforced composite can be predicted using the properties of the constituent materials (fiber and matrix). The strength values are measured as the ultimate failure values in uniaxial tests since they cannot be accurately predicted using available analytical models. These failures are attributed to the internal damage that results in reduction in stiffness and stress redistribution among layers of the composite. Several models are available for predicting the damage behavior of composites prior to failure.

(a) Ply discount methods are very approximate methods and the predicted damage behavior is not accurate.

(b) Micromechanical models are used to predict the damage behavior of a single ply by assembling the damage response of the constituent materials [19]. They are computationally intensive and require large number of material parameters.

(c) Continuous damage mechanics models require only a few parameters to describe the damage behavior of a composite material. In most of the CDM models available in the literature, the parameters have to be obtained from non-standard and special tests, which make them expensive [20]. 
Therefore, the objective is to develop a model based on available data (stiffness and strength values) using the concept of continuous damage mechanics coupled with thermodynamics $[3,21,22,25]$. Certain assumptions are made for the damage model.

- The model cannot predict the microscopic features of damage. It predicts the reduction in stiffness and stress redistribution in the laminae in an average sense (meso-scale level).

- Friction effects at the fiber-matrix interphases are neglected.

- The model has been validated for monotonic loading [3,21] and unloading [22].

The damage model accounts for damage initiation, evolution, and failure at critical values of damage in a composite material. The model uses a set of internal variables to describe the damage behavior $[3,21,22,25]$. The simplicity of the model lies in the fact that only a few parameters are required for describing the non-linear behavior and they can be obtained from standard tests of a unidirectional ply. On the whole, the damage model predicts non-linear behavior of a composite by averaging the microstructural details using continuous damage mechanics.

\subsection{Damage Mechanics}

Damage can be defined as the loss of material due to nucleation and growth of micro cracks and micro voids in composites. The damage mechanics domain lies between the virgin undamaged states of the material and the macroscopic crack initiation [23]. Beyond this, is the domain of fracture mechanics. Damage in composite materials are in the form of matrix cracks, voids, fiber-matrix debond, fiber breakages, and transverse cracks, which takes place either in parallel or normal to fiber direction. Experimental 
results show that different damage modes exist when the laminate in subjected to longitudinal, transverse and shear (in-plane and inter-laminar) loading. In addition, shear loading leads to longitudinal and mostly transverse damage [21]. Therefore, a second order symmetric damage tensor $\mathrm{D}$ is used to describe the anisotropic evolution of damage along matrix and fiber directions. Since the damage principal directions are coincident with the material directions, as evident from experimental observations, the damage tensor $D$ is represented as a three-component array $D=\left[d_{1}, d_{2}, d_{3}\right]^{T}$. The values $d_{1}, d_{2}, d_{3}$ represent the net area reduction along the material directions as shown in Figs. 3.1, 3.2 and 3.3. According to the concepts of continuous damage mechanics $[3,21,22,25]$, the effective stress (over bar) can be calculated from apparent stress (P/A) as

$$
\bar{\sigma}_{\mathrm{ij}}=\mathrm{M}_{\mathrm{ijkl}}^{-1}(\mathrm{D}) \sigma_{\mathrm{kl}}
$$

where $\mathrm{M}$ is a fourth order tensor obtained from second order integrity tensor $\Omega$ as $\mathrm{M}_{\mathrm{ijk} 1}=\Omega_{\mathrm{ij}} \Omega_{\mathrm{kl}}$. The integrity tensor is obtained from damage tensor $\mathrm{D}$ as $\Omega=\sqrt{\mathrm{I}-\mathrm{D}}$ where I is the identity tensor [22]. In contracted notation [1],

$$
\mathrm{M}=\left[\begin{array}{cccccc}
\Omega_{1}^{2} & 0 & 0 & 0 & 0 & 0 \\
& \Omega_{2}^{2} & 0 & 0 & 0 & 0 \\
& & \Omega_{3}^{2} & 0 & 0 & 0 \\
& & & \frac{\Omega_{2} \Omega_{3}}{2} & 0 & 0 \\
& & & & \frac{\Omega_{1} \Omega_{3}}{2} & 0 \\
& & & & & \frac{\Omega_{1} \Omega_{2}}{2}
\end{array}\right]
$$




$$
\bar{\sigma}=\left[\begin{array}{ccc}
\frac{\sigma_{11}}{\Omega_{1}^{2}} & \frac{\sigma_{12}}{\Omega_{1} \Omega_{2}} & \frac{\sigma_{13}}{\Omega_{1} \Omega_{3}} \\
& \frac{\sigma_{22}}{\Omega_{2}^{2}} & \frac{\sigma_{23}}{\Omega_{2} \Omega_{3}} \\
\text { sym } & & \frac{\sigma_{33}}{\Omega_{3}^{2}}
\end{array}\right]
$$

\subsection{Damage model}

The damage process is modeled using a set of internal variables that describes the inelastic behavior of the material. The elastic strain energy of the damaged material is given by

$$
\Phi(\varepsilon, \mathrm{D})=\frac{1}{2} \sigma(\mathrm{E})^{-1} \sigma
$$

where $\sigma$ represents the apparent stress tensor $(\mathrm{P} / \mathrm{A})$ and $\mathrm{E}$ represents the damaged stiffness tensor. According to the principle of equivalent elastic energy, the elastic energy of the damaged material is the same in the form as that of an effective material except that the stress tensor is replaced by the effective stress

$$
\Phi(\bar{\sigma}, 0)=\frac{1}{2} \sigma(\mathrm{E})^{-1} \sigma=\frac{1}{2} \bar{\sigma}(\overline{\mathrm{E}})^{-1} \bar{\sigma}=\frac{1}{2} \sigma \mathrm{M}^{-1}(\overline{\mathrm{E}})^{-1} \mathrm{M}^{-1} \sigma
$$

where $\overline{\mathrm{E}}$ represents the undamaged stiffness tensor. Therefore, the damage stiffness matrix can be written as $\mathrm{E}=\mathrm{M}: \overline{\mathrm{E}}: \mathrm{M}^{\mathrm{T}}$. In contracted notation,

$$
\mathrm{E}(\mathrm{D})=\left[\begin{array}{cccccc}
\overline{\mathrm{E}}_{11} \Omega_{1}^{4} & \overline{\mathrm{E}}_{12} \Omega_{1}^{2} \Omega_{2}^{2} & \overline{\mathrm{E}}_{13} \Omega_{1}^{2} \Omega_{3}^{2} & 0 & 0 & 0 \\
& \overline{\mathrm{E}}_{22} \Omega_{2}^{4} & \overline{\mathrm{E}}_{23} \Omega_{2}^{2} \Omega_{3}^{2} & 0 & 0 & 0 \\
& & \overline{\mathrm{E}}_{33} \Omega_{3}^{4} & 0 & 0 & 0 \\
& & & \overline{\mathrm{E}}_{44} \Omega_{2}^{2} \Omega_{3}^{2} & 0 & 0 \\
& & & & \overline{\mathrm{E}}_{55} \Omega_{1}^{2} \Omega_{3}^{2} & \\
& & & & & \overline{\mathrm{E}}_{66} \Omega_{1}^{2} \Omega_{2}^{2}
\end{array}\right]
$$


Since the damage model is set in the thermodynamic framework, the second order symmetric tensor $\mathrm{Y}$, dual to the damage tensor $\mathrm{D}$ is given by

$$
\mathrm{Y}=-\frac{\partial \Phi}{\partial \mathrm{D}}=-\frac{1}{2} \sigma \frac{\partial}{\partial \mathrm{D}}\left(\mathrm{M}^{-1}(\overline{\mathrm{E}})^{-1} \mathrm{M}^{-1}\right) \sigma
$$

Using Eqs. (3.3) and (3.7) we get the three components of the $\mathrm{Y}$ tensor

$$
\begin{aligned}
& Y_{1}=\frac{1}{\Omega_{1}^{2}}\left[\bar{C}_{11} \bar{\sigma}_{1}^{2}+\overline{\mathrm{C}}_{12} \bar{\sigma}_{1} \bar{\sigma}_{2}+\overline{\mathrm{C}}_{66} \bar{\sigma}_{6}^{2}+\overline{\mathrm{C}}_{55} \bar{\sigma}_{5}^{2}+\overline{\mathrm{C}}_{13} \bar{\sigma}_{1} \bar{\sigma}_{3}\right] \\
& \mathrm{Y}_{2}=\frac{1}{\Omega_{2}^{2}}\left[\overline{\mathrm{C}}_{22} \bar{\sigma}_{2}^{2}+\overline{\mathrm{C}}_{12} \bar{\sigma}_{1} \bar{\sigma}_{2}+\overline{\mathrm{C}}_{66} \bar{\sigma}_{6}^{2}+\overline{\mathrm{C}}_{44} \bar{\sigma}_{4}^{2}+\overline{\mathrm{C}}_{23} \bar{\sigma}_{2} \bar{\sigma}_{3}\right] \\
& \mathrm{Y}_{3}=\frac{1}{\Omega_{3}^{2}}\left[\overline{\mathrm{C}}_{33} \bar{\sigma}_{3}^{2}+\overline{\mathrm{C}}_{55} \bar{\sigma}_{5}^{2}+\overline{\mathrm{C}}_{44} \bar{\sigma}_{4}^{2}+\overline{\mathrm{C}}_{13} \bar{\sigma}_{1} \bar{\sigma}_{3}+\overline{\mathrm{C}}_{23} \bar{\sigma}_{2} \bar{\sigma}_{3}\right]
\end{aligned}
$$

where $\overline{\mathrm{C}}$ is the undamaged compliance matrix and is the inverse of the undamaged stiffness tensor $\overline{\mathrm{E}}$.

The damage surface, which is analogous to the yield surface in plasticity theory, is given by

$$
\mathrm{g}^{\mathrm{d}}=\left(\mathrm{Y}_{\mathrm{ij}} \cdot \mathrm{J}_{\mathrm{ijhk}} \mathrm{Y}_{\mathrm{hk}}\right)^{\frac{1}{2}}+\left(\left|\mathrm{H}_{\mathrm{ij}} \cdot \mathrm{Y}_{\mathrm{ij}}\right|\right)^{\frac{1}{2}}-\gamma(\delta)-\gamma_{0}
$$

where

$$
\begin{aligned}
& \mathrm{Y}=\text { Thermodynamic force tensor } \\
& \mathrm{J}, \mathrm{H}=\text { Internal material constants } \\
& \gamma(\delta)=\text { Damage evolution variable } \\
& \gamma_{0} \quad=\text { Damage threshold representing the initial size of the damage surface }
\end{aligned}
$$

No damage occurs until the thermodynamic forces $\mathrm{Y}$ reach the damage surface. For undamaged material, $\gamma=0$, and $\mathrm{g}^{\mathrm{d}}$ has the shape of the Tsai-Wu surface. 
At failure, $\gamma^{*}+\gamma_{0}=1$ and the shape and size of $\mathrm{g}^{\mathrm{d}}$ matches the Tsai-Wu surface (Fig. 3.4), where $\gamma^{*}$ represents the value of $\gamma$ at failure. Comparing the two surfaces, we arrive at a set of a linear system of equations that allow us to determine the internal material constants $[3,21,22,25]$.

The damage evolution parameters $\left(c_{1}, c_{2}\right)$ and the damage threshold $\left(\gamma_{0}\right)$ are calculated by adjusting the shear stress-strain obtained from finite element analysis (ANSYS) of a unidirectional ply subjected to pure shear conditions to match the experimental shear response.

\subsubsection{Procedure for calculating the internal material constants}

The internal material constants are related to the experimental properties. They are calculated based on the set of equations as discussed below, using the MAPLE, Version 5 program (Appendix B).

The input variables required for calculating the material constants are

- The stiffness values $\left(\mathrm{E}_{1}, \mathrm{E}_{2}=\mathrm{E}_{3}, \mathrm{G}_{12}=\mathrm{G}_{13}, \mathrm{G}_{23}, v_{12}\right)$ of the composite material

- The strength values of the composite in tension $\left(F_{1 t}, F_{2 t}\right)$, compression $\left(F_{1 c}\right)$ and shear $\left(\mathrm{F}_{4}, \mathrm{~F}_{5}, \mathrm{~F}_{6}\right)$

- Critical damage values in tension $\left(\mathrm{D}_{1 \mathrm{t}}\right)$, compression $\left(\mathrm{D}_{1 \mathrm{c}}\right)$, transverse tension $\left(\mathrm{D}_{2 \mathrm{t}}\right)$

- Damaged shear modulus at failure $\left(\mathrm{G}_{12}^{*}, \mathrm{G}_{13}^{*}, \mathrm{G}_{23}^{*}\right)$

The input variables are calculated as follows,

(a) For transversely isotropic materials, only five properties are required $\left(E_{1}, E_{2}, G_{12}\right.$, $\left.v_{12}, v_{23}\right)$. The properties are computed using periodic microstructure model (PMM [18]) as explained in Chapter 2. 
(b) The strength values are obtained from uniaxial experimental tests of unidirectional composites. If the strength data is not available, empirical relations are used for calculating the strength values [1].

(c) The critical damage values are obtained for a unidirectional laminate. $\mathrm{D}_{1 \mathrm{t}}$ is critical damage value for longitudinal tensile loading and it indicates the area fraction of broken fibers. $\mathrm{D}_{1 \mathrm{c}}$ is the critical damage value for longitudinal compressive loading and it indicates the area fraction of fibers buckled. $\mathrm{D}_{2 \mathrm{t}}$ is the critical damage value for transverse tensile loading and it indicates the area fraction of broken matrix links. The critical damage values for $\mathrm{D}_{1 \mathrm{t}}, \mathrm{D}_{1 \mathrm{c}}, \mathrm{D}_{2 \mathrm{t}}$ are obtained from [21].

(d) The damaged shear modulus can be approximated as the ratio of shear strength to the ultimate strain at failure assuming elastic unloading to the origin. If unrecoverable (plastic) strains occur, damaged moduli must be obtained from the unloading portion of the stress-strain plot. In most composites, ultimate shear strain around $2 \%-3 \%$. So, the damage shear modulus is computed under the assumption that failure shear strain is $3 \%$.

The internal constants are defined by a fourth and second order tensor J and H. They appear in the formulation of the damage surface $\mathrm{g}^{\mathrm{d}}$ (Eq. 3.11) in thermodynamic force space, which represents the Tsai-Wu surface in stress space at failure. Since principal directions of the damage tensor coincides with the material direction, the $\mathrm{J}$ and $\mathrm{H}$ tensors are diagonal.

$$
\left[\begin{array}{ccc}
\mathrm{J}_{11} & 0 & 0 \\
0 & \mathrm{~J}_{22} & 0 \\
0 & 0 & \mathrm{~J}_{33}
\end{array}\right] \quad ; \quad\left[\mathrm{H}_{1}, \mathrm{H}_{2}, \mathrm{H}_{3}\right]
$$




\subsubsection{Calculation of $J_{11}, H_{1}$}

When the composite lamina is subjected to uniaxial load in the longitudinal direction, all the stress components other than $\sigma_{1}$ are zero. Therefore (Eq. 3.11) reduces to

$$
\mathrm{g}=\sqrt{\mathrm{J}_{11}} \frac{\overline{\mathrm{C}_{11}}}{\Omega_{1}^{6}} \sigma_{1}^{2}+\sqrt{\left|\mathrm{H}_{1}\right| \frac{\overline{\mathrm{C}_{11}}}{\Omega_{1}^{6}}} \sigma_{1}-\left(\gamma+\gamma_{0}\right)
$$

At failure, the damage variables reach the critical values $\left(D_{1 t}, D_{1 c}\right)$. If $F_{1 t}$ represents the tensile strength and $\mathrm{F}_{1 \mathrm{c}}$ the compressive strength, (Eq. 3.13) becomes

$$
\begin{gathered}
\sqrt{\mathrm{J}_{11}} \frac{\overline{\mathrm{C}_{11}}}{\frac{\Omega_{1 \mathrm{t}}^{6}}{6}} \mathrm{~F}_{1 \mathrm{t}}^{2}+\sqrt{\left|\mathrm{H}_{1}\right| \frac{\overline{\mathrm{C}_{11}}}{\Omega_{1 \mathrm{t}}^{6}}} \mathrm{~F}_{1 \mathrm{t}}=\left(\gamma^{*}+\gamma_{0}\right) \\
\sqrt{\mathrm{J}_{11}} \frac{\overline{\mathrm{C}_{11}}}{\Omega_{1 \mathrm{c}}^{6}} \mathrm{~F}_{1 \mathrm{c}}^{2}+\sqrt{\left|\mathrm{H}_{1}\right| \frac{\overline{\mathrm{C}_{11}}}{\Omega_{1 \mathrm{c}}^{6}}} \mathrm{~F}_{1 \mathrm{c}}=\left(\gamma^{*}+\gamma_{0}\right) \\
\Omega_{1 \mathrm{t}}=1-\mathrm{D}_{1 \mathrm{t}} \text { and } \Omega_{1 \mathrm{c}}=1-\mathrm{D}_{\mathrm{lc}}
\end{gathered}
$$

The Tsai-Wu criterion for uniaxial loading in the fiber direction is given by

$$
\mathrm{f}_{1} \mathrm{~F}_{1 \mathrm{t}}+\mathrm{f}_{11} \mathrm{~F}_{1 \mathrm{t}}^{2}=1 \text { and } \mathrm{f}_{1} \mathrm{~F}_{1 \mathrm{c}}+\mathrm{f}_{11} \mathrm{~F}_{1 \mathrm{c}}^{2}=1
$$

Hence the right hand side of Eqs. (3.14) and (3.15) should equal 1 so that the damage surface matches with the Tsai-Wu surface at failure. The critical damage values are obtained from statistical methods [21]. Then, the two equations are solved simultaneously and the values of $\mathrm{J}_{11}$ and $\mathrm{H}_{1}$ are obtained.

\subsubsection{Calculation of $\mathrm{J}_{22}, \mathrm{H}_{2}$}

When the composite lamina is subjected to transverse uniaxial loading, all the stress components other than $\sigma_{2}$ are zero. At failure, (Eq . 3.11) reduces to

$$
\sqrt{\mathrm{J}_{22}} \frac{\overline{\mathrm{C}_{22}}}{\Omega_{2 \mathrm{t}}^{6}} \mathrm{~F}_{2 \mathrm{t}}^{2}+\sqrt{\left|\mathrm{H}_{2}\right| \frac{\overline{\mathrm{C}_{22}}}{\Omega_{2 \mathrm{t}}^{6}}} \mathrm{~F}_{2 \mathrm{t}}=\left(\gamma^{*}+\gamma_{0}\right)=1
$$




$$
\Omega_{2 \mathrm{t}}=1-\mathrm{D}_{2 \mathrm{t}}
$$

When the lamina is subjected to in-plane shear loading, all the stress components other than $\sigma_{6}$ are zero. At failure, (Eq. 3.11) becomes

$$
\sqrt{\frac{\mathrm{J}_{11}}{\Omega_{1 \mathrm{~s}}^{4}}+\frac{\mathrm{J}_{22}}{\Omega_{2 \mathrm{~s}}^{4}}} \frac{2 \overline{\mathrm{C}_{66}}}{\Omega_{1 \mathrm{~s}}^{2} \Omega_{2 \mathrm{~s}}^{2}} \mathrm{~F}_{6}^{2}+\sqrt{\frac{\mathrm{H}_{1}}{\Omega_{1 \mathrm{~s}}^{2}}+\frac{\mathrm{H}_{2}}{\Omega_{2 \mathrm{~s}}^{2}} \mid \frac{2 \overline{\mathrm{C}_{66}}}{\Omega_{1 \mathrm{~s}}^{2} \Omega_{2 \mathrm{~s}}^{2}}} \mathrm{~F}_{6}=\left(\gamma^{*}+\gamma_{0}\right)=1
$$

Since the shear response of the lamina does not depend on the sign of the shear stress, the coefficient of the linear term in (Eq. 3.20) should be zero. Therefore we get

$$
\begin{gathered}
\mathrm{H}_{2}=-\frac{\Omega_{2 \mathrm{~s}}^{2}}{\Omega_{1 \mathrm{~s}}^{2}} \mathrm{H}_{1}=-\mathrm{r}_{\mathrm{s} 12} \mathrm{H}_{1} ; \mathrm{r}_{\mathrm{s} 12}=\frac{\Omega_{2 \mathrm{~s}}^{2}}{\Omega_{1 \mathrm{~s}}^{2}} \\
\sqrt{\frac{\mathrm{J}_{11} \mathrm{r}_{\mathrm{s} 12}}{\mathrm{k}_{\mathrm{s} 12}}+\frac{\mathrm{J}_{22}}{\mathrm{k}_{\mathrm{s} 12} \mathrm{r}_{\mathrm{s} 12}}} \frac{2 \overline{\mathrm{C}_{66}}}{\mathrm{k}_{\mathrm{s} 12}} \mathrm{~F}_{6}^{2}=\left(\gamma^{*}+\gamma_{0}\right)=1 ; \mathrm{k}_{\mathrm{s} 12}=\Omega_{1 \mathrm{~s}}^{2} \Omega_{2 \mathrm{~s}}^{2}
\end{gathered}
$$

$\mathrm{k}_{\mathrm{s} 12}$ can be approximated as the ratio of damaged shear modulus to the undamaged shear modulus [21].

$$
\mathrm{k}_{\mathrm{s} 12}=\Omega_{1 \mathrm{~s}}^{2} \Omega_{2 \mathrm{~s}}^{2}=\frac{\mathrm{G}_{12}^{*}}{\mathrm{G}_{12}}
$$

Also, it has been experimentally observed that most of the shear damage is in the form of longitudinal cracks rather than the transverse cracks [21], so $\mathrm{D}_{2 \mathrm{~s}}>\mathrm{D}_{1 \mathrm{~s}}$ and from (Eq. 3.21) we obtain the following restriction on $r_{\text {s12 }}$

$$
0<\mathrm{r}_{\mathrm{s} 12}<1
$$

Substituting this value in (Eq. 3.22) and solving (Eq. 3.18) (Eq. 3.21) and (Eq. 3.22) we obtain the values of $\mathrm{J}_{22}$ and $\mathrm{H}_{2}$. 


\subsubsection{Calculation of $\mathbf{J}_{33}, \mathbf{H}_{3}$}

In this case the inter-laminar stresses are taken into consideration. The formulation of equations is similar as that of the in-plane case.

When the lamina is subjected to inter-laminar stresses, at failure, (Eq. 3.11) reduces to

$$
\begin{aligned}
& \sqrt{\frac{\mathrm{J}_{11}}{\Omega_{1 \mathrm{~s}}^{4}}+\frac{\mathrm{J}_{33}}{\Omega_{3 \mathrm{~s}}^{4}}} \frac{2 \overline{\mathrm{C}_{55}}}{\Omega_{1 \mathrm{~s}}^{2} \Omega_{3 \mathrm{~s}}^{2}} \mathrm{~F}_{5}^{2}+\sqrt{\frac{\mathrm{H}_{1}}{\Omega_{1 \mathrm{~s}}^{2}}+\frac{\mathrm{H}_{3}}{\Omega_{3 \mathrm{~s}}^{2}} \mid \frac{2 \overline{\mathrm{C}_{55}}}{\Omega_{1 \mathrm{~s}}^{2} \Omega_{2 \mathrm{~s}}^{2}}} \mathrm{~F}_{5}=\left(\gamma^{*}+\gamma_{0}\right)=1 \\
& \sqrt{\frac{\mathrm{J}_{33}}{\Omega_{3 \mathrm{~s}}^{4}}+\frac{\mathrm{J}_{22}}{\Omega_{2 \mathrm{~s}}^{4}}} \frac{2 \overline{\mathrm{C}_{44}}}{\Omega_{3 \mathrm{~s}}^{2} \Omega_{2 \mathrm{~s}}^{2}} \mathrm{~F}_{4}^{2}+\sqrt{\frac{\mathrm{H}_{3}}{\Omega_{3 \mathrm{~s}}^{2}}+\frac{\mathrm{H}_{2}}{\Omega_{2 \mathrm{~s}}^{2}} \mid \frac{2 \overline{\mathrm{C}_{44}}}{\Omega_{3 \mathrm{~s}}^{2} \Omega_{2 \mathrm{~s}}^{2}}} \mathrm{~F}_{4}=\left(\gamma^{*}+\gamma_{0}\right)=1
\end{aligned}
$$

Since the shear response does not depend on the sign of the shear stress, the coefficients of the linear term must be zero. Therefore we get,

$$
\begin{aligned}
& \mathrm{H}_{3}=-\frac{\Omega_{3 \mathrm{~s}}^{2}}{\Omega_{1 \mathrm{~s}}^{2}} \mathrm{H}_{1}=-\mathrm{r}_{\mathrm{s} 13} \mathrm{H}_{1} ; \mathrm{r}_{\mathrm{s} 13}=\frac{\Omega_{3 \mathrm{~s}}^{2}}{\Omega_{1 \mathrm{~s}}^{2}} \\
& \mathrm{H}_{2}=-\frac{\Omega_{2 \mathrm{~s}}^{2}}{\Omega_{3 \mathrm{~s}}^{2}} \mathrm{H}_{3}=-\mathrm{r}_{\mathrm{s} 23} \mathrm{H}_{3} ; \mathrm{r}_{\mathrm{s} 23}=\frac{\Omega_{2 \mathrm{~s}}^{2}}{\Omega_{3 \mathrm{~s}}^{2}}
\end{aligned}
$$

Also, it has been experimentally observed that $r_{s 13}$ should be less than 1 [3]. Similar to $\mathrm{k}_{\mathrm{s} 12}$ in (Eq. 3.22) we have $\mathrm{k}_{\mathrm{s} 13}$ and $\mathrm{k}_{\mathrm{s} 23}$ given by

$$
\begin{aligned}
& \mathrm{k}_{\mathrm{s} 13}=\Omega_{1 \mathrm{~s}}^{2} \Omega_{3 \mathrm{~s}}^{2}=\frac{\mathrm{G}_{13}^{*}}{\mathrm{G}_{13}} \\
& \mathrm{k}_{\mathrm{s} 23}=\Omega_{2 \mathrm{~s}}^{2} \Omega_{3 \mathrm{~s}}^{2}=\frac{\mathrm{G}_{23}^{*}}{\mathrm{G}_{23}}
\end{aligned}
$$

Therefore (Eq. 3.25) and (Eq. 3.26) reduce to

$$
\sqrt{\frac{\mathrm{J}_{11} \mathrm{r}_{\mathrm{s} 13}}{\mathrm{k}_{\mathrm{s} 13}}+\frac{\mathrm{J}_{33}}{\mathrm{k}_{\mathrm{s} 13} \mathrm{r}_{\mathrm{s} 13}}} \frac{2 \overline{\mathrm{C}_{55}}}{\mathrm{k}_{\mathrm{s} 13}} \mathrm{~F}_{5}^{2}=\left(\gamma^{*}+\gamma_{0}\right)=1
$$




$$
\sqrt{\frac{\mathrm{J}_{22} \mathrm{r}_{\mathrm{s} 23}}{\mathrm{k}_{\mathrm{s} 23}}+\frac{\mathrm{J}_{33}}{\mathrm{k}_{\mathrm{s} 23} \mathrm{r}_{\mathrm{s} 23}}} \frac{2 \overline{\mathrm{C}_{44}}}{\mathrm{k}_{\mathrm{s} 23}} \mathrm{~F}_{4}^{2}=\left(\gamma^{*}+\gamma_{0}\right)=1
$$

Solving (Eq. 3.31) and (Eq. 3.32) we obtain the values of $\mathrm{J}_{33}, \mathrm{H}_{3}$. The internal material constants calculated for AS4/Vinyl Ester material using the MAPLE software are shown in Appendix B. The next step is to determine the evolution or hardening parameters $c_{1}, c_{2}$ and damage threshold $\gamma_{0}$.

\subsubsection{Flow and Hardening rules}

A non-associated flow rule is used for the damage model [21]. The flow potential surface is given by the following equation

$$
\mathrm{f}=\left(\mathrm{Y}_{\mathrm{ij}} \cdot \mathrm{J}_{\mathrm{ijhk}} \mathrm{Y}_{\mathrm{hk}}\right)^{\frac{1}{2}}-\gamma(\delta)-\gamma_{0}
$$

The damage and flow surface expand as a function of evolution variable $\gamma$. Lacking any experimental data to indicate any type of anisotropic hardening, the isotropic hardening rule [21] is proposed as the evolution law (Eq. 3.34)

$$
\gamma=-\frac{\partial \pi}{\partial \delta}=\mathrm{c}_{1}\left(\exp \left(\frac{\delta}{\mathrm{c}_{2}}\right)-1\right)
$$

where $\pi(\delta)$ is the dissipation energy and $\mathrm{c}_{1}, \mathrm{c}_{2}$ are material constants, which have to be determined from experimental data. Since the dissipation energy should be convex [21], its second derivative should be positive. In that case the signs of $c_{1}, c_{2}$ should be different.

$$
\pi^{\prime \prime}=-\frac{\mathrm{c}_{1}}{\mathrm{c}_{2}} \exp \left(\frac{\delta}{\mathrm{c}_{2}}\right)
$$

The flow rule for damage and hardening is given by 


$$
\mathrm{dD}=\mathrm{d} \lambda \frac{\partial \mathrm{f}}{\partial \mathrm{Y}} \quad ; \quad \mathrm{d} \delta=\mathrm{d} \lambda \frac{\partial \mathrm{f}}{\partial \gamma}
$$

Taking into account (Eq. 3.33) we get

$$
\frac{\partial \mathrm{f}}{\partial \gamma}=-1 ; \mathrm{d} \delta=-\mathrm{d} \lambda
$$

where $\mathrm{d} \lambda$ is the damage multiplier whose value can be determined from the consistency condition $\left(g^{d}=0, \mathrm{dg}^{\mathrm{d}}=0\right)[21]$, or

$$
\mathrm{d} \lambda=\frac{\frac{\partial \mathrm{g}^{\mathrm{d}}}{\partial \mathrm{Y}} \frac{\partial \mathrm{Y}}{\partial \varepsilon}}{\left[\frac{\partial \mathrm{g}^{\mathrm{d}}}{\partial \gamma} \frac{\partial \gamma}{\partial \delta}-\frac{\partial \mathrm{g}^{\mathrm{d}}}{\partial \mathrm{Y}} \frac{\partial \mathrm{Y}}{\partial \mathrm{D}} \frac{\partial \mathrm{f}}{\partial \mathrm{D}}\right]} \mathrm{d} \varepsilon
$$

Substituting in (Eq. 3.36) we get,

$$
\mathrm{dD}=\frac{\frac{\partial \mathrm{g}^{\mathrm{d}}}{\partial \mathrm{Y}} \frac{\partial \mathrm{Y}}{\partial \varepsilon}}{\left[\frac{\partial \mathrm{g}^{\mathrm{d}}}{\partial \gamma} \frac{\partial \gamma}{\partial \delta}-\frac{\partial \mathrm{g}^{\mathrm{d}}}{\partial \mathrm{Y}} \frac{\partial \mathrm{Y}}{\partial \mathrm{D}} \frac{\partial \mathrm{f}}{\partial \mathrm{D}}\right]} \frac{\partial \mathrm{f}}{\partial \mathrm{Y}} \mathrm{d} \varepsilon
$$

The incremental stress- strain relations for damage evolution is given by

$$
\mathrm{d} \sigma=\frac{\partial \sigma}{\partial \varepsilon} \mathrm{d} \varepsilon+\frac{\partial \sigma}{\partial \mathrm{D}} \mathrm{dD}
$$

where $\varepsilon$ is the total strain. Substituting dD from (Eq. 3.39) into (Eq. 3.40) we get,

$$
\mathrm{d} \sigma=\left(\frac{\partial \sigma}{\partial \varepsilon}+\frac{\partial \sigma}{\partial \mathrm{D}} \frac{\frac{\partial \mathrm{g}^{\mathrm{d}}}{\partial \mathrm{Y}} \frac{\partial \mathrm{Y}}{\partial \varepsilon}}{\left[\frac{\partial \mathrm{g}^{\mathrm{d}}}{\partial \gamma} \frac{\partial \gamma}{\partial \delta}-\frac{\partial \mathrm{g}^{\mathrm{d}}}{\partial \mathrm{Y}} \frac{\partial \mathrm{Y}}{\partial \mathrm{D}} \frac{\partial \mathrm{f}}{\partial \mathrm{D}}\right]} \frac{\partial \mathrm{f}}{\partial \mathrm{Y}}\right) \mathrm{d} \varepsilon=\mathrm{E}_{\text {non-linear }} \mathrm{d} \varepsilon
$$

where

$$
\mathrm{E}_{\text {non-linear }}=\frac{\partial \sigma}{\partial \varepsilon}+\frac{\partial \sigma}{\partial \mathrm{D}} \frac{\frac{\partial \mathrm{g}^{\mathrm{d}}}{\partial \mathrm{Y}} \frac{\partial \mathrm{Y}}{\partial \varepsilon}}{\left[\frac{\partial \mathrm{g}^{\mathrm{d}}}{\partial \gamma} \frac{\partial \gamma}{\partial \delta}-\frac{\partial \mathrm{g}^{\mathrm{d}}}{\partial \mathrm{Y}} \frac{\partial \mathrm{Y}}{\partial \mathrm{D}} \frac{\partial \mathrm{f}}{\partial \mathrm{D}}\right]} \frac{\partial \mathrm{f}}{\partial \mathrm{Y}}
$$

$E_{\text {non-linear }}$ represents the tangent stiffness due to the material non-linearity. These results are tracked at integration points of the each element in the finite element analysis. As the 
damage increases, the stiffness gets reduced. The damage $d_{i}$ in the model grows beyond critical value $D_{\text {icr }}$ and failure is predicted when the model can no longer withstand the damage in the elements and the finite element program stops.

\subsubsection{Adjusting the hardening parameters $\left(c_{1}, c_{2}\right)$ and damage threshold $\left(\gamma_{0}\right)$}

The hardening parameters control the damage evolution and the damage threshold represents the initial size of the damage surface. Since the material behavior is highly non-linear for a composite lamina for in-plane shear mode, as indicated from experimental observations, the damage is assumed to be notable in this case [21]. Therefore, $c_{1}, c_{2}$ and $\gamma_{0}$ are adjusted to predict the experimental shear response of the lamina subjected to pure shear conditions using Finite Element Analysis. In case the experimental shear plot is not available for a material, but only $\mathrm{G}_{12}$ and $\mathrm{F}_{6}$ are known, the curve can be determined using the empirical relation [1]

$$
\sigma_{6}=\mathrm{F}_{6} \tanh \left(\frac{\mathrm{G}_{12}}{\mathrm{~F}_{6}} 2 \varepsilon_{6}\right)
$$

The finite element model is then subjected to pure shear condition as shown in Fig. 3.5. The rear nodes are clamped, and the nodes in the side faces are free to move only in the $\mathrm{Y}$ direction as illustrated in Fig. 3.5. The nodes in the front face of the lamina are given a strain of two percent $\left(\varepsilon_{\mathrm{xy}}=2 \%\right)$ in the $\mathrm{Y}$ direction to simulate the pure shear condition. The input data is given in Appendix D for the shear test.

During the post processing stage, the sum of the reaction forces $\left(\mathrm{F}_{\mathrm{xy}}\right)$ in the inplane shear direction and the deformation in the front face of the lamina are recorded for each substep. The average shear stress is calculated by dividing $F_{x y}$ by the shear area and the shear strain is calculated from the deformation of nodes in the front face of the lamina. 
The shear stress-strain from the analysis is plotted and compared to the experimental shear response. If the curves do not match, then the values of $c_{1}, c_{2}$ and $\gamma_{0}$ are adjusted and the procedure is repeated until the shear stress-strain plot matches the experimental shear response.

\subsubsection{ANSYS Implementation}

In order to include the material non-linearity, a user subroutine is written in FORTRAN [3] and linked with ANSYS. The procedure is explained in Appendix C. A user defined ANSYS is obtained from this procedure. A single lamina is modeled in I-DEAS and meshed using 20 noded solid brick elements. The finite element model is then exported to the user defined ANSYS. The equivalent element in ANSYS is Solid186, which allows user material properties to be defined. The material properties and parameters are input in the ANSYS user-material model definition. A mesh sensitivity analysis is performed in order to get accurate results. The non-linear analysis is run with optimum number of substeps.

\subsection{Summary}

A meso level damage model is developed for analyzing the non-linear behavior of plain weave laminated composites. The model is simple, as it is based on the stiffness and strength values of a unidirectional lamina that can be obtained from standard tests. No damage occurs until the thermodynamic forces $Y$ reach the damage surface $g^{d}$. The shape of the damage surface in the thermodynamic space is equivalent to the shape of the TsaiWu surface in stress space. If the thermodynamic forces exceed the damage surface the material starts to harden based on the hardening law and the size of the damage surface 
increases. Failure occurs when the size of the damage surface matches the size of TsaiWu surface. The hardening parameters $c_{1}, c_{2}$ control the damage evolution and $\gamma_{0}$ determines the initial size of the damage surface. They are adjustable parameters and are obtained by matching the shear response of FE model (Sect. 3.3.3) with the experimental stress-strain plot. Intermediate material constants $\mathrm{J}_{11}, \mathrm{~J}_{22, \text {,.., }} \mathrm{H}_{3}$ determine the shape of the damage surface and are obtained from the stiffness and strength values of a unidirectional lamina. 


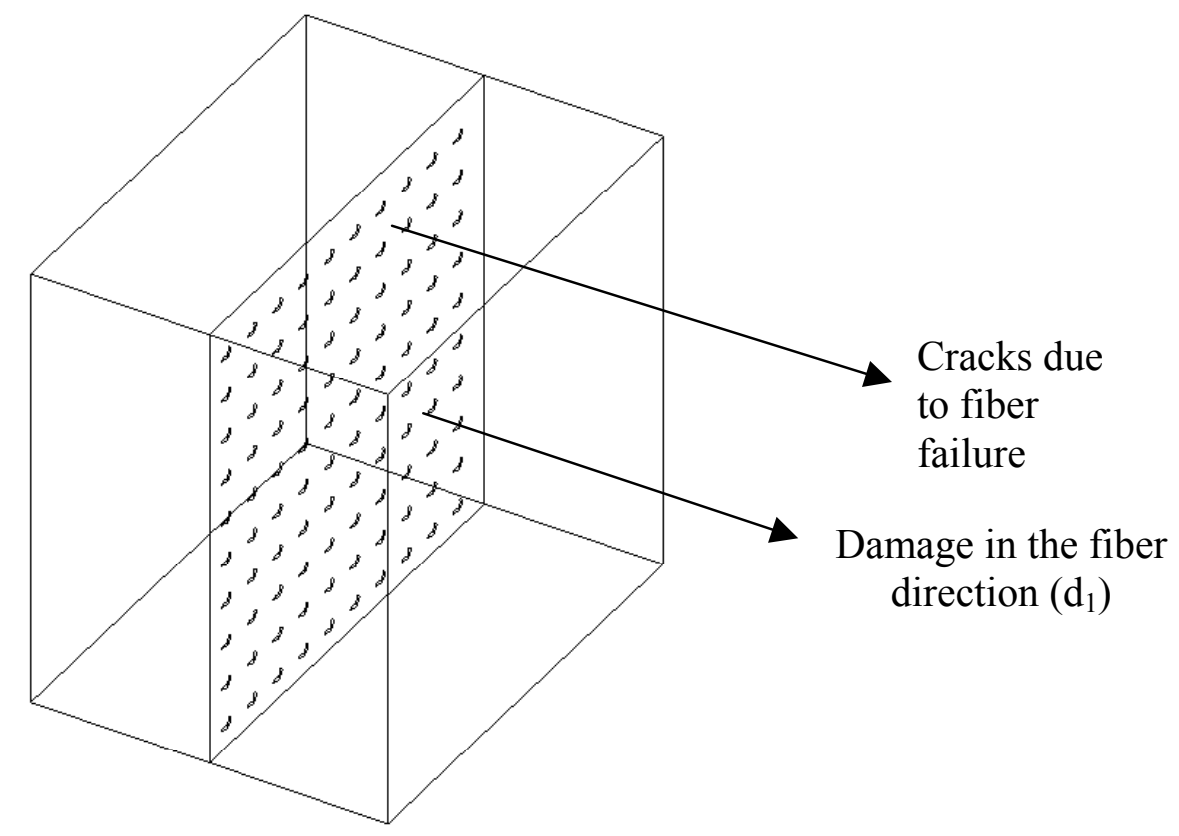

Fig. 3.1 Net area reduction in the fiber direction

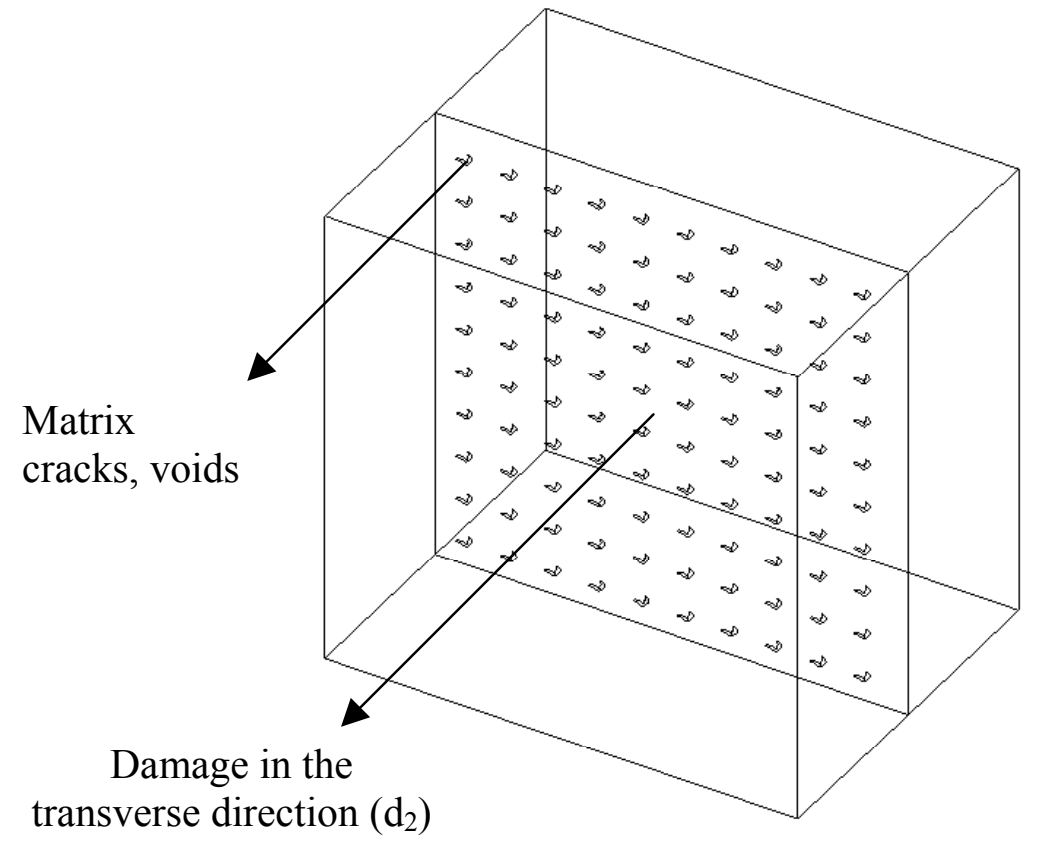

Fig. 3.2 Net area reduction in the transverse direction 


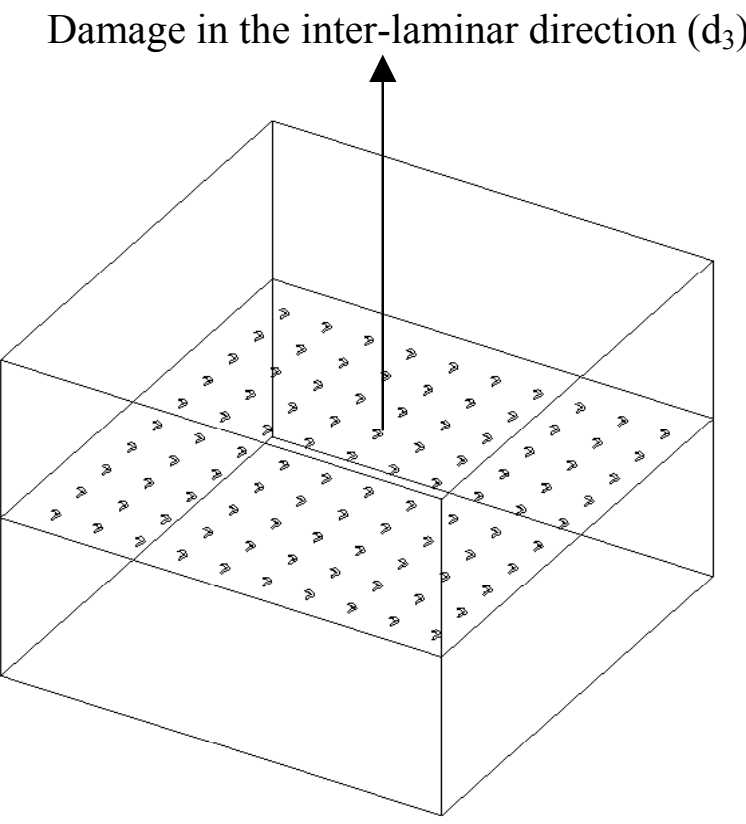

Fig. 3.3 Net area reduction in the inter-laminar direction

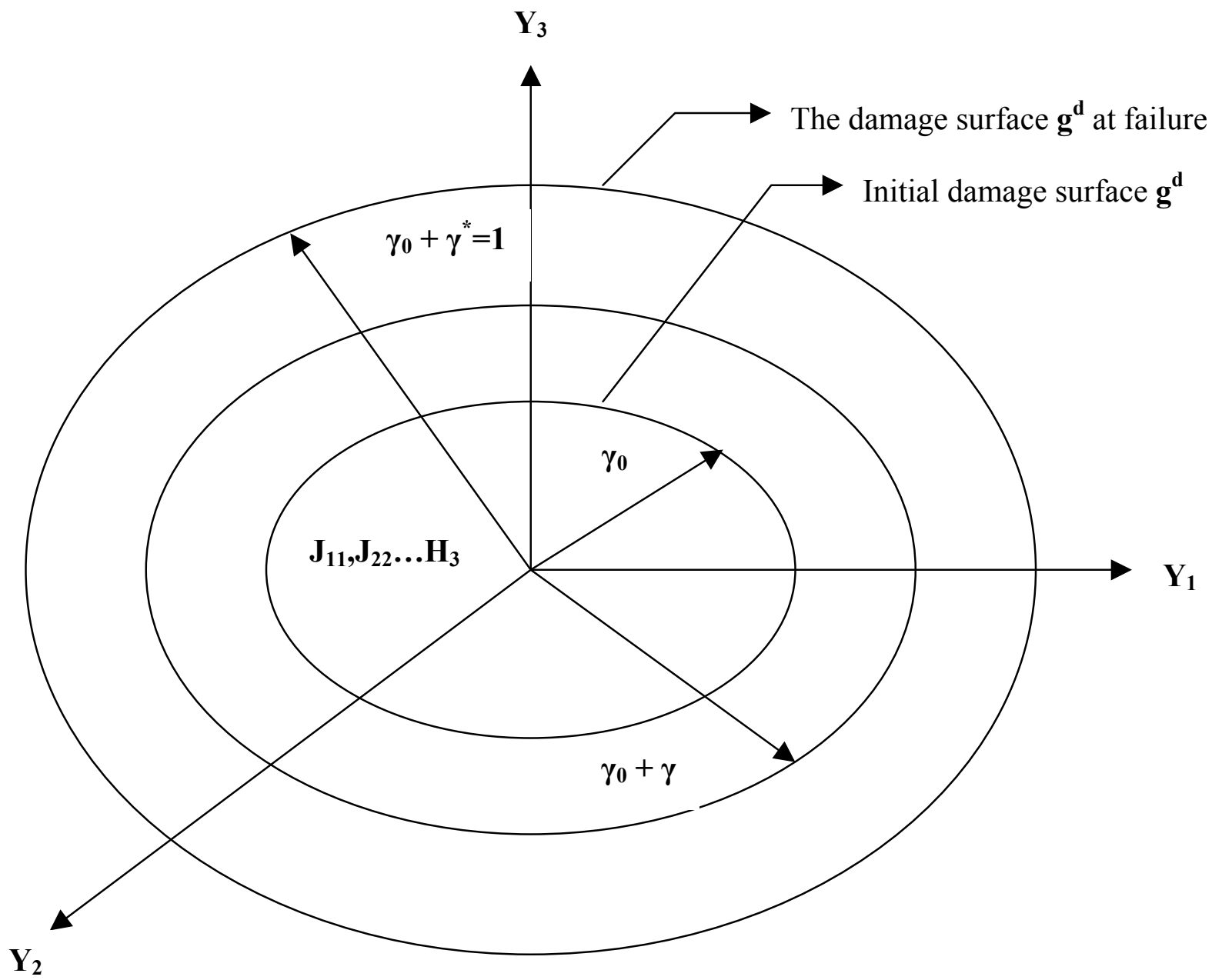

Fig. 3.4 Damage surface in the thermodynamic space 


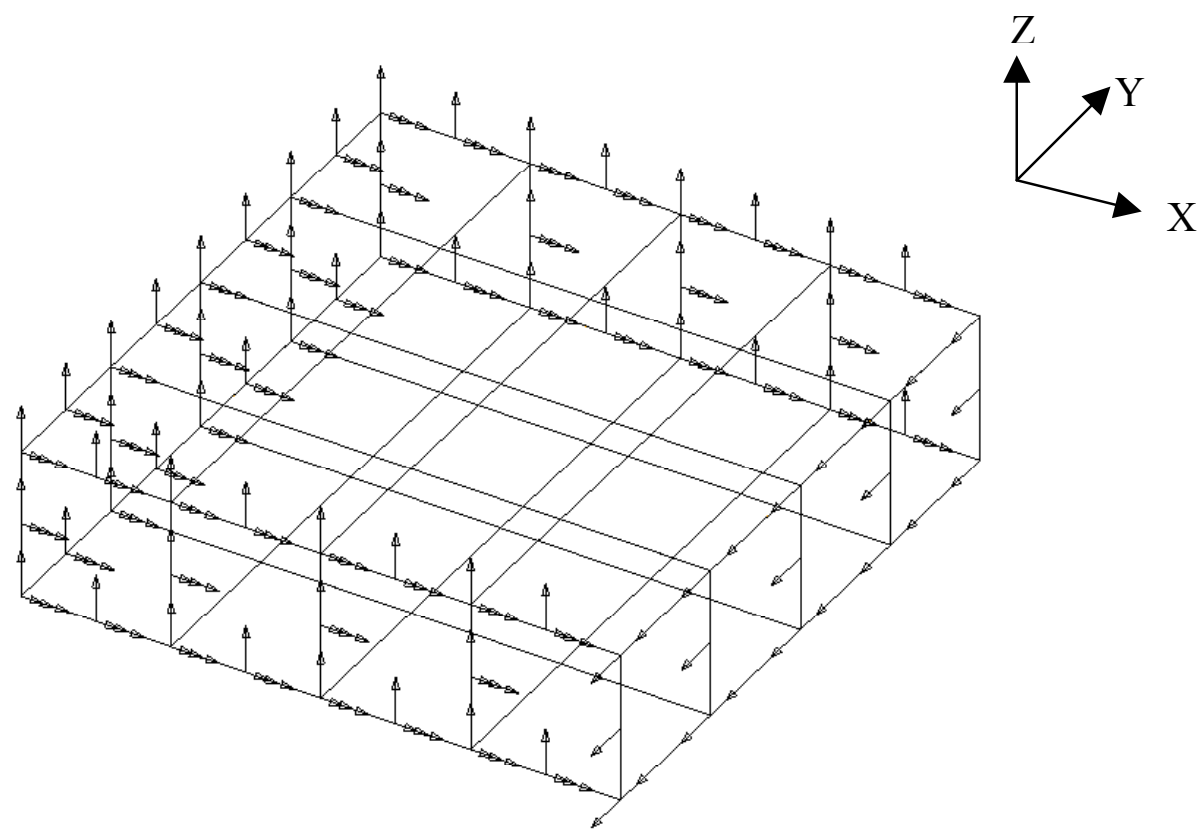

Fig. 3.5 Boundary conditions for pure shear in a composite lamina 


\section{CHAPTER 4: RESULTS AND DISCUSSION}

\subsection{Introduction}

This chapter is divided into two parts. The first part explains the procedure for validation of the damage model and the second part gives a detailed description of the damage analysis of the plain weave fabrics. In order to validate the damage model in ANSYS, T300/5208 laminates with different fiber orientations are analyzed with the model under uniaxial tensile loading and results are compared with experimental data [26]. In case of the plain weave laminates, uniaxial tensile behavior of the FE models (Chapter 2) are analysed with the damage model in ANSYS and the results are compared with the experimental data [10].

\subsection{Validation of the damage model}

A T300/5208 laminate consisting of eight layers is modeled in I-DEAS and meshed using 20 noded brick elements. The meso-scale approach is used for predicting the stiffness of the laminates. Four configurations of T300/5208 laminate $-[10 /-10]_{2 \mathrm{~s}},[0 / 45 /-45 / 90]_{\mathrm{s}}$, $[30 /-30]_{2 \mathrm{~s}}$ and $[45 /-45]_{2 \mathrm{~s}}$, are tested using the damage model and compared with experimental data. The material co-ordinates for each configuration are specified using the material orientation option in I-DEAS. In order to perform the tensile test, the rear face of the laminate is fixed and the front face is subjected to uniform strain as shown in Fig 4.1. The FE model is exported to user defined ANSYS as an input file. The equivalent element in ANSYS is Solid186, which allows user material properties to be defined. The material properties and the damage parameters of T300/5208 obtained from [26] are reported in Table 4.1. Only in-plane stresses are considered for the analysis. In 
order to obtain the hardening parameters $\left(\mathrm{c}_{1}, \mathrm{c}_{2}\right)$ and damage threshold $\left(\gamma_{0}\right)$, the shear response of T300/5208 material is matched with the experimental shear stress-strain plot (Isopescu test) as explained in Chapter 3 (Sect. 3.3.3) in user defined ANSYS. The shear plot is shown in Fig. 4.2. The values are also reported in Table 4.1. Then, each configuration of T300/5208 laminate is analyzed with the damage model in ANSYS. The non-linear analysis is performed with optimum number of substeps. The damage is tracked at each integration point. The stiffness is reduced as the damage increases at the integration points of each element. The damage $d_{i}$ is allowed to grow beyond the critical value $D_{\text {icr. }}$ At a given substep, some elements may fail while others may not. Eventually, the finite element program stops when the FE model becomes unstable due to damage. A mesh sensitivity analysis is performed in order to get accurate solution. The results for the analysis are shown in Fig. 4.3. The results show a good correlation with the experimental data.

\subsection{Damage analysis of Plain Weave Fabrics}

The FE models of iso-phase and out-of-phase laminates developed in Chapter 2 are exported to user defined ANSYS as input files. The equivalent element in ANSYS is Solid187 that is used to define the user material model. In order to perform the tensile test, symmetric conditions are applied to the back surface and the left surface of the RVE and uniform strain is applied to the front surface of the RVE as explained in Chapter 2. Each layer of the RVE is visualized as four independent single lamina (two warp and two fill yarns) surrounded by isotropic matrix. The damage model is applied only to the yarns and the matrix is assumed to be elastic. Here both in-plane and inter-laminar stresses are 
taken into consideration. The parameters of the damage model for AS4/Vinyl ester yarns are obtained as follows,

- The elastic properties of AS4/Vinyl ester computed using periodic micro mechanics model (PMM) is obtained from Table 2.4 in Chapter 2.

- The transverse tensile strength $F_{2 t}$ and inter-laminar strength $F_{5}$ are available from [10]. The longitudinal tensile strength $F_{1 t}$ is calculated using the strength of the AS4 fiber (3930 MPa) available in [10] and Eq. 4.59 from [1]. $F_{5}$ is assumed to be same as $\mathrm{F}_{6} . \mathrm{F}_{4}$ is assumed to be $43 \mathrm{MPa}$. F1c is obtained using the empirical relation (Eq. 4.75 in [1]).

$$
\begin{gathered}
\mathrm{F}_{1 \mathrm{c}}=\left(\frac{\chi}{\mathrm{a}}+1\right)^{\mathrm{b}} \mathrm{G}_{12} \\
\chi=\frac{\mathrm{G}_{12} \Omega}{\mathrm{F}_{6}}
\end{gathered}
$$

where

$\Omega$ is the standard deviation of the Gaussian distribution of fiber misalignment

$a, b$ are constants

$\mathrm{G}_{12}$ is the in-plane shear modulus

$F_{6}$ is the in-plane shear strength.

The value of $\Omega$ is assumed to be 2.8 . In case of the fabrics, the fiber misalignment is more than that of a unidirectional fiber tow because the yarns are twisted. Hence a high value of standard deviation is assumed.

- The critical damage values $\mathrm{D}_{1 \mathrm{t}}$, and $\mathrm{D}_{2 \mathrm{t}}$ are obtained from [3]. The longitudinal compressive critical damage $D_{1 c}$ for a plain weave is higher than that for a 
unidirectional laminate because of the fiber misalignment, and it is calculated as follows

$$
\mathrm{D}_{\mathrm{lc}}=1-\operatorname{erf}\left(\frac{\alpha_{\mathrm{cr}}}{\Lambda \sqrt{2}}\right)
$$

where erf is the error function, $\alpha_{\mathrm{cr}}$ is the critical misalignment angle at failure (Eq.23 in [24]) and $\Lambda$ is the standard deviation of the Gaussian distribution of fiber misalignment.

- The unloading damaged shear moduli $\left(\mathrm{G}_{12}^{*}, \mathrm{G}_{13}^{*}, \mathrm{G}_{23}^{*}\right)$ are calculated assuming the ultimate shear strain to be $3 \%$.

- The internal constants $\mathrm{J}_{11}, \mathrm{~J}_{22}, \mathrm{~J}_{33}, \mathrm{H}_{1}, \mathrm{H}_{2}, \mathrm{H}_{3}$ are calculated using Eqs. (3.13-3.32) in Chapter 3.

- The hardening parameters $\left(\mathrm{c}_{1}, \mathrm{c}_{2}\right)$ and damage threshold $\left(\gamma_{0}\right)$ are adjusted by matching the in-plane shear response of AS4/Vinyl ester composite obtained using the damage model with the experimental shear plot. The process is explained in Chapter 3 (Sect. 3.3.3). The shear plot is shown in Fig. 4.4.

The material properties and the damage parameters of AS4/Vinyl ester are reported in Tables 4.2 and 4.3. The non-linear analysis is performed with optimum number of substeps. The damage growth is tracked at each integration point as explained in Sect. 4.2. As the damage in the elements increase, the stiffness of the element decreases in accord to the respective damage mode and the stresses are redistributed. Eventually, the finite element program fails to converge and the model cannot withstand any more damage. 
The results obtained for the damage analysis of iso-phase laminate is shown in Fig. 4.6. The linear curve indicates the case for which there is no damage considered for the analysis. This condition is achieved by specifying a large value for the damage threshold $\left(\gamma_{0}=1 \mathrm{E} 20\right)$, which means that the initial damage surface is very large and hence no damage occurs.

In case of the damage analysis of iso-phase laminate, the damage model predicts the inelastic experimental curve until 8400 microstrains. The model fails to converge at a stress level of $306 \mathrm{MPa}$, which predicts well the initiation of microcracks reported to take place at $281 \mathrm{MPa}$. The actual failure stress of the iso-phase laminate occurs at $489 \mathrm{MPa}$ at 16000 microstrains from experiments [10]. But it has been observed in the experiments that at a stress level of $281 \mathrm{MPa}$, initiation of interfacial debonding takes place and the layers start to separate. This is in the domain of fracture mechanics and the proposed damage model cannot predict the macroscopic effects due to the cracks. Also, stiffening of the laminate was observed after interfacial debonding at a stress level of $374 \mathrm{MPa}$, once the warp yarns are straightened. The damage model predicts the in-elastic curve using the stiffness reduction scheme. Therefore, the model does not predict the stiffening effect.

The knee of the in-elastic curve is well predicted by the damage model. The sequence of failures in the iso-phase laminate for the loading in longitudinal direction (Fig. 4.5) is as follows,

a. Transverse tensile failure in the fill or transverse yarns.

b. Inter-laminar failures in fill and warp yarns.

c. Fiber damage in the warp yarns 
In order to illustrate the evolution of damage, damage state variables $\left(d_{1}, d_{2}, d_{3}\right)$ are plotted against the axial strain for each substep of the analysis as shown in Fig. 4.7. The plot is indicative of the damage evolution and growth in the iso-phase model. The damage variables are chosen at integration points where they are maximum. In Fig. 4.7, the plot for $d_{1}$ shows that maximum value of damage is $d_{1}=0.0784$ at a gauss point in the warp yarn (see Fig. 2.7 where "warp" and "fill" yarn are labeled). The reason being that the warp yarn takes up most of the applied load, which is applied in the warp direction, and hence the fibers undergo significant damage. The damage value is less than the critical value in the longitudinal direction $\left(\mathrm{D}_{\text {lcr }}=0.116\right)$. The numbers in the parenthesis indicate the location of the point in the RVE where the damage value is maximum. The co-ordinates of the location are with respect to the origin of the RVE, which is indicated in Fig. 4.5. The plot for $d_{2}$ shows that the damage reaches the critical value $D_{2 c r}=0.5$ at a gauss point in the transverse yarn at 7480 microstrains. The damage then grows and reaches a final value of 0.98 at failure of the iso-phase laminate. The reason it occurs in the fill yarns is because the load is applied transverse to the fill yarn. Therefore, the transverse tensile stress in the yarn exceeds the transverse tensile strength in the local coordinate system. The stress is redistributed once the stiffness is reduced.

. The inter-laminar damage variable $d_{3}$ is plotted for both fill and warp yarns. When the iso-phase laminate is subjected to a uniform tensile strain along the warp direction, the sinusoidal warp yarns try to become straight. During the process of straightening, the yarns tend to twist, as they are not free to do so due to the presence of the fill yarns. Also, the fill yarns are twisted to some extent when warp yarns straighten. The twisting of the yarns under tensile load is shown in Fig. 4.8. Therefore, the inter-laminar effect becomes 
important for an iso-phase laminate. In case of an integration point in the fill yarn element, $d_{3}$ reaches a critical value $D_{3 c r}=0.5$. The critical value is reached at a stress level of $294 \mathrm{MPa}$, which coincide with the appearance of a macrocrack in the experiments [10]. The final value of $d_{3}$ in the fill yarn at failure is 0.566 . The maximum value of $d_{3}$ for an integration point in the warp yarn element is $d_{3}=0.374$. After the critical value is reached inter-laminar direction, the model is not able to withstand the load and hence fails at a stress level of $306 \mathrm{MPa}$. Ito and Chou [10] observed initiation of interfacial debonding of the yarns at a stress level of $281 \mathrm{MPa}$ due to the presence of transverse cracks in yarns. Since the damage model cannot predict effects due to macroscopic cracks, the model fails at a stress of $306 \mathrm{MPa}$, which is in agreement with experimental observations. Therefore, inter-laminar damage has a siginficant effect on the strength of the iso-phase laminate.

The non-linear plot for the out-of-phase laminate is shown in Fig. 4.9. The plot shows that the damage curve does not give a good prediction of the experimental data. This is because the initial Young's modulus of the FE model is $49.5 \mathrm{GPa}$ whereas for the experimental model it is $51.8 \mathrm{GPa}$. Also, it has been experimentally observed that through-the-thickness cracks (normal to the thickness co-ordinates $\mathrm{Z}$ ) are present in the out-of-phase configuration. Paradoxically, the experimental curve of [10] is observed to be linear with transverse cracks not affecting the linearity. Transverse cracks are also present in the FE model, but they cause the stiffness to decrease and hence the predicted curve is inelastic and not linear. In the experiment, the failure of the out-of-phase laminate was observed at 9300 microstrains due to the transverse stress $\sigma_{3}$ in the warp yarn. Since the effect due to $\sigma_{3}$ is not considered for the damage model, failure is not 
predicted. To see if the magnitude of $\sigma_{3}$ in the present FE model is high, an element is chosen where $\sigma_{3}$ is the maximum. Also, the values of $\sigma_{1}$ and $\sigma_{2}$, in the local co-ordinate system, are noted at the same point. Then, the stress values are normalized with respect to their strength values (i.e.) $\sigma_{1}$ is normalized with respect to $F_{1 t ;} \sigma_{2}$ is normalized with respect to $F_{2 t}$ and $\sigma_{3}$ is normalized with respect to $F_{2 t}$. The normalized values are plotted with axial strain for each substep as shown in Fig. 4.10. It can be seen that the normalized value of $\sigma_{3}$ is very high compared to other stresses. Therefore, the effect due $\sigma_{3}$ becomes important in case of the out-of-phase laminate. The damage model has to be modified so as to include the effect of $\sigma_{3}$ and is left for future studies. The damage variables plot is shown in Fig. 4.11. The $d_{1}$ has a maximum value of 0.089 , which is below the critical value. The damage value due to $d_{2}$ has maximum of 0.282 in the fill yarn. The damage value due to $d_{3}$ has a maximum of 0.266 in the warp yarn. None of the damage values reach the critical values. 
Table 4.1 Elastic properties and Damage parameters for T300/5208 material

\begin{tabular}{|c|c|}
\hline Property & T300/5208 \\
\hline $\mathrm{E}_{1}(\mathrm{~Pa})$ & $1.36 \mathrm{E}+11$ \\
\hline $\mathbf{E}_{2}(\mathrm{~Pa})$ & $9.8 \mathrm{E}+9$ \\
\hline $\mathrm{G}_{12}(\mathrm{~Pa})$ & $4.7 \mathrm{E}+9$ \\
\hline$v_{12}$ & 0.28 \\
\hline $\mathrm{F}_{1 \mathrm{t}}(\mathrm{Pa})$ & $1.55 \mathrm{E}+9$ \\
\hline $\mathbf{F}_{1 \mathrm{c}}(\mathrm{Pa})$ & $1.09 \mathrm{E}+9$ \\
\hline$F_{2 t}(\mathrm{~Pa})$ & $5.9 \mathrm{E}+7$ \\
\hline$F_{6}(\mathrm{~Pa})$ & $7.5 \mathrm{E}+7$ \\
\hline $\mathbf{k}_{\mathrm{s} 12}$ & 0.631 \\
\hline$D_{1 t}$ & 0.1161 \\
\hline $\mathbf{D}_{1 \mathrm{c}}$ & 0.1109 \\
\hline $\mathbf{D}_{2 t}$ & 0.5 \\
\hline$D_{3}{ }^{\text {cr }}$ & 0.5 \\
\hline $\mathbf{J}_{11}$ & $1.56 \mathrm{E}-15$ \\
\hline $\mathbf{J}_{22}$ & $5.157 \mathrm{E}-014$ \\
\hline $\mathbf{H}_{1}$ & $1.575 \mathrm{E}-007$ \\
\hline $\mathrm{H}_{2}$ & $-4.427 \mathrm{E}-008$ \\
\hline $\mathbf{r}_{\mathrm{s}}$ & 0.2817 \\
\hline $\mathbf{c}_{1}$ & 0.5 \\
\hline $\mathbf{c}_{2}$ & $-9 \mathrm{E}+5$ \\
\hline$\gamma_{0}$ & 0.15 \\
\hline
\end{tabular}


Table 4.2 Elastic properties of AS4/Vinyl Ester material

\begin{tabular}{|c|c|}
\hline Property & AS4/Vinyl Ester \\
\hline $\mathbf{E}_{\mathbf{1}}$ (MPa) & $1.51 \mathrm{E}+5$ \\
\hline $\mathbf{E}_{\mathbf{2}}$ (MPa) & 9040 \\
\hline $\mathbf{G}_{\mathbf{1 2}}$ (MPa) & 3900 \\
\hline $\mathbf{G}_{\mathbf{2 3}}$ (MPa) & 3360 \\
\hline $\mathbf{v}_{\mathbf{1 2}}$ & 0.272 \\
\hline $\mathbf{F}_{\mathbf{1 t}} \mathbf{( M P a )}$ & 2690 \\
\hline $\mathbf{F}_{\mathbf{1 c}} \mathbf{( M P a )}$ & 630 \\
\hline $\mathbf{F}_{\mathbf{2 t}} \mathbf{( M P a )}$ & 60 \\
\hline $\mathbf{F}_{\mathbf{4}} \mathbf{( M P a )}$ & 43 \\
\hline $\mathbf{F}_{\mathbf{5}}$ (MPa) & 80 \\
\hline $\mathbf{F}_{\mathbf{6}}$ (MPa) & 80 \\
\hline $\mathbf{G}_{\mathbf{1 2}}$ damaged (MPa) & 2857 \\
\hline $\mathbf{G}_{\mathbf{1 3}}$ damaged (MPa) & 2652 \\
\hline $\mathbf{G}_{\mathbf{2 3}}$ damaged (MPa) & 1310 \\
\hline
\end{tabular}


Table 4.3 Damage parameters of AS4/ Vinyl Ester Material

\begin{tabular}{|c|c|}
\hline Property & AS4/Vinyl Ester \\
\hline $\mathbf{J}_{11}$ & 0.0028070 \\
\hline $\mathbf{J}_{22}$ & 0.0454383 \\
\hline $\mathbf{J}_{33}$ & 0.0533 \\
\hline $\mathbf{H}_{1}$ & 0.103237 \\
\hline $\mathbf{H}_{2}$ & -0.0323228 \\
\hline $\mathbf{H}_{3}$ & 0.0477 \\
\hline $\mathbf{k}_{\mathrm{s} 12}$ & 0.732 \\
\hline $\mathbf{k}_{\mathrm{s} 13}$ & 0.68 \\
\hline$k_{\mathbf{s} 23}$ & 0.315 \\
\hline $\mathbf{r}_{\mathrm{s} 12}$ & 0.31309 \\
\hline $\mathbf{r}_{\mathbf{s} 13}$ & 0.4620 \\
\hline $\mathbf{r}_{\mathrm{s} 23}$ & 1.4759 \\
\hline$D_{1 t}$ & 0.1161 \\
\hline $\mathbf{D}_{1 \mathrm{c}}$ & 0.207 \\
\hline $\mathbf{D}_{2 \mathrm{t}}$ & 0.5 \\
\hline $\mathbf{D}_{3}{ }^{\mathrm{cr}}$ & 0.5 \\
\hline $\mathbf{c}_{1}$ & 0.2 \\
\hline $\mathbf{c}_{2}$ & -0.65 \\
\hline$\gamma_{0}$ & 0.1 \\
\hline
\end{tabular}




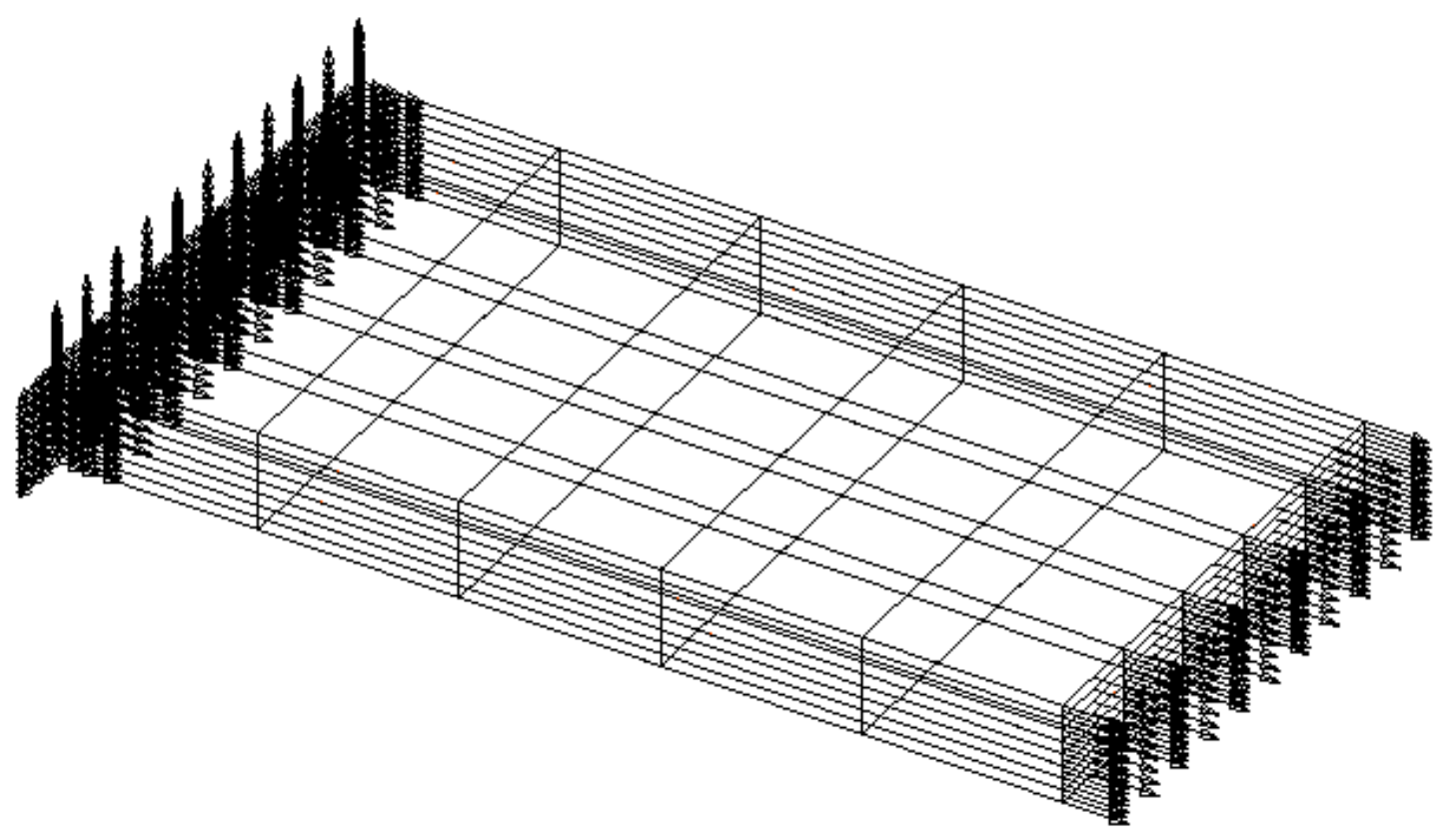

Fig. 4.1 FE model of T300/5208 laminate

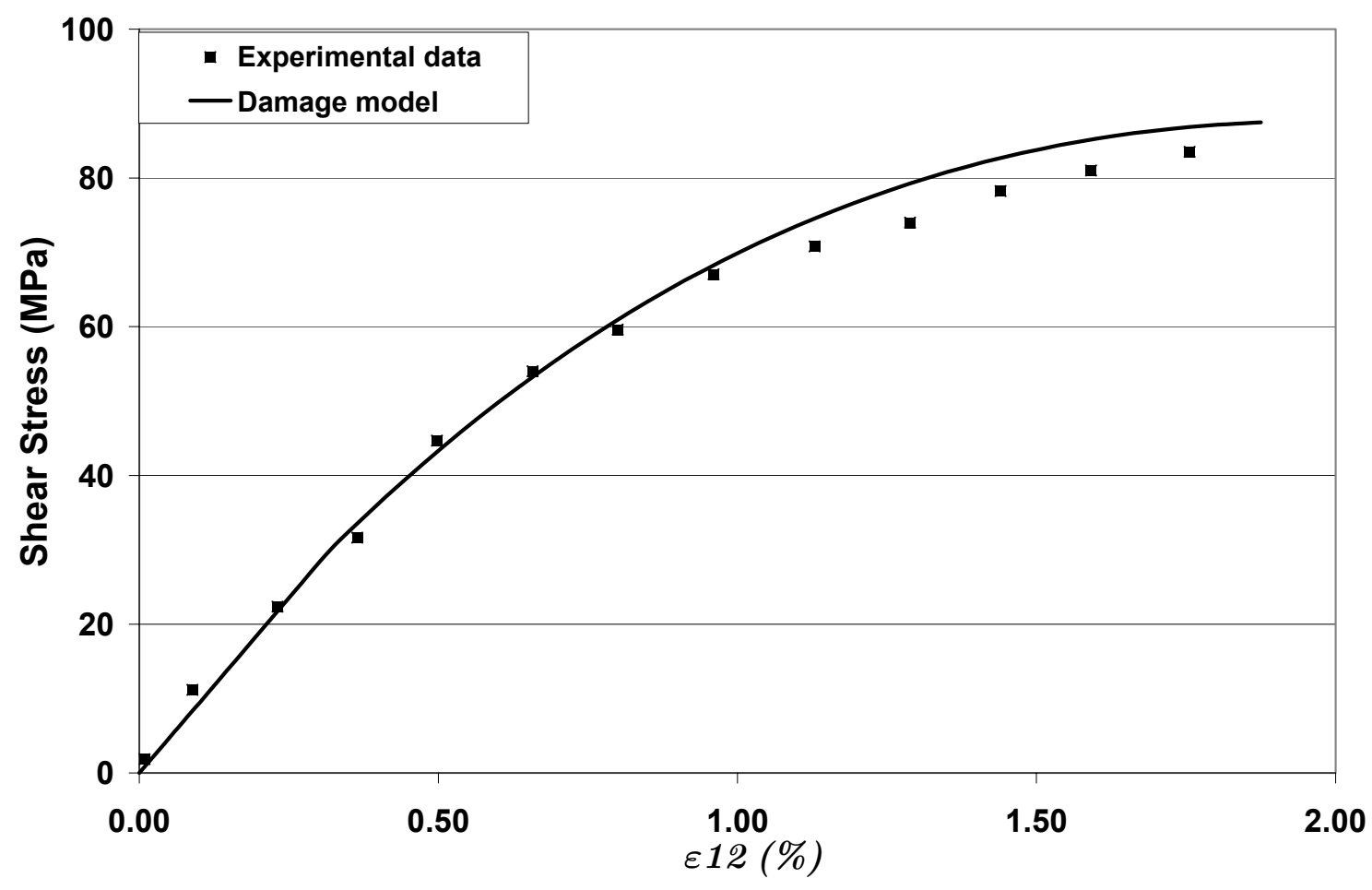

Fig. 4.2 Matching of shear response of $\mathrm{T300/5208}$ with the experimental data 


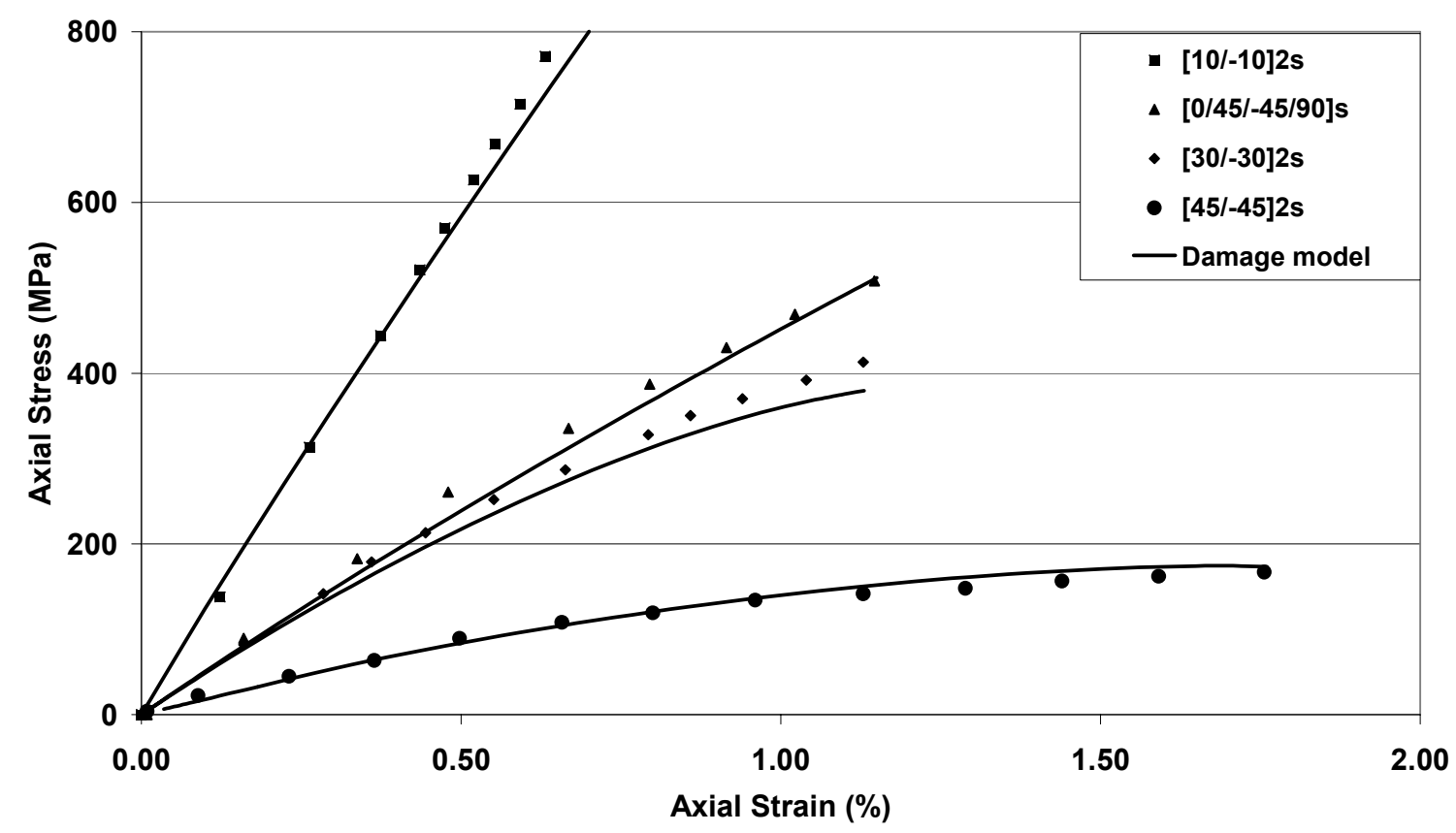

Fig. 4.3 Experimental and damage model results for T300/5208 laminate

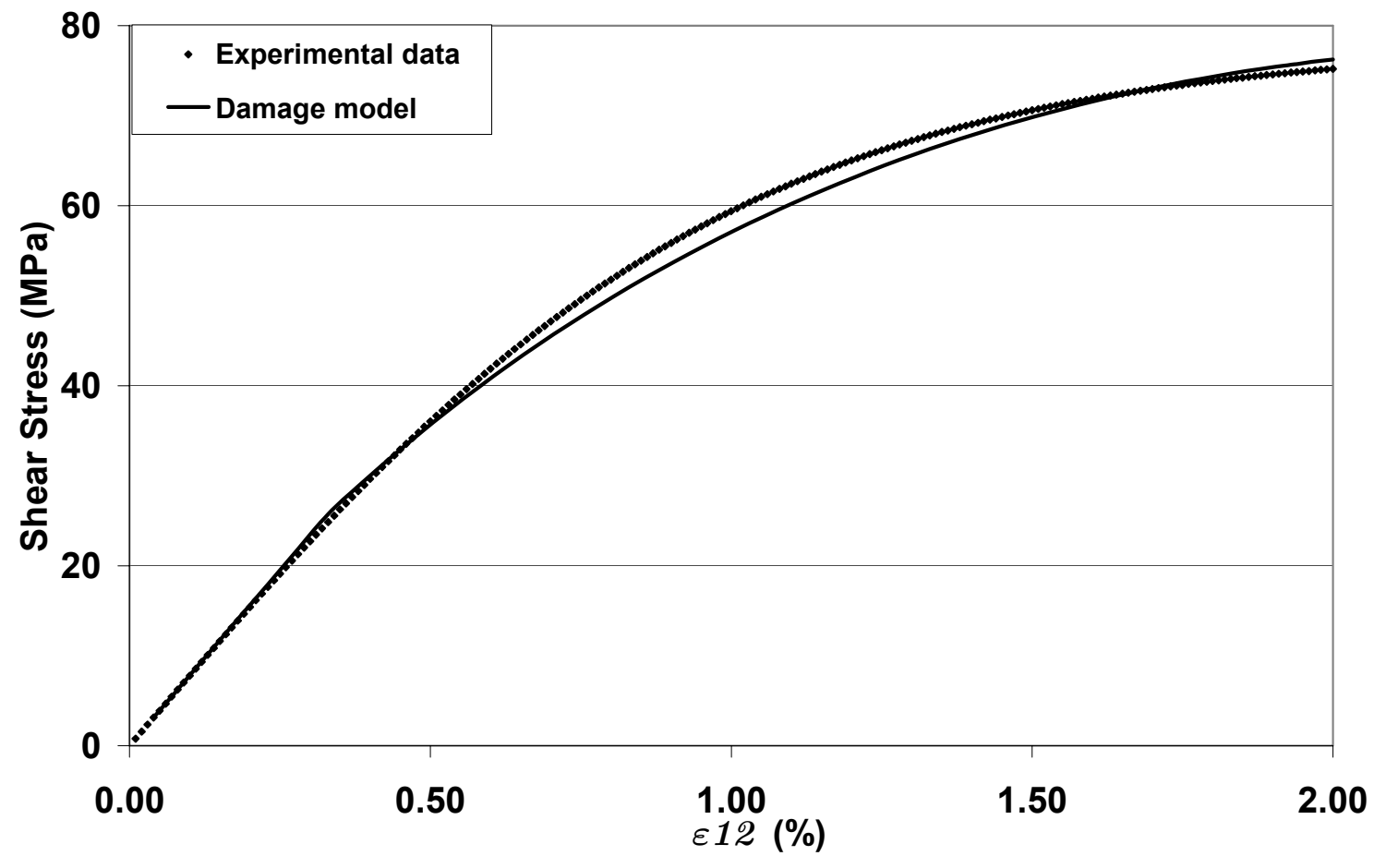

Fig. 4.4 Matching the shear response of AS4/Vinyl Esther with experimental data 


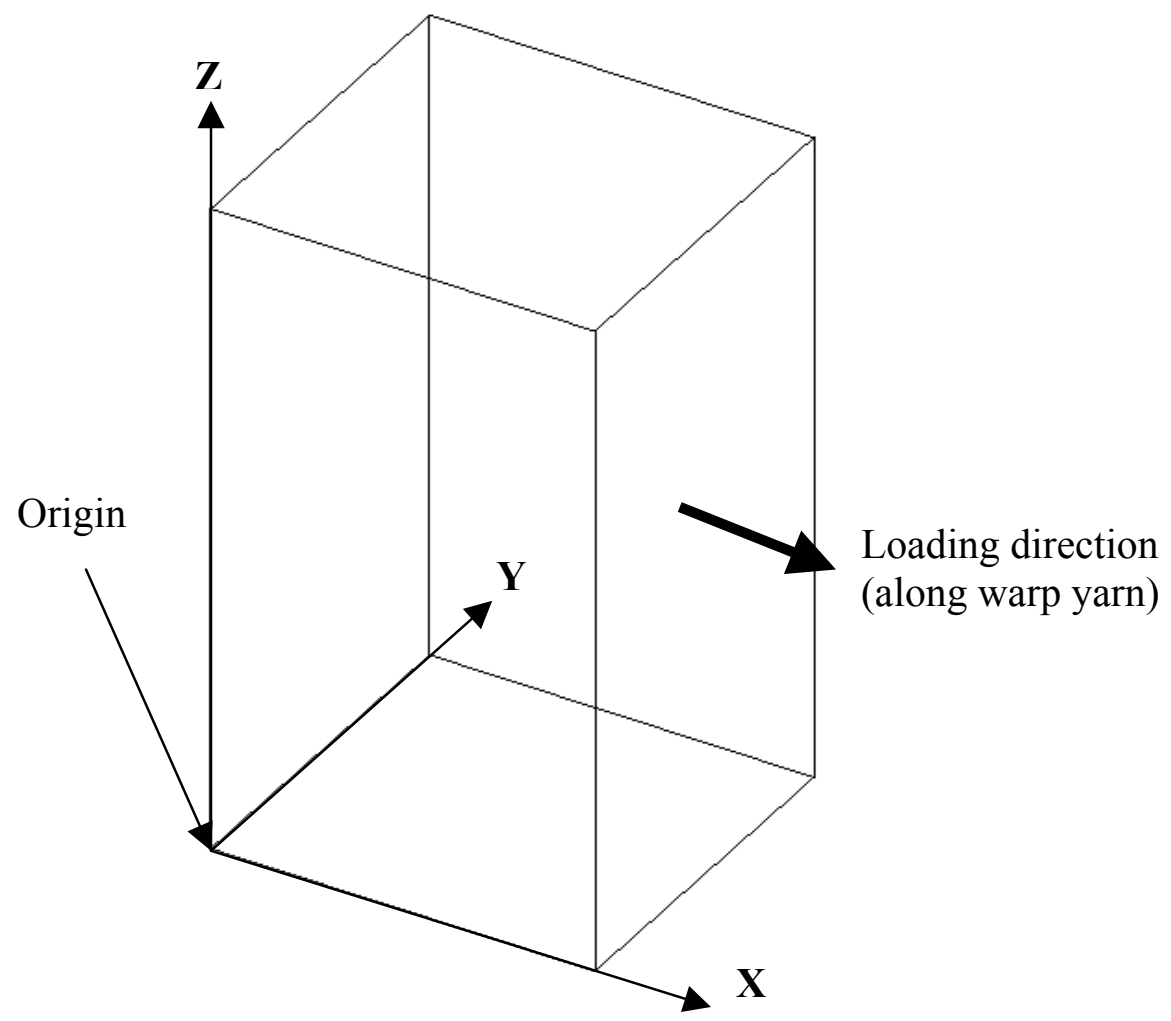

Fig.4.5 Loading direction and origin of the FE model

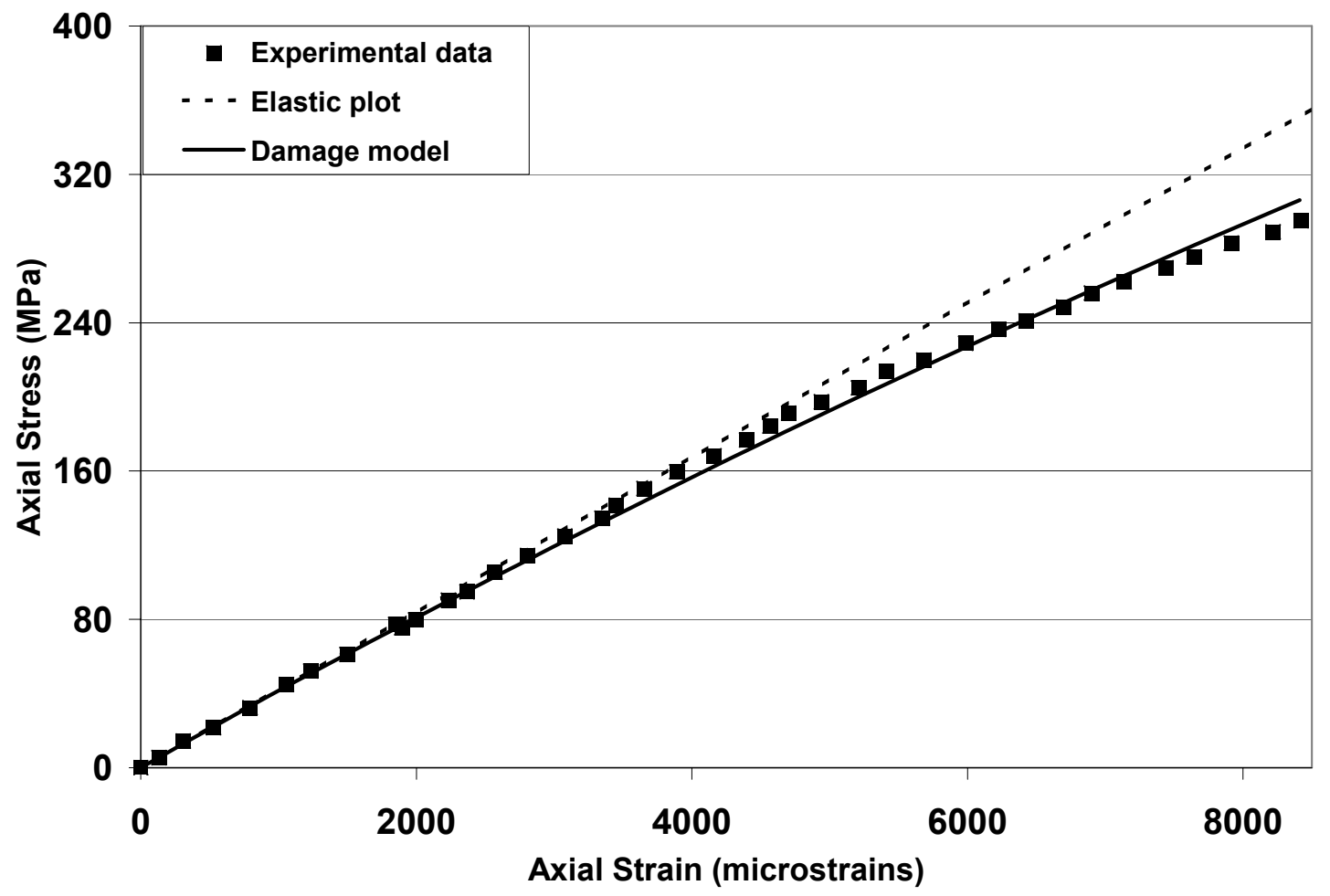

Fig. 4.6 Damage analysis for the iso-phase laminate 


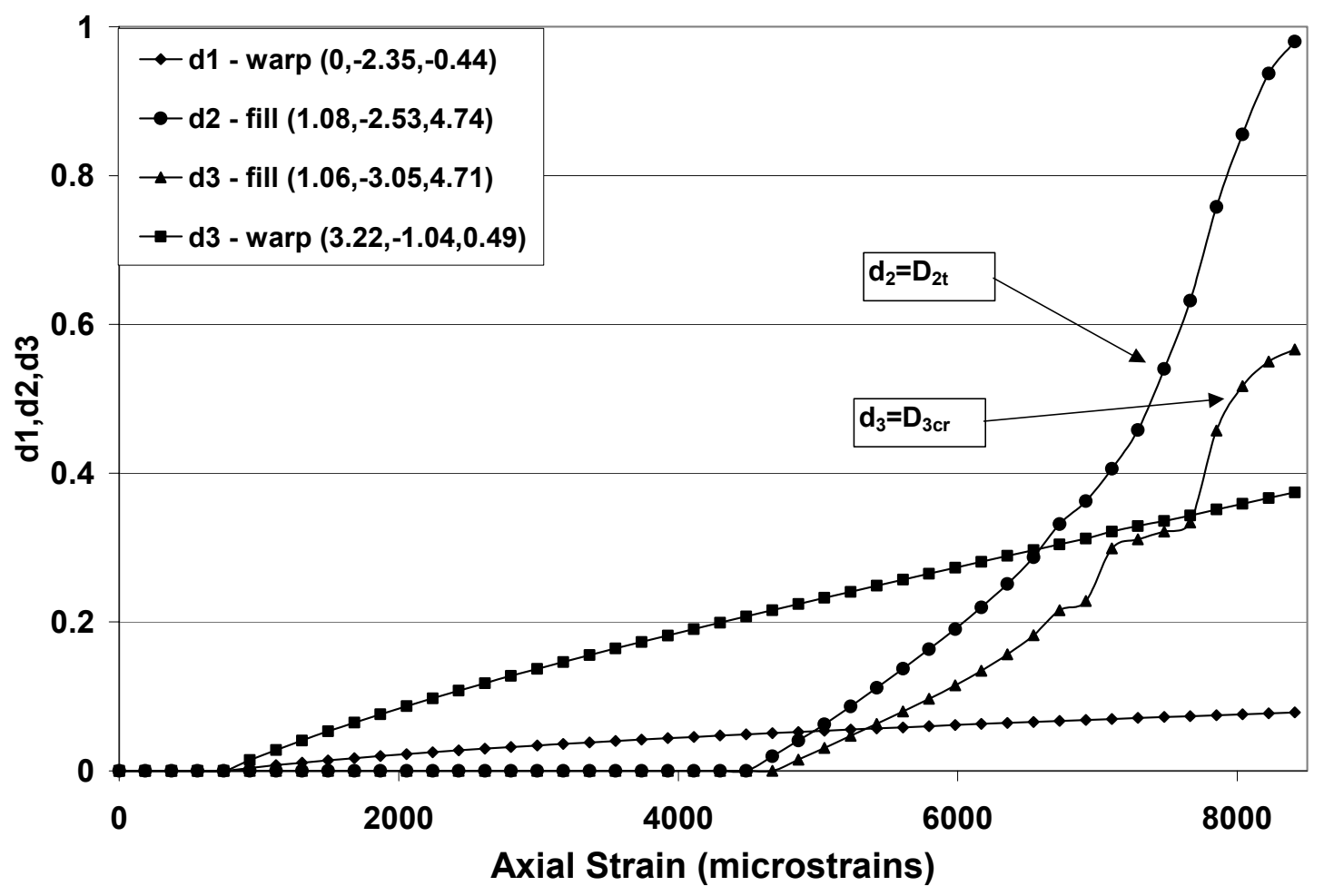

Fig. 4.7 Damage evolution in the iso-phase model at location indicated in the parenthesis

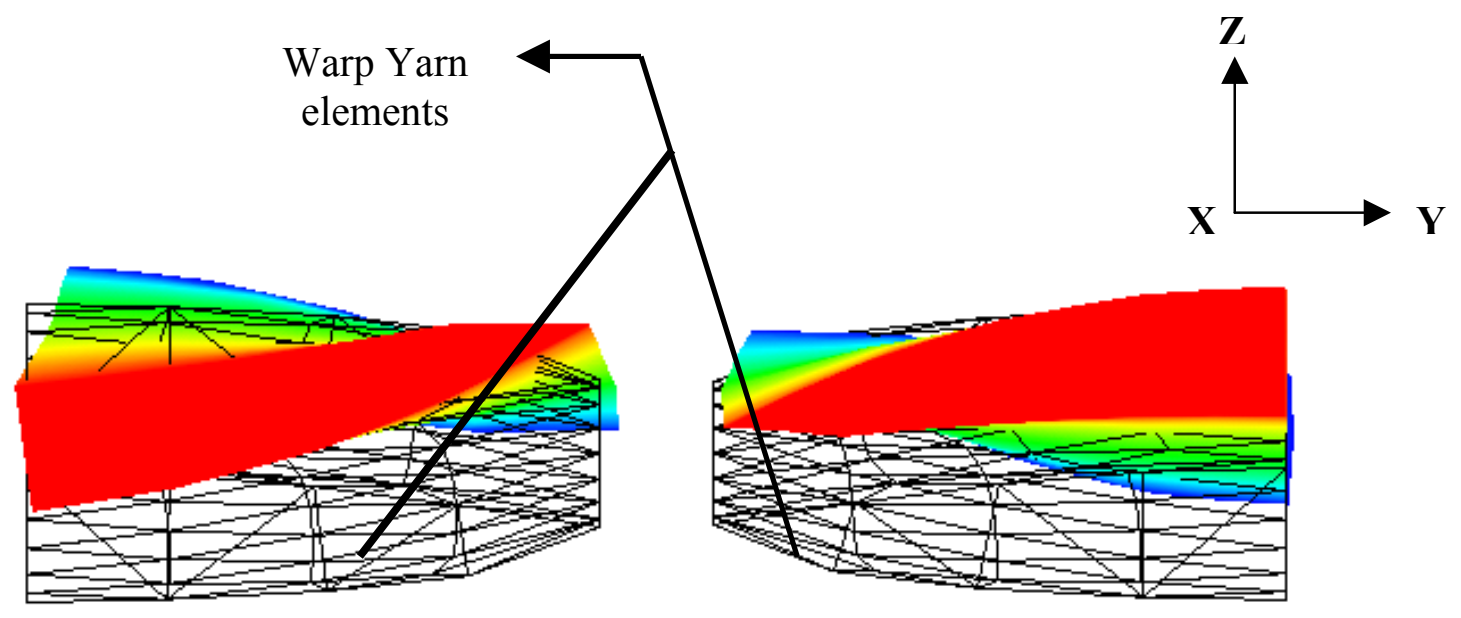

Fig. 4.8 Twisting in the warp yarns 


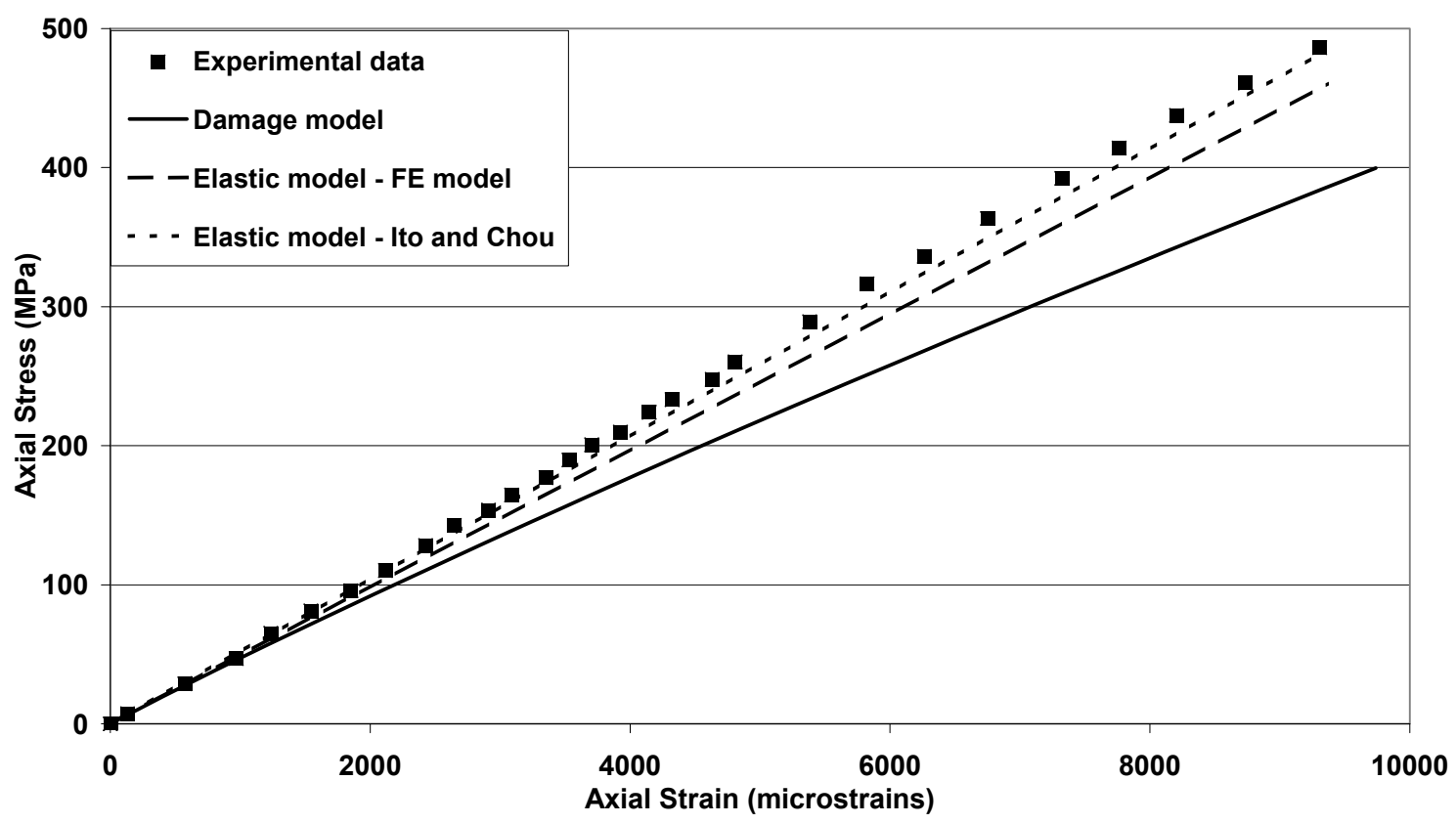

Fig. 4.9 Damage analysis of the out-of-phase laminate

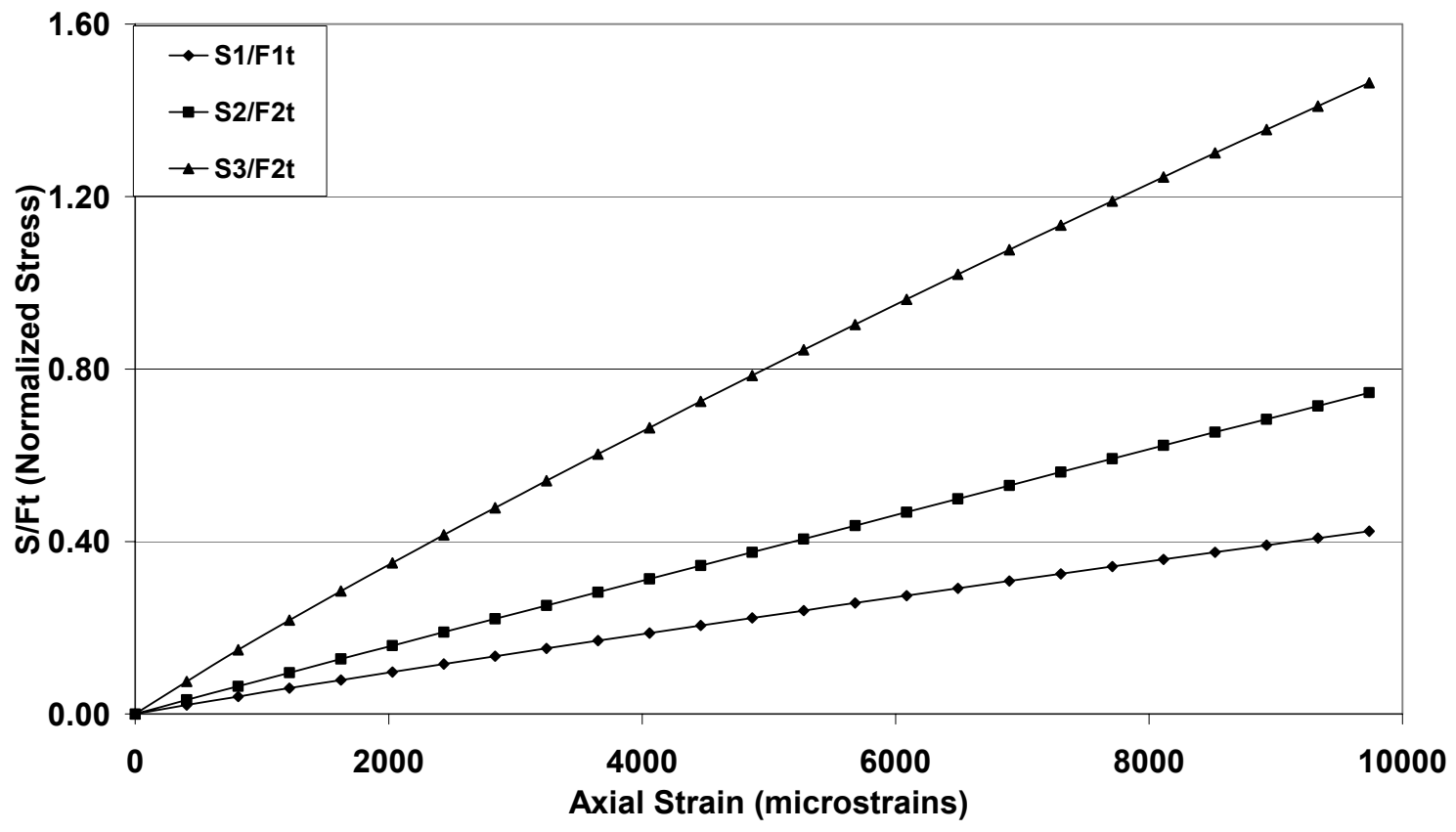

Fig. 4.10 Normalized stress plot for an element in the out-of-phase model 


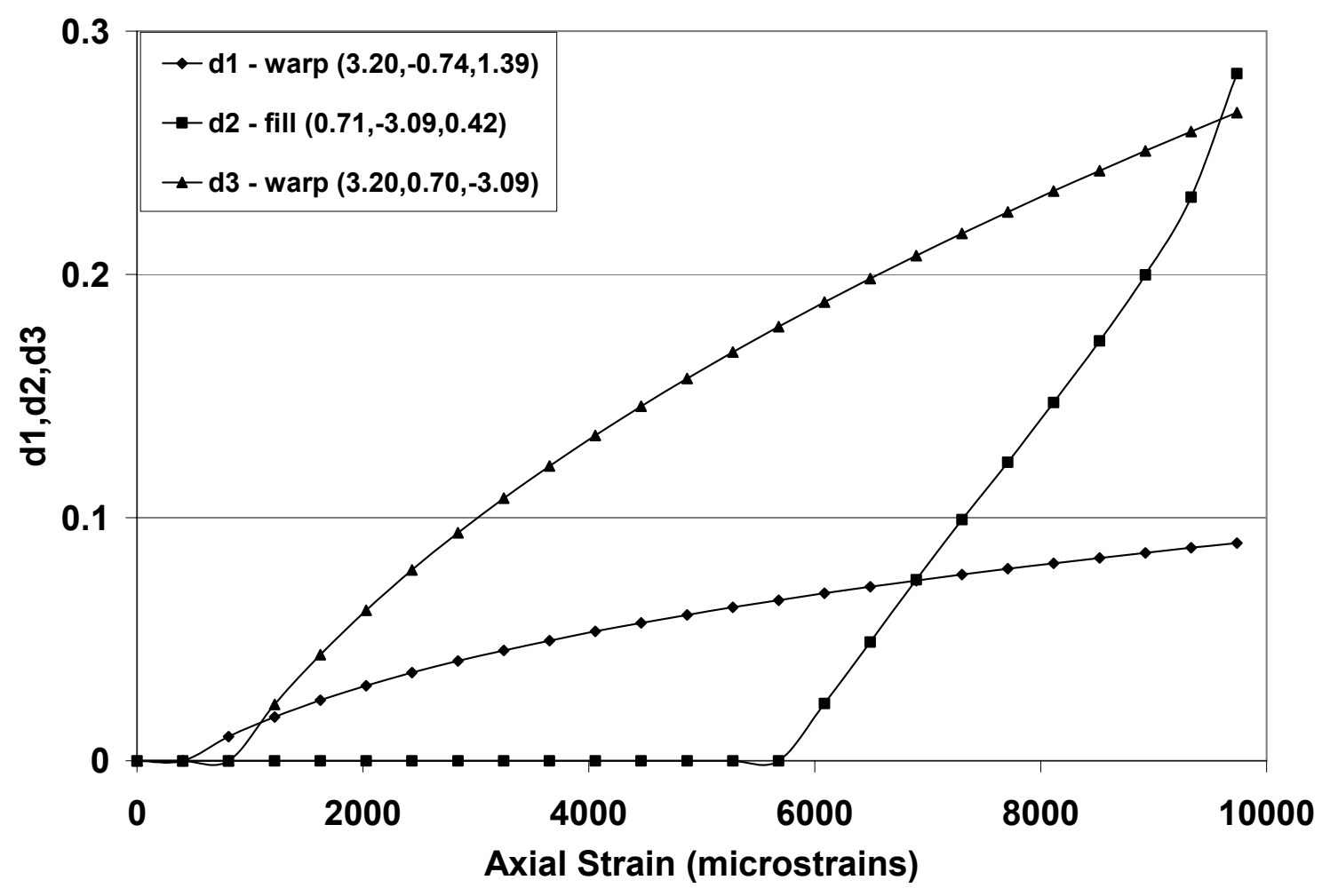

Fig. 4.11 Damage evolution in the out-of-phase laminate at location indicated in the parenthesis 


\section{CHAPTER 5: SUMMARY AND CONCLUSIONS}

Plain weave laminated composites are as important as the unidirectional laminates as the former have better damage and impact tolerance when inter-laminar stresses are present. But the stiffness and strength of such fabrics are low due to 'yarn crimps' in the fabric geometry. Therefore, major focus is laid on determining the stiffness and strength of the plain weave fabrics in this study. Summary and conclusions of the research work is given below.

\subsection{Research Work}

\section{Chapter 1}

Literature survey of currently available models of plain weave fabrics is discussed. An extensive review of various micromechanical and finite element models for prediction of stiffness and strength is presented. The thesis objective is identified and presented.

\section{Chapter 2}

In order to accurately determine the properties of the fabrics, emphasis is given to identifying and modeling the representative volume element (RVE). The parameters for determining the fabric geometry of CERL model and Ito and Chou models are discussed. An exclusive procedure is developed for meso level modeling of yarns and matrix geometry in single, iso-phase and out-of-phase laminates. A simple procedure is developed to obtain the elastic properties of the yarns having transversely isotropic fibers using periodic microstructure model for isotropic fibers [16]. The predicted properties are in good correlation with the values obtained from periodic microstructure model for 
transversely isotropic fibers [18]. The elastic modulus $\left(E_{x}\right)$ of the plain weave laminate models, under tension, is obtained using finite element analysis. The $\mathrm{E}_{\mathrm{x}}$ values predicted by the FE models compare favorably with the experimental values [10].

\section{Chapter 3}

A meso level damage model $[3,21,22]$ for predicting the in-elastic behavior of composite laminates is discussed. The model predicts the non-linear behavior as reduction in stiffness and increments of damage. The model is simple and requires a few parameters that can be obtained from standard tests for composites. The model is based on Tsai-Wu failure criterion and hence accounts for different damage behavior in tension and compression in the fiber direction. The incremental stress-strain analysis for damage is discussed. A known user subroutine [3,21,22] written in FORTRAN is used for incorporating the model in ANSYS. A brief procedure is explained for linking the model with ANSYS. The model requires a total of 20 parameters in order to predict damage. The procedure for obtaining the parameters is presented. Also, a finite element model has been developed in order to adjust the hardening parameters and predict the shear response of a unidirectional composite.

\section{Chapter 4}

The damage model is validated for T300/5208 composite with different material orientation configurations using ANSYS. The model accurately predicts the shear response of T300/5208 material using the finite element model presented in Chapter 3. The hardening parameters and damage threshold obtained from the shear test is used for predicting the damage behavior of T300/5208 material for $[10 /-10]_{2 s},[0 / 45 /-45 / 90]_{\mathrm{s}}$, $[30 /-$ $30]_{2 \mathrm{~s}}$ and $[45 /-45]_{2 \mathrm{~s}}$ lay-ups. A simple FE model is developed for the laminate and is 
subjected to tensile loading. The damage model predicts correctly the in-elastic curve for each lay-up due to damage. The damage is tracked at each integration point of the elements in the laminate. When damage reaches the critical value, the damage surface matches the Tsai-Wu surface. Also the stiffness in that mode is reduced leading to stress redistribution in the laminate. Failure is predicted when the finite element model can no longer withstand the damage and the finite element solution fails to converge. The tensile strength of each lay-up is also predicted and compare favorably with the experimental results.

The damage analysis of iso-phase and out-of-phase laminate using ANSYS is also discussed. The damage model accurately predicts shear response of AS4/Vinyl Esther material using the finite element model presented in Chapter 3. The hardening parameters and damage threshold obtained from the shear test is used for predicting the damage behavior of iso-phase and out-of-phase laminates under tension. In case of the iso-phase laminate, the damage behavior is correctly predicted until a stress level of $306 \mathrm{MPa}$, where the finite element model fails. The failure is mainly attributed to

- Transverse damage in the fill yarns.

- Inter-laminar damage in fill and warp yarns

- Fiber damage in warp yarns

The experimental model [10] fails at a stress level of $489 \mathrm{MPa}$. But, observations [10] show the evolution of interfacial debonding in the yarns at a stress level of $281 \mathrm{MPa}$ and stiffening of the laminate at a stress level of $374 \mathrm{MPa}$. Since the proposed model does not account for damage due to macroscopic cracks, the finite element model fails at 306 
MPa. Also, the experiments show evolution of transverse cracks in the thickness direction due to inter-laminar stresses. The damage model also predicts this phenomenon.

In case of the out-of-phase laminate, the damage model does not give a good prediction of the experimental curve. The experimental model [10] fails at a stress level of $491 \mathrm{MPa}$ and the stress-strain plot is linear. But observations [10] show the presence of transverse cracks. This phenomenon is also observed in the finite element model due to which the stiffness of the laminate is reduced and hence the stress-strain relation no longer remains linear. Also the initial Young's modulus of the finite element model, $49.5 \mathrm{GPa}$, is lower than the experiment value, which is $51.8 \mathrm{GPa}$. The experimental model of the out-ofphase laminate fails due to transverse tensile stress in the warp yarns in the thickness direction. The present damage model does not account for tensile behavior in the thickness direction and results from the finite element model show that the magnitude of the transverse tensile stress is high in the warp yarns. Hence, the damage model does not predict the failure.

Therefore, the damage model correctly predicts the damage behavior of iso-phase laminate but is not accurate when it comes to the out-of-phase laminate.

\subsection{Recommendations}

- Lack of proper strength data leads to the assumption of certain strength values, especially the inter-laminar strengths, which may lead to the damage model failure to give a good prediction of the behavior of the material. If all the stiffness and strength properties of a unidirectional composite are available, the damage model can correctly predict the damage behavior. 
- The critical damage values for plain weave finite element damage model are taken from $[3,21,22]$. The critical damage values affect the internal constants $\left(\mathrm{J}_{11}, \mathrm{~J}_{22}, .\right.$. , $\mathrm{H}_{3}$ ). This might have been different for the experimental models tested [10] and hence may lead to approximate predictions.

\subsection{Future Studies}

- The damage model does not take into account the damage behavior due to transverse tension in the thickness direction. This has to be incorporated to predict the in-elastic behavior of out-of-phase plain weave laminates.

- The stiffening effect needs to be coupled with the damage model in order to study the behavior of the iso-phase laminate. This can be done by incorporating geometric non-linearity.

- The damage model can be extended for analyzing the damage behavior of stitched fabrics, which perform better than plain weave fabrics. 


\section{REFERENCES}

1. Barbero E.J. (1999), Introduction to Composite Materials Design, Taylor and Francis, Philadelphia, PA.

2. Pandey R. (1995), Micromechanics Based Computer-Aided Design and Analysis of Two-Dimensional and Three-Dimensional Fabric Composites, Dissertation, Pennsylvania State University, PA.

3. Barbero E.J., Lonetti P., Zinno R. and Greco F. (2003), Interlaminar Damage Model for Polymer Matrix Composites, Journal of Composite Materials, 1-20.

4. Huang Z.M. (1999), The Mechanical Properties of Composites Reinforced with Woven and Braided Fabrics, Composites Science and Technology, 479 - 498, Vol. 60 .

5. Naik N.K. and Ganesh V.K. (1992), Prediction of On-Axes Elastic Properties of Plain Weave Fabric Composites, Composites Science and Technology, 135-152, Vol.45.

6. Vandeurzen Ph. and Ivens J.,Verpoest I. (1996), A Three-Dimensional Micromechanical Analysis of Woven- Fabric Composites: I .Geometric Analysis, Composites Science and Technology, 1303-1315,Vol. 56.

7. Vandeurzen Ph. and Ivens J.,Verpoest I. (1996), A Three-Dimensional Micromechanical Analysis of Woven- Fabric Composites: II . Elastic Analysis, Composites Science and Technology, 1317-1327, Vol. 56.

8. Hahn H.T. and Pandey R. (1994), A Micromechanics Model for Thermo-elastic Properties of Plain Weave Fabric Composites, Journal of Engineering Materials and Technology, 517-523, Vol. 116. 
9. Scida D., Aboura Z., Benzeggagh M.L. and Bocherens E. (1999), A Micromechanics Model for 3D Elasticity and Failure of Woven-Fiber Composite Materials, Composites Science and Technology, 505-517, Vol. 59.

10. Chou T.W., Ito M. (1998), An Analytical and Experimental Study of Strength and Failure Behavior of Plain Weave Composites, Journal of Composite Materials, 2-30, Vol.32.

11. Aitharaju V.R. and Averill R.C. (1999), Three-Dimensional Properties of WovenFabric Composites, Composites Science and Technology, 1901-1911, Vol. 59.

12. Blackletter D.M., Walrath D.E. and Hansen A.C. (1993), Modeling Damage in a Plain Weave Fabric- Reinforced Composite Material, Journal of Composites Technology \& Research, 136-142, Vol. 15.

13. Kollegal M.G. and Sridharan S. (1998), Strength Prediction of Plain Woven Fabrics, Journal of Composite Materials, 241-257, Vol. 34.

14. Kollegal M.G. and Sridharan S. (1998), A Simplified Model for Plain Woven Fabrics, Journal of Composite Materials, 1757-1785, Vol. 34.

15. Travillion J. (2002), Construction Engineering Research Lab, CERL, UrbanaChampagne, Illinois, Private Communication.

16. Barbero E.J. and Luciano R. (1994), Formulas for the Stiffness of Composites with Periodic Microstructure, International Journal of Solid Structures, 29332943, Vol. 31.

17. MAE 646 class notes (2002), Mechanical and Aerospace Engineering, West Virginia University, Morgantown, WV

18. Barbero E.J. and Luciano R. (1995), Micromechanical Formulas for the Relaxation Tensor of linear Viscoelastic Composites with Transversely Isotropic Fibers, International Journal of Solid Structures, 1859-1872, Vol. 32. 
19. Abdelal, G. F., Caceres, A. and Barbero, E. J. (2002), A Micromechanics Damage Approach for Fatigue of Composite Materials, J. Composite Structures, 413-422. Vol. 56.

20. Ladeveze P. and LeDantec E.(1992), Damage Modeling of the Elementary Ply for Laminated Composites, Composites Science and Technology, 257-267, Vol. 43.

21. Barbero E.J. and Lonetti P. (2001), Damage Model for Composites Defined in Terms of Available Data, Mechanics of Composite Materials and Structures, 299315, Vol.8.

22. Barbero, E. J. and Lonetti, P. (2002), An Inelastic Damage Model for Fiber Reinforced Laminates, Journal of Composite Materials, 941-962, Vol. 36.

23. Lemaitre J., Chaboche J.L. (1990), Mechanics of Solid Materials, Cambridge University Press, Cambridge, UK.

24. Barbero E.J. (1998), Prediction of Compression Strength of Unidirectional Polymer Matrix Composites, Journal of Composite Materials, 483-501, Vol. 32.

25. Barbero E.J. and Devivo L. (2001), A Constitutive Model for Elastic Damage in Fiber-Reinforced PMC Laminae, Journal of Damage Mechanics, 73-93, Vol 10.

26. Herakovich C.T. (1998), Mechanics of Fibrous Composites, Wiley, New York 27. ANSYS Inc, PA, USA.

28. Ishikawa T. and Chou T.W. (1983), One-Dimensional Micromechanical Analysis of Woven Fabric Composites, Journal of American Institute of Aeronautics and Astronautics, 1714-1721, Vol. 21.

29. Ishikawa T. and Chou T.W. (1982), Stiffness and Strength Behavior of Woven Fabric Composites, Journal of Material Science, 3211-3220, Vol. 17. 


\section{APPENDIX A}

The appendix explains the parameter values that are required for modeling the plain

weave fabric. RVE for HW0V023 indicates the measurements made in the warp

RVE for HWOV023

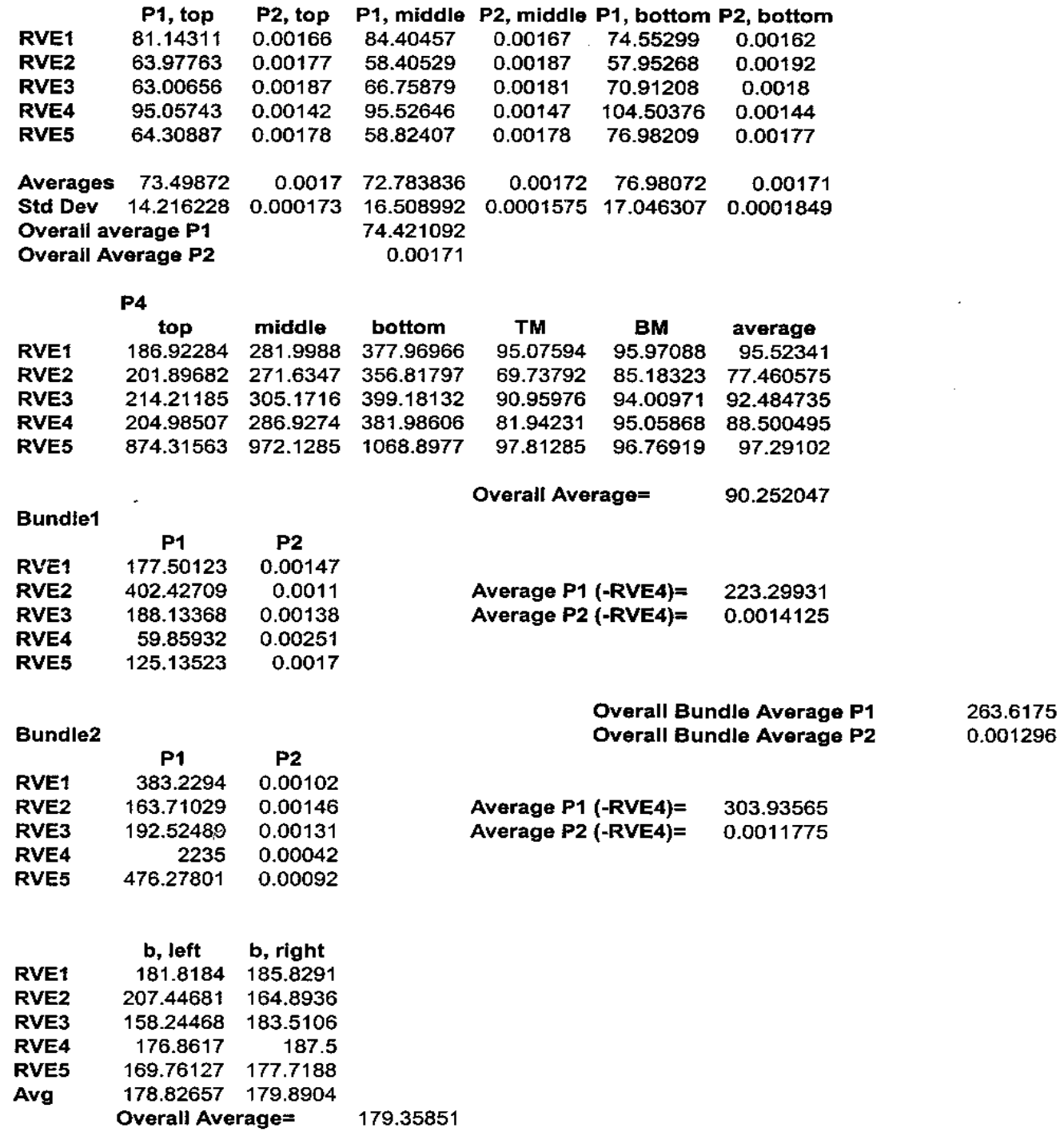


RVE for 90 deg HW0V023 indicates the measurements made in the fill direction

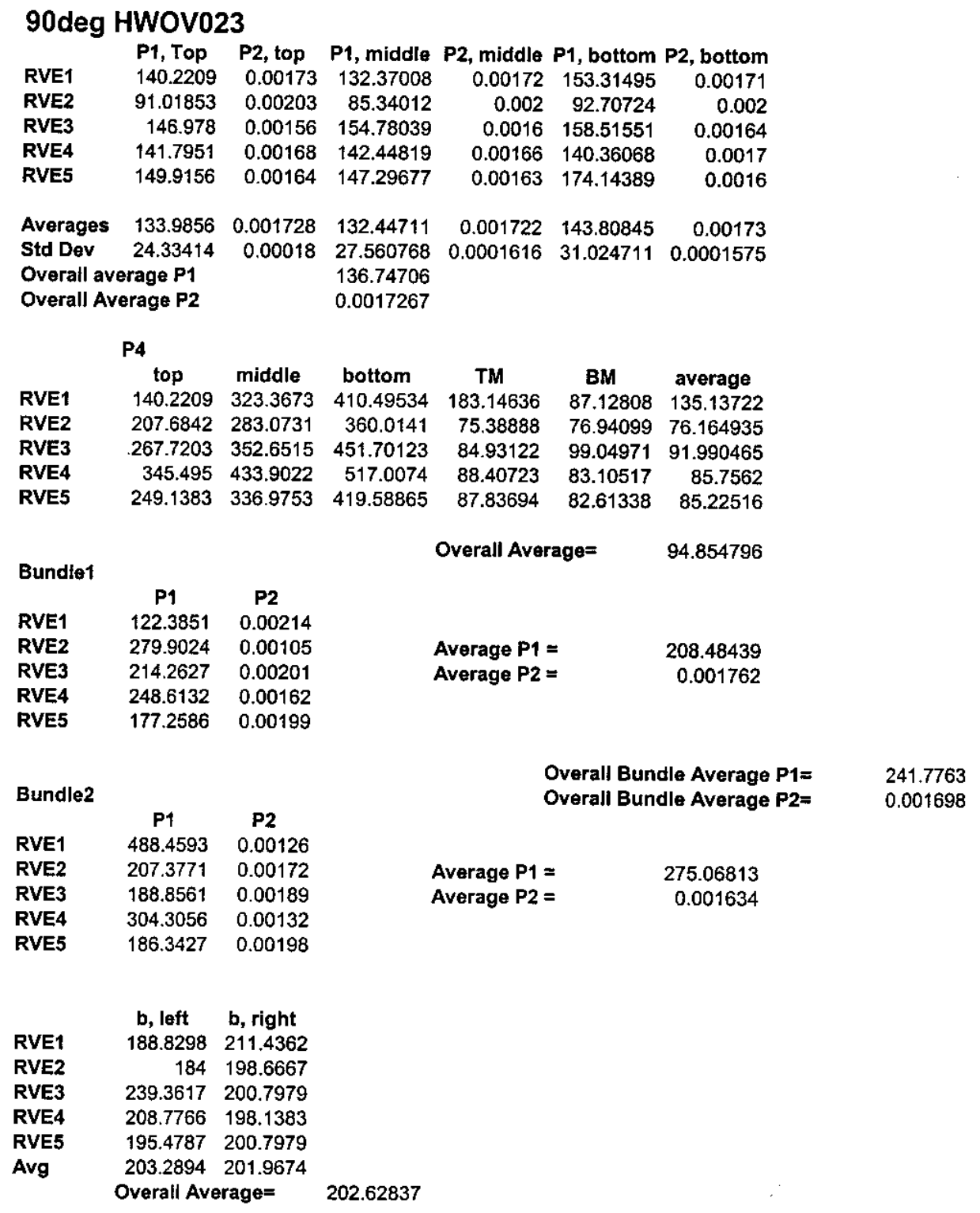




\section{APPENDIX B \\ CALCULATION OF INTERNAL CONSTANTS}

The following procedure explains the calculation of internal constants $\mathrm{J}_{11}, \mathrm{~J}_{22}, \mathrm{~J}_{33}, \mathrm{H}_{1}, \mathrm{H}_{2}$ and $\mathrm{H}_{3}$ in the damage model using the MAPLE software.

>\# include all the linear algebraic functions

$>$ restart: with(linalg):

Warning, new definition for norm

Warning, new definition for trace

$>\#$ entering the critical damage values in the material directions

$>\mathrm{D} 1 \mathrm{t}:=0.1161 ; \mathrm{D} 1 \mathrm{c}:=0.2 ; \mathrm{D} 2 \mathrm{t}:=0.5 ; \mathrm{D} 3:=0.5$;

$\mathrm{D} 1 \mathrm{t}:=.1161$

$\mathrm{D} 1 \mathrm{c}:=.2$

$\mathrm{D} 2 \mathrm{t}:=.5$

$\mathrm{D} 3:=.5$

$>$ \# calculating the critical integrity values

$>$ Om1c:= sqrt(1-D1c); Om1t:= sqrt(1-D1t); Om2t:= sqrt(1-D2t);Om3:= $\operatorname{sqrt}(1-D 3) ;$

Om1c $:=.8944271910$

Om1t $:=.9401595609$

Om2t $:=.7071067812$

Om3 $:=.7071067812$

$>\#$ entering the input variables (stiffness,strength values as presented in Section 3.3.1)

$>\mathrm{E} 1:=1.51 \mathrm{e} 5: \mathrm{E} 2:=9.04 \mathrm{E} 3: \mathrm{G} 12:=3.9 \mathrm{e} 3:$ nu12: $=0.27$ :

$>$ F1t: $=2.69^{*} 10^{\wedge} 3:$ F1c: $=.630^{*} 10^{\wedge} 3:$ F2t:=60: F6:=80.00: gamm:=0.028:

$>$ E44:=3.360e3:E55: $=3.9 \mathrm{e} 3: \mathrm{F} 4:=43: \mathrm{F} 5:=80.00$ :

$>$ G12s:=F6/gamm: ks $:=\mathrm{G} 12 \mathrm{~s} / \mathrm{G} 12 ; \mathrm{ks} 23:=0.315 ; \mathrm{ks} 13:=0.68$;

ks $:=.7326007326$

ks23:=.315

$\mathrm{ks} 13:=.68$ 
$>$ \#calculating the compliance matrix of the undamaged material

$>\mathrm{C} 11:=1 / \mathrm{E} 1: \mathrm{C} 22:=1 / \mathrm{E} 2: \mathrm{C} 66:=1 /(2 * \mathrm{G} 12): \mathrm{C} 55:=1 /(2 * \mathrm{E} 55): \mathrm{C} 44:=1 /(2 * \mathrm{E} 44)$ :

$>$ \#solving for J11, H1 using Eqs. (3.14) and (3.15)

$>$ eq1b:=(sJ11)*C11/Om1t^ $6^{*} \mathrm{~F} 1 \mathrm{t}^{\wedge} 2+(\mathrm{sH} 1)^{*} \operatorname{sqrt}\left(\mathrm{C} 11 / \mathrm{Om} 1 \mathrm{t}^{\wedge} 6\right)^{*} \mathrm{~F} 1 \mathrm{t}-1$;

$>$ eq2b: $=(\mathrm{sJ} 11)^{*} \mathrm{C} 11 / \mathrm{Om} 1 \mathrm{c}^{\wedge} 6^{*} \mathrm{~F} 1 \mathrm{c}^{\wedge} 2-(\mathrm{sH} 1)^{*} \operatorname{sqrt}\left(\mathrm{C} 11 / \mathrm{Om} 1 \mathrm{c}^{\wedge} 6\right)^{*} \mathrm{~F} 1 \mathrm{c}-1$;

eq1b $:=69.39340709 \mathrm{sJ} 11+8.330270530 \mathrm{sH} 1-1$

eq2b $:=5.133743792 \mathrm{sJ} 11-2.265776642 \mathrm{sH} 1-1$

$>$ \# solve in terms of the square root of J11 and H1

$>$ sols: $=\operatorname{solve}(\{$ eq $1 \mathrm{~b}, \mathrm{eq} 2 \mathrm{~b}\},\{\mathrm{sJ} 11, \mathrm{sH} 1\})$;

sols $:=\{\mathrm{sJ} 11=.05298144503, \mathrm{sH} 1=-.3213056495\}$

$>$ assign(sols);

$>\#$ calculating $\mathrm{J} 11$ and $\mathrm{H} 1$ from the square root values

$>\mathrm{H} 1:=(\mathrm{sH} 1 \wedge 2) ; \mathrm{J} 11:=\mathrm{sJ} 11^{\wedge} 2$;

$\mathrm{H} 1:=.1032373204$

$\mathrm{J} 11:=.002807033517$

$>$ \# writing $\mathrm{H} 2$ in terms of rs (Eq. 3.21)

$>\mathrm{H} 2:=-1 * \mathrm{rs} * \mathrm{H} 1$;

$\mathrm{H} 2:=-.1032373204$ rs

$>$ \#Solving Eq. 3.18

$>\mathrm{J} 22:=\left(1-\operatorname{sqrt}\left(\mathrm{abs}(\mathrm{H} 2)^{*} \mathrm{C} 22 / \mathrm{Om} 2 \mathrm{t}^{\wedge} 6\right)^{*} \mathrm{~F} 2 \mathrm{t}\right)^{\wedge} 2 /\left(\mathrm{C} 22 / \mathrm{Om} 2 \mathrm{t}^{\wedge} 6^{*} \mathrm{~F} 2 \mathrm{t}^{\wedge} 2\right)^{\wedge} 2 ;$

$\mathrm{J} 22:=.09852623464(1-.5734959962 \mathrm{sqrt}(|\mathrm{rs}|))^{2}$

$>$ \#Squaring Eq. 3.22

$>$ eq2:=(J11*rs/ks+J22/(ks*rs) $)^{\wedge} 0.5 *\left(2 * \mathrm{C} 66 / \mathrm{ks}^{*} \mathrm{~F} 6 \wedge 2\right)-1$;

eq2 $:=2.240000000\left[.003831600751 \mathrm{rs}+.1344883103 \frac{(1-.5734959962 \mathrm{sqrt}(|\mathrm{rs}|))^{2}}{\mathrm{rs}}\right]^{0.5}-1$

$>$ \# Solving eq2 for rs, rs should be $<1$

$>$ rs $1:=$ solve(eq2,rs);

rs $1:=45.65943690, .3130926311$

$>\mathrm{rs} 2:=\min (\mathrm{rs} 1[1], \mathrm{rs} 1[2])$;

rs2 $:=.3130926311$

>\# Calculating the values of J22, $\mathrm{H} 2$ by substituting the values of rs in Eqs. (3.21) and (3.22)

$>$ J22e: $=\operatorname{evalf}(\operatorname{subs}(\mathrm{rs}=\mathrm{rs} 2, \mathrm{~J} 22))$;

J22e $:=.04543830170$

$>\mathrm{H} 2 \mathrm{e}:=\operatorname{subs}(\mathrm{rs}=\mathrm{rs} 2, \mathrm{H} 2)$;

$\mathrm{H} 2 \mathrm{e}:=-.03232284427$ 
$>$ \# Calculating the internal constants due to interlaminar effects

$>$ eq1b3d: $=\left(\mathrm{J} 22 \mathrm{e}^{*} \mathrm{rs} 23 / \mathrm{ks} 23+\mathrm{J} 33 /(\mathrm{rs} 23 * \mathrm{ks} 23)\right)^{\wedge} 0.5^{*}(2 * \mathrm{C} 44 / \mathrm{ks} 23 * \mathrm{~F} 4 \wedge 2)-1$;

$>$ eq2b3d: $=(\mathrm{J} 11 * \mathrm{rs} 13 / \mathrm{ks} 13+\mathrm{J} 33 /(\mathrm{rs} 13 * \mathrm{ks} 13))^{\wedge} 0.5 *(2 * \mathrm{C} 55 / \mathrm{ks} 13 * \mathrm{~F} 5 \wedge 2)-1$;

$>$ eq3b3d:=abs(H3+H2e*rs23);eq4b3d:=abs(H3-H1*rs13);

eq1b3d $:=1.746976568\left[.1442485768 \mathrm{rs} 23+3.174603175 \frac{\mathrm{J} 33}{\mathrm{rs} 23}\right]^{0.5}-1$

eq2b3d $:=2.413273000\left[.004127990466 \mathrm{rs} 13+1.470588235 \frac{\mathrm{J} 33}{\mathrm{rs} 13}\right]^{0.5}-1$

eq3b3d $:=\mid \mathrm{H} 3-.03232284427$ rs $23 \mid$

eq4b3d $:=\mid \mathrm{H} 3-.1032373204$ rs13|

$>$ \# Solving the 4 equations in order to calculate $\mathrm{J} 33$ and $\mathrm{H} 3$

$>$ sols: $=\operatorname{solve}(\{$ eq1b3d,eq2b3d,eq3b3d,eq4b3d $\},\{\mathrm{J} 33, \mathrm{H} 3$, rs 23, rs 13$\})$;

sols $:=\{$ rs $13=.4620957927$, rs $23=1.475907597$,

$\mathrm{H} 3=.04770553140, \mathrm{~J} 33=.05335515015\}$

$>$ 'J11'=J11;'J22'=J22e';'J33'=J33;H1'=H1;'H2'=H2e;'H3'=H3

$\mathrm{J} 11=.002807033517$

$\mathrm{J} 22=.04543830170$

$\mathrm{J} 33=.05335515015$

$\mathrm{H} 1=.1032373204$

$\mathrm{H} 2=-.03232284427$

$\mathrm{H} 3=.04770553140$ 


\section{APPENDIX C \\ USER PROGRAMMABLE FEATURES IN ANSYS}

The procedure for obtaining the user defined ANSYS executable file, which includes the damage model, is described by the ANSYS Installation and Configuration Guide.

In order to include the user programmable features, it is necessary to perform custom installation of ANSYS. In this case, the FORTRAN source files (usermat3d.f, usermat.f) for the subroutines, which can be modified to include the user-defined material behavior, are stored in the subdirectory lcustomluserlintel [27]. Once the files are modified, they can be linked with ANSYS to get the customized ANSYS file. The procedure for getting the executable file [27] is as follows:

A new directory is created in the drive where ANSYS is installed.

The following files are then copied to the new directory from the lcustomluser sub directory in ANSYS.

Anscust.bat

Makefile

Ansysex.def

Ansysb.dll

Mnflib.dll

The user subroutine file (usermar3d.f) written in FORTRAN.

The FORTRAN files are then compiled and linked with ANSYS program by running the Anscust.bat file. The procedure will load object files and library files after the compilation and a new executable ANSYS file (ANSYS.exe) will be created and will 
reside in the new directory. This file is used for solving composite models that follow the damage behavior described in the subroutine. Typing the command following command runs the executable file: ansys 61 cust - custom $<$ path $>$-p ansysuh where $<$ path $>$ indicates the full path and executable file name (ANSYS.exe). 


\section{APPENDIX D}

\section{INPUT FILE FOR IN-PLANE SHEAR TEST}

\section{! Input file for obtaining shear stress-strain plot in order to adjust the hardening ! parameters}

\section{/COM I-DEAS TO ANSYS TRANSLATOR}

/PREP7

/UNITS,SI

! node definitions for the unidirectional laminate

CSYS,0

$\mathrm{N}, 1,-1 .,-0.25,1$.

$\mathrm{N}, 2,-1,0 ., 1$.

$\mathrm{N}, 3,-1 ., 0.25,1$.

$\mathrm{N}, 4,-0.75,-0.25,1$.

$\mathrm{N}, 5,-0.75,0.25,1$.

$\mathrm{N}, 6,-0.5,-0.25,1$.

$\mathrm{N}, 7,-0.5,0 ., 1$.

$\mathrm{N}, 8,-0.5,0.25,1$.

$\mathrm{N}, 9,-0.25,-0.25,1$.

$\mathrm{N}, 10,-0.25,0.25,1$.

$\mathrm{N}, 11,0 .,-0.25,1$.

$\mathrm{N}, 12,0,0 ., 1$.

$\mathrm{N}, 13,0 ., 0.25,1$.

$\mathrm{N}, 14,0.25,-0.25,1$.

$\mathrm{N}, 15,0.25,0.25,1$.

$\mathrm{N}, 16,0.5,-0.25,1$.

$\mathrm{N}, 17,0.5,0 ., 1$.

$\mathrm{N}, 18,0.5,0.25,1$.

$\mathrm{N}, 19,0.75,-0.25,1$.

$\mathrm{N}, 20,0.75,0.25,1$. 


$$
\begin{aligned}
& \text { N,21,1.,-0.25,1. } \\
& \mathrm{N}, 22,1 ., 0 ., 1 \text {. } \\
& \mathrm{N}, 23,1 ., 0.25,1 \text {. } \\
& \mathrm{N}, 24,-1 .,-0.25,0.75 \\
& \mathrm{~N}, 25,-1,0.25,0.75 \\
& \mathrm{~N}, 26,-0.5,-0.25,0.75 \\
& \mathrm{~N}, 27,-0.5,0.25,0.75 \\
& \mathrm{~N}, 28,0 .,-0.25,0.75 \\
& \mathrm{~N}, 29,0 ., 0.25,0.75 \\
& \mathrm{~N}, 30,0.5,-0.25,0.75 \\
& \mathrm{~N}, 31,0.5,0.25,0.75 \\
& \mathrm{~N}, 32,1 .,-0.25,0.75 \\
& \mathrm{~N}, 33,1 ., 0.25,0.75 \\
& \mathrm{~N}, 34,-1 .,-0.25,0.5 \\
& \mathrm{~N}, 35,-1,0 ., 0.5 \\
& \mathrm{~N}, 36,-1 ., 0.25,0.5 \\
& \mathrm{~N}, 37,-0.75,-0.25,0.5 \\
& \mathrm{~N}, 38,-0.75,0.25,0.5 \\
& \mathrm{~N}, 39,-0.5,-0.25,0.5 \\
& \mathrm{~N}, 40,-0.5,0 ., 0.5 \\
& \mathrm{~N}, 41,-0.5,0.25,0.5 \\
& \mathrm{~N}, 42,-0.25,-0.25,0.5 \\
& \mathrm{~N}, 43,-0.25,0.25,0.5 \\
& \mathrm{~N}, 44,0 .,-0.25,0.5 \\
& \mathrm{~N}, 45,0 ., 0 ., 0.5 \\
& \mathrm{~N}, 46,0,0.25,0.5 \\
& \mathrm{~N}, 47,0.25,-0.25,0.5 \\
& \mathrm{~N}, 48,0.25,0.25,0.5 \\
& \mathrm{~N}, 49,0.5,-0.25,0.5 \\
& \mathrm{~N}, 50,0.5,0 ., 0.5 \\
& \mathrm{~N}, 51,0.5,0.25,0.5
\end{aligned}
$$


$\mathrm{N}, 52,0.75,-0.25,0.5$

$\mathrm{N}, 53,0.75,0.25,0.5$

$\mathrm{N}, 54,1,-0.25,0.5$

$\mathrm{N}, 55,1 ., 0 ., 0.5$

$\mathrm{N}, 56,1 ., 0.25,0.5$

N,57,-1,,-0.25,0.25

$\mathrm{N}, 58,-1,0.25,0.25$

$\mathrm{N}, 59,-0.5,-0.25,0.25$

$\mathrm{N}, 60,-0.5,0.25,0.25$

$\mathrm{N}, 61,0 .,-0.25,0.25$

$\mathrm{N}, 62,0 ., 0.25,0.25$

$\mathrm{N}, 63,0.5,-0.25,0.25$

$\mathrm{N}, 64,0.5,0.25,0.25$

$\mathrm{N}, 65,1 .,-0.25,0.25$

N,66, 1.,0.25,0.25

$\mathrm{N}, 67,-1 .,-0.25,0$.

N,68,-1.,0.,0.

$\mathrm{N}, 69,-1,0.25,0$.

$\mathrm{N}, 70,-0.75,-0.25,0$.

$\mathrm{N}, 71,-0.75,0.25,0$.

$\mathrm{N}, 72,-0.5,-0.25,0$.

$\mathrm{N}, 73,-0.5,0 ., 0$.

$\mathrm{N}, 74,-0.5,0.25,0$.

$\mathrm{N}, 75,-0.25,-0.25,0$.

$\mathrm{N}, 76,-0.25,0.25,0$.

$\mathrm{N}, 77,0 .,-0.25,0$.

$\mathrm{N}, 78,0 ., 0 ., 0$.

$\mathrm{N}, 79,0,0.25,0$.

$\mathrm{N}, 80,0.25,-0.25,0$.

$\mathrm{N}, 81,0.25,0.25,0$.

$\mathrm{N}, 82,0.5,-0.25,0$. 
$\mathrm{N}, 83,0.5,0 ., 0$.

$\mathrm{N}, 84,0.5,0.25,0$.

$\mathrm{N}, 85,0.75,-0.25,0$.

$\mathrm{N}, 86,0.75,0.25,0$.

$\mathrm{N}, 87,1 .,-0.25,0$.

$\mathrm{N}, 88,1,0.0$.

$\mathrm{N}, 89,1.0 .25,0$.

$\mathrm{N}, 90,-1 .,-0.25,-0.25$

$\mathrm{N}, 91,-1 ., 0.25,-0.25$

$\mathrm{N}, 92,-0.5,-0.25,-0.25$

$\mathrm{N}, 93,-0.5,0.25,-0.25$

$\mathrm{N}, 94,0 .,-0.25,-0.25$

$\mathrm{N}, 95,0 ., 0.25,-0.25$

$\mathrm{N}, 96,0.5,-0.25,-0.25$

$\mathrm{N}, 97,0.5,0.25,-0.25$

$\mathrm{N}, 98,1,-0.25,-0.25$

$\mathrm{N}, 99,1,0.25,-0.25$

$\mathrm{N}, 100,-1 .,-0.25,-0.5$

$\mathrm{N}, 101,-1,0 .,-0.5$

$\mathrm{N}, 102,-1,0.25,-0.5$

$\mathrm{N}, 103,-0.75,-0.25,-0.5$

$\mathrm{N}, 104,-0.75,0.25,-0.5$

$\mathrm{N}, 105,-0.5,-0.25,-0.5$

$\mathrm{N}, 106,-0.5,0 .,-0.5$

$\mathrm{N}, 107,-0.5,0.25,-0.5$

$\mathrm{N}, 108,-0.25,-0.25,-0.5$

$\mathrm{N}, 109,-0.25,0.25,-0.5$

$\mathrm{N}, 110,0 .,-0.25,-0.5$

$\mathrm{N}, 111,0 ., 0 .,-0.5$

$\mathrm{N}, 112,0 ., 0.25,-0.5$

$\mathrm{N}, 113,0.25,-0.25,-0.5$ 
$\mathrm{N}, 114,0.25,0.25,-0.5$

$\mathrm{N}, 115,0.5,-0.25,-0.5$

$\mathrm{N}, 116,0.5,0 .,-0.5$

$\mathrm{N}, 117,0.5,0.25,-0.5$

$\mathrm{N}, 118,0.75,-0.25,-0.5$

$\mathrm{N}, 119,0.75,0.25,-0.5$

$\mathrm{N}, 120,1 .,-0.25,-0.5$

$\mathrm{N}, 121,1 ., 0 .,-0.5$

$\mathrm{N}, 122,1 ., 0.25,-0.5$

$\mathrm{N}, 123,-1 .,-0.25,-0.75$

$\mathrm{N}, 124,-1 ., 0.25,-0.75$

$\mathrm{N}, 125,-0.5,-0.25,-0.75$

$\mathrm{N}, 126,-0.5,0.25,-0.75$

$\mathrm{N}, 127,0 .,-0.25,-0.75$

$\mathrm{N}, 128,0 ., 0.25,-0.75$

$\mathrm{N}, 129,0.5,-0.25,-0.75$

$\mathrm{N}, 130,0.5,0.25,-0.75$

$\mathrm{N}, 131,1 .,-0.25,-0.75$

$\mathrm{N}, 132,1 ., 0.25,-0.75$

$\mathrm{N}, 133,-1 .,-0.25,-1$.

$\mathrm{N}, 134,-1,0 .,-1$.

$\mathrm{N}, 135,-1,0.25,-1$.

$\mathrm{N}, 136,-0.75,-0.25,-1$.

$\mathrm{N}, 137,-0.75,0.25,-1$.

$\mathrm{N}, 138,-0.5,-0.25,-1$.

$\mathrm{N}, 139,-0.5,0 .,-1$.

$\mathrm{N}, 140,-0.5,0.25,-1$.

$\mathrm{N}, 141,-0.25,-0.25,-1$.

$\mathrm{N}, 142,-0.25,0.25,-1$.

$\mathrm{N}, 143,0 .,-0.25,-1$.

$\mathrm{N}, 144,0 ., 0 .,-1$. 
$\mathrm{N}, 145,0 ., 0.25,-1$.

$\mathrm{N}, 146,0.25,-0.25,-1$.

$\mathrm{N}, 147,0.25,0.25,-1$.

$\mathrm{N}, 148,0.5,-0.25,-1$.

$\mathrm{N}, 149,0.5,0 .,-1$.

$\mathrm{N}, 150,0.5,0.25,-1$.

$\mathrm{N}, 151,0.75,-0.25,-1$.

$\mathrm{N}, 152,0.75,0.25,-1$.

$\mathrm{N}, 153,1,-0.25,-1$.

$\mathrm{N}, 154,1,0 .,-1$.

$\mathrm{N}, 155,1 ., 0.25,-1$.

! defining the user material properties

! defining the state variables

TB,STAT, 1, 1,11,

TBTEMP,0

TBDATA,,,,,,

TBDATA,,,,,",

! defining the user constants, which includes the stiffness, internal constants,

! hardening parameters and the critical damage values

TBDE,USER, 1, ,

TB,USER, 1,1,32,

TBTEMP,0

TBDATA, ,1.51E+005,9040,9040,3360,3900,3900

TBDATA, $0.343,0.27,0.27,0.002807,0.045438,0.056468$

TBDATA,0.10324,-0.032323,0.050522,0.2,-0.65,0.1

TBDATA, $0.12,0.5,0.5,1,1,1$

TBDATA, $1,1,1,1,1,0.1$

TBDATA,,1E+020,0,,,

! element type, solid186

ET, 1, 186, 0, 0, 0, 0, 0, 0

! defining the material orientation, local coordinate system 
LOCAL,11,0,0.,0.,0.,90.,270.00001,90.

ESYS, 11

!defining the elements

EN, $1,1,3,8,6,34,36,41,39$

EMORE, 2,5,7,4,35,38,40,37

EMORE,24,25,27,26

EN,2,6,8,13,11,39,41,46,44

EMORE, 7,10,12,9,40,43,45,42

EMORE,26,27,29,28

EN,3,11,13,18,16,44,46,51,49

EMORE, $12,15,17,14,45,48,50,47$

EMORE,28,29,31,30

EN,4,16,18,23,21,49,51,56,54

EMORE, 17,20,22,19,50,53,55,52

EMORE,30,31,33,32

EN,5,34,36,41,39,67,69,74,72

EMORE,35,38,40,37,68,71,73,70

EMORE,57,58,60,59

EN,6,39,41,46,44,72,74,79,77

EMORE,40,43,45,42,73,76,78,75

EMORE,59,60,62,61

EN,7,44,46,51,49,77,79,84,82

EMORE,45,48,50,47,78,81,83,80

EMORE,61,62,64,63

$\mathrm{EN}, 8,49,51,56,54,82,84,89,87$

EMORE, 50,53,55,52,83,86,88,85

EMORE,63,64,66,65

EN,9,67,69,74,72,100,102,107,105

EMORE,68,71,73,70,101,104,106,103

EMORE,90,91,93,92

EN,10,72,74,79,77,105,107,112,110 
EMORE,73,76,78,75,106,109,111,108

EMORE,92,93,95,94

EN, $11,77,79,84,82,110,112,117,115$

EMORE, $78,81,83,80,111,114,116,113$

EMORE,94,95,97,96

EN,12,82,84,89,87,115,117,122,120

EMORE, $83,86,88,85,116,119,121,118$

EMORE,96,97,99,98

EN,13,100,102,107,105,133,135,140,138

EMORE,101,104,106,103,134,137,139,136

EMORE,123,124,126,125

EN,14,105,107,112,110,138,140,145,143

EMORE,106,109,111,108,139,142,144,141

EMORE,125,126,128,127

EN,15,110,112,117,115,143,145,150,148

EMORE,111,114,116,113,144,147,149,146

EMORE,127,128,130,129

EN,16,115,117,122,120,148,150,155,153

EMORE,116,119,121,118,149,152,154,151

EMORE,129,130,132,131

! changing to global coordinate system

CSYS, 0

! defining the boundary conditions

! selecting the end nodes of the laminate and fixing them

NSEL,S,LOC,X,-1

D,ALL,ALL, 0

NSEL,ALL

! selecting the nodes in the front face and applying shear displacement NSEL,S,LOC,X,1

D,ALL,UZ,.08

NSEL,ALL 
! selecting nodes in the side faces and fixing them in $\mathbf{x}$ and $\mathbf{y}$ directions

NSEL,S,LOC,Z,-1

$\mathrm{D}, \mathrm{ALL}, \mathrm{UX}, 0$

D,ALL,UY, 0

NSEL,ALL

NSEL,S,LOC,Z,1

D,ALL,UX,0

D,ALL,UY,0

NSEL,ALL

FINISH

! solving the model

/SOLU

! static analysis

ANTYPE, 0

! number of substeps $=40$

NSUBST, 50,51,40

! show all results

OUTRES,ALL,ALL

! solving the model under pure shear conditions

SOLVE

FINISH 